\title{
Regulatory Analysis for the Revision of 10 CFR Part 20
}
S. E. Merwin
J. J. Tawil
J. A. MacLellan
R. J. Traub
M. F. Mullen
M. G. Woodruff
K. L. Swinth

November 1988

Prepared for

Division of Regulatory Applications

Office of Nuclear Regulatory Research

U.S. Nuclear Regulatory Commission

under Contract DE-AC06-76RLO 1830

NRC FIN B2918

Pacific Northwest Laboratory

Operated for the U.S. Department of Energy

by Battelle Memorial Institute 


\title{
DISCLAIMER
}

This report was prepared as an account of work sponsored by an agency of the United States Government. Neither the United States Government nor any agency thereof, nor Battelle Memorial Institute, nor any or their employees, makes any warranty, expressed or implied, or assumes any legal liability or responsibility for the accuracy, completeness, or usefulness of any information, apparatus, product, or process disclosed, or represents that its use would not infringe privately owned rights. Reference herein to any specific commercial product, process, or service by trade name, trademark, manufacturer, or otherwise does not necessarily constitute or imply its endorsement, recommendation, or favoring by the United States Government or any agency thereof, or Battelle Memorial Institute. The views and opinions of authors expressed herein do not necessarily state or reflect those of the United States Covernment or any agency thereof.

\author{
PACIFIC NORTHWEST LABORATORY \\ operated by \\ BATTELLE MEMORIAL INSTITUTE \\ for the \\ UNITED STATES DEPARTMENT OF ENERGY \\ under Contract DE-AC06-76RLO 1830
}


PNL -6712

TECHNICAL EVALUATION REPORT

REGULATORY ANALYSIS FOR THE

REVISION OF 10 CFR PART 20
S. E. Merwin
J. A. MacLellian
J. J. Tawil
M. F. Mullen
R. J. Traub
K. L. Swinth
M. G. Woodruff

November 1988

Prepared for

Division of Regulatory Applications

Office of Nuclear Regulatory Research

U.S. Nuclear Regulatory Commission under Contract DE-AC06-76RLO 1830

NRC FIN B2918

Pacific Northwest Laboratory

Richland, Washington 


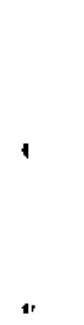

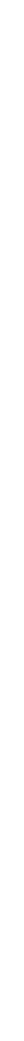




\section{ABSTRACT}

The revised 10 CFR Part 20, "Standards for Protection Against Radiation," would have substantial impacts on both U.S. Nuclear Regulatory Commission (NRC) and Agreement State licensees. It is estimated that the revision will cost licensees over $\$ 170$ million (present value); more than half of these costs are related to the new requirement to sum external and internal doses to demonstrate compliance with the annual whole-body effective dose equivalent limit of 5 rem. Fuel fabrication and processing facilities will incur significant costs to reduce levels of airborne uranium to below the applicable derived air concentrations (DACs). The revision would also have substantial benefits, most notably by reducing doses to both workers and the unborn. Of the $\$ 44$ million (present value) in benefits identified in this analys is, over $80 \%$ are related to dose reductions. There were large uncertainties in these estimates, however, and the actual value of the benefit from the reduced doses could be much lower. Although the quantified benefits from the revision do not appear to outweigh the costs, many benefits identified in this analysis were not quantified and their consideration could favor revising 10 CFR Part 20 as planned. 


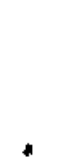

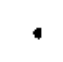

1 


\section{EXECUTIVE SUMMARY}

\section{STATEMENT OF THE PROBLEM}

The basic philosophy and scientific basis for the present 10 CFR Part 20 is over 30 years old. Hewer concepts of radiation protection and updated biological data have rendered the present Part 20 outdated and inconsistent with current recommendations of national and international radiation protection organizations. Both the National Council on Radiation Protection and Measurements (NCRP) and the International Commission on Radiological Protection (ICRP) have published recommendations on limits for exposure to ionizing radiation that are in some ways significantly different from the limits promulgated in the present Part 20. In addition, the Environmental Protection Agency (EPA) has published in the Federal Register (1987) "Radiation Protection Guidance to Federal Agencies for 0ccupational Exposure," (referred to hereafter as Federal Guidance) signed by the President. This Federal Guidance incorporates the basic elements of both the ICRP and NCRP recommendations. In the past, it has been the Nuclear Regulatory Commission's (HRC's) policy to comply with Federal Guidance promulgated by the EPA.

The present Part 20 is in need of revision in six principal areas to become consistent with the Federal Guidance, ICRP recommendations, and/or NCRP recommendations:

1. Use of the current $3 \mathrm{rem} /$ quarter limit on whole-body exposures allows some (usually older) workers to receive doses greater than $5 \mathrm{rem} / \mathrm{yr}$. The Federal Guidance includes an annual whole-body effective dose equivalent limit of 5 rem.

2. Under the current Part 20, internal doses are not included in the assessment of whole-body dose. It is possible for a worker to legally receive internal doses from some radionuclides that are equivalent to whole-body doses of 10 rem or more (using the newer ICRP method for risk assessment) in addition to annual external doses of 12 rem. Because the effective whole-body dose limit of 5 rem, as stated in the Federal Guidance, includes the sum of internal and external doses, under the current Part 20 a worker can legally receive an effective whole-body dose equivalent that is four or more times higher than the limit recommended in the Federal Guidance.

3. The current Part 20 limits on intake for some radionuclides do not reflect recent biological information or models of radionuclide retention and consequent risk. As a result, the current limits are too high for most alpha-emitting radionuclides and too low for most other radionuclides. The associated errors approach or exceed one order of magnitude in many cases.

4. The current Part 20 dose limits for specific organs and parts of the body are not consistent with recent recommendations of the ICRP and HCRP. 
5. The current Part 20 does not promulgate a dose limit for the embryo/fetus, even though such a limit is addressed in both an NRC Regulatory Guide and staff position paper. Recent studies suggest that the embryo/fetus is more biologically sensitive to radiationinduced damage from ionizing radiation, and the current dose limits for adults may not ensure adequate protection of the unborn. The Federal Guidance includes a dose limit of 0.5 rem to the embryo/ fetus.

6. For licensees not covered by the Uranium Fuel Cycle Standard (40 CFR 190) or the Clean Air Act Standard (40 CFR 61), there is no explicitly stated annual dose limit for individual members of the public in the current Part 20. Although the Federal Guidance does not include such a limit, the NCRP recomends an annual dose limit of 100 mrem for continuing long term exposures.

\section{OBJECTIVES}

The principal objective of revising Part 20 is to make the NRC's "Standards for Protection Against Radiation" consistent with the recommendations of national (NCRP and EPA) and international (ICRP) organizations responsible for providing radiation protection standards. The ICRP and NCRP recommendations serve as the primary scientific bas is for federal standards for protection against radiation. Also, as a matter of policy, the former Atomic Energy Commission (AEC) and the NRC have considered past Federal Radiation Council (FRC) and EPA federal guidance as binding and have implemented the guidance in their regulations.

The revision of Part 20 was also prepared to satisfy other objectives of the MRC. The revision would resolve several petitions for rulemaking and rulemaking proceedings that are still pending. These include limitation of dose to the embryo/fetus (NPRM, 1-3-75), deletion of the $5(\mathrm{~N}-18)$ doseaveraging formula (NPRM, 2-20-79) and petitions to lower dose limits (PRM-20-6 and PRM-20-6A). The revision would also correct some errors and inconsistencies in the current Part 20.

\section{ALTERNATIVES}

This regulatory analysis focused on the consequences of the planned revision of Part 20 . This alternative and others available to the NRC are described below.

\section{Alternative 1: Revise Part 20 as Planned}

Adoption of this alternative would result in a comprehensive revision of 10 CFR Part 20. This would be the final step in a process initiated by the NRC almost 10 years ago to incorporate the recomendations of the ICRP into the rule. The revision would also incorporate many of the recent recommendations of the NCRP and would be consistent with the recent Federal Guidance. 


\section{Alternative 2: No Action}

Under this alternative, the NRC would terminate the existing rulemaking, publish a notice to this effect in the Federal Register, and initiate individual rulemaking actions as the situation demands. This would leave the principles underlying the current Part 20 in place and the rule would be inconsistent with ICRP and NCRP recommendations as well as the Federal Guidance.

Alternative 3: Modify the Revision and Proceed with the Rulemaking

Under this alterative, the NRC would modify the current revision to reduce the costs identified in this regulatory analysis. Several provisions of the revision could be modified to lessen the impact on licensees; however, some of these modifications would compromise the primary benefits of the revision.

Alternative 4: Incorporate Only Those Provisions Necessary for Compliance with the Federal Guidance

Adoption of this alternative would require an extensive modification of the revision. The modified revision would be consistent with the Federal Guidance but would not contain some of the changes present in the currently planned revision.

\section{CONSEQUENCES}

\section{Alternative 1: Revise Part 20 as Planned}

This alternative was the basis for the analysis provided in this report. The present value of the costs of the revision of Part 20 was estimated to be $\$ 170,000,000$, based on 1989 dollars, a discount rate of $10 \%$, and a 30 -year period. This estimate includes all costs that will be incurred in response to the promulgation of Part 20 . If only those costs thought to be necessary for compliance are included in the cost estimate, this value would be reduced by about $\$ 50$ million.

Approximately $70 \%$ of the estimated costs of the revision are related to the revised provisions for monitoring, evaluating and recording internal doses. Table S.1 provides a breakdown of the costs by section of the rule.

The greatest impact of the revision is expected to be sustained by fuel fabrication facilities, where both the new Derived Air Concentration (DAC) values for uranium and the requirement to control intakes based on DACS and Annual Limits on Intakes (ALIs) will necessitate engineering modifications to reduce airborne uranium levels. It is estimated that $44 \%$ of the costs of the revision of Part 20 will be incurred by fuel fabrication facilities. Commercial nuclear power plants, medical facilities, academic/research institutions, and manufacturing and distribution facilities will incur an estimated $36 \%, 13 \%, 3 \%$, and $2 \%$ of the costs of the revision, respectively. other facilities would incur relatively insignificant costs. The costs to 
TABLE S.1. Costs Incurred by Section of the Final Rule

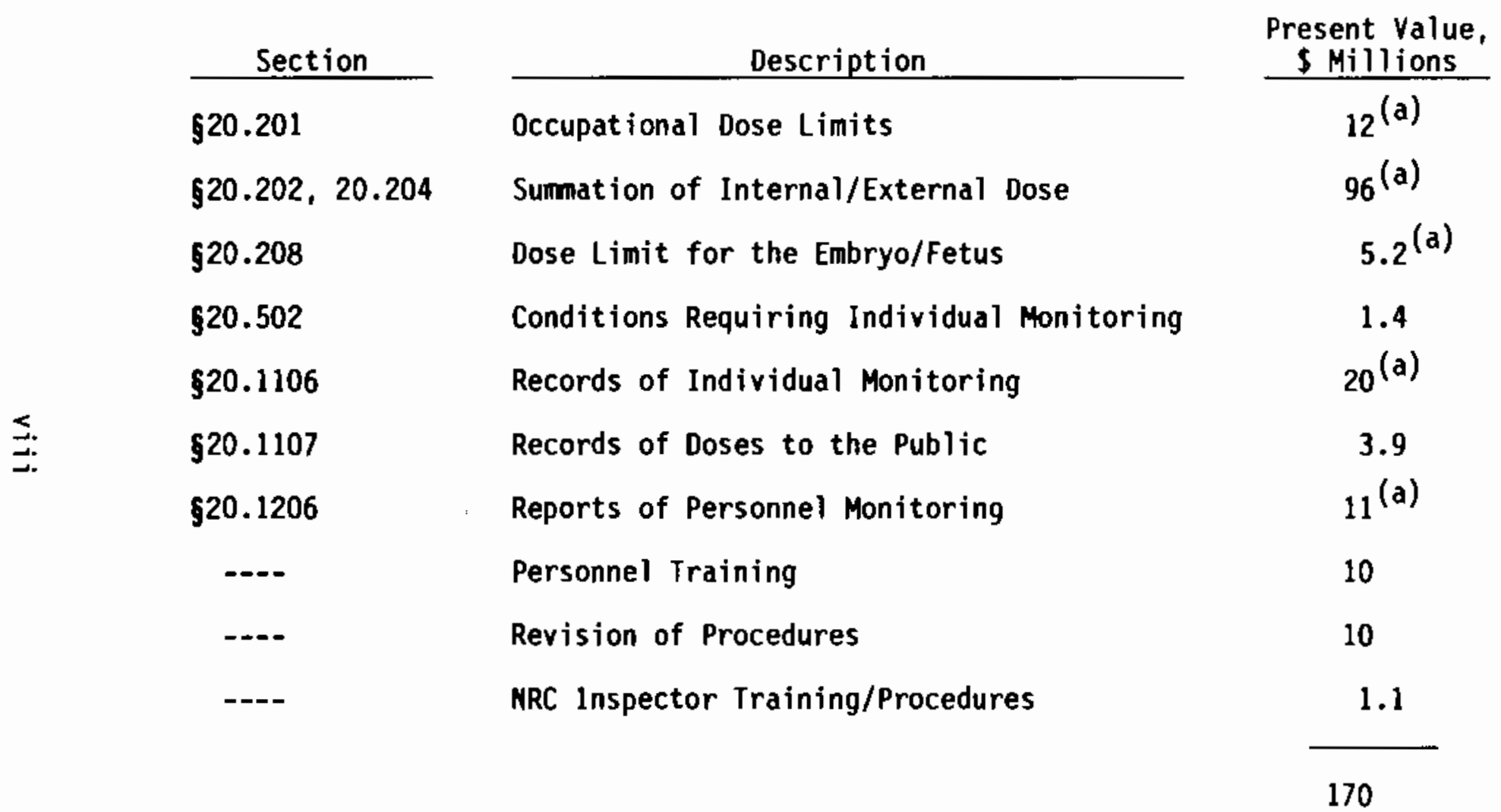

(a) These costs are directly related to specific recommendations in the Federal Guidance. A total of $\$ 144 \mathrm{million}$, or $85 \%$ of the quantified costs of the revision are directly related to those recomendations. 
the NRC were estimated to be $\$ 2,900,000$, or about $2 \%$ of the total cost of the revision. Tables $S .2$ and $S .3$ provide a summary of the quantified costs by facility type.

The benefits of revising Part 20 include both quantifiable and unquantifiable components. One of the principal benefits of the revision is that it would make NRC regulations consistent with ICRP and NCRP recommendations and the recent Federal Radiation Protection Guidance. This benefit is significant but cannot be measured in dollars. Other benefits of revising Part 20 are more readily quantified. These quantified benefits included an annual savings of $\$ 880,000$ in operating costs and reduced annual doses of 1200 rem and 300 rem to adult workers and the unborn, respectively. The present value of the quantified benefits was estimated to be $\$ 44,000,000$, over $80 \%$ of which was related to dose savings. The present value of the estimated dose savings was highly dependent on several assumptions, including the value of both avoiding a rem to an adult worker and avoiding a rem to a fetus ( $\$ 1000$ and $\$ 10,000$, respectively).

One section of the revision was identified to have benefits that greatly exceeded the associated costs. It was estimated that Section 20.208, "Dose to an Embryo/Fetus," will result in costs of $\$ 5,200,000$ (present value) to licensees and reduced doses of $300 \mathrm{rem} / \mathrm{yr}$ to the unborn. In view of the perceived risk associated with dose to the embryo/fetus, this section of the rule is anticipated to provide a significant net benefit. The anticipated net benefit does not include consideration of the ramifications of the limits with regard to civil rights of female workers.

There were many uncertainties in the cost estimates provided in this report. A sensitivity analysis of the assumptions used to determine the net benefit of the revision suggested that the present value of the net benefit ranges from $-\$ 40$ million to $-\$ 170$ million. Based on this quantitative analysis, it appears that the revision of Part 20 does not have a favorable benefit/cost ratio. However, many of the benefits of the revision were not quantified in this analysis, and consideration of these benefits could justify the revision of Part 20 as planned.

\section{Alternative 2: No Action}

The primary consequence of this alternative would be that the NRC would not implement the Federal Radiation Protection Guidance. Licensees would be free to voluntarily implement some or all of the recomnendations; however. they would not be required to do so by 10 CFR Part 20 . Development costs already incurred by the NRC should not be considered as a consequence of this alternative.

Alternative 3: Modify the Revision and Proceed with the Rulemaking

The primary consequences of this alternative would be twofold. First, the modifications would reduce the cost impact on licensees. Second, the modifications would lessen the consistency of the revision with the Federal Guidance. Three potential modifications to the rule are presented. 
TABLE 5.2. Implementation Costs of the Part 20 Revision by Facility Type

\begin{tabular}{|c|c|c|c|c|c|}
\hline Facility Category & $\begin{array}{c}\text { Initiat } \\
\text { Cost } \\
\end{array}$ & $\begin{array}{c}\text { Annua } \\
\text { Cost } \\
\end{array}$ & $\begin{array}{c}\text { Present value } \\
\text { of Costs } \\
\end{array}$ & \multicolumn{2}{|c|}{$\begin{array}{c}\text { Total Licensee } \\
\text { Costs, } 8\end{array}$} \\
\hline Fuel Fabrication and Processing & 33 & 5.3 & 75 & 44.7 & $(44.7)^{(a)}$ \\
\hline Commercial Power Reactors & 30 & 4.0 & 61 & 36.4 & $(81.1)$ \\
\hline Medical & 7.4 & 1.8 & 22 & 13.1 & $(94.2)$ \\
\hline Academic/Research 1nstitutions & 1.8 & 0.34 & 4.5 & 2.7 & $(96.9)$ \\
\hline Manufacturing and Distribution & 0.53 & 0.24 & 2.6 & 1.6 & $(98.5)$ \\
\hline Other Measuring Systems & 0.31 & 0.043 & 0.65 & 0.4 & $(98.9)$ \\
\hline Research and Test Reactors & 0.65 & 0.004 & 0.62 & 0.4 & $(99.3)$ \\
\hline Industrial Radiography & 0.29 & 0.022 & 0.45 & 0.3 & $(99.6)$ \\
\hline Hell Logging & 0.012 & 0.044 & 0.39 & 0.2 & $(99.8)$ \\
\hline All others & 0.081 & 0.049 & 0.50 & 0.3 & $(100.0)$ \\
\hline Total Licensee Costs & 74.1 & 11.8 & 167.7 & $100 \%$ & \\
\hline MRC Costs & 1.4 & 0.21 & 2.9 & & \\
\hline Total Costs & 75.5 & 12.0 & 170.6 & & \\
\hline
\end{tabular}

(a) Numbers in parentheses refer to cumulative percentages. 
TABLE S.3. Cost Per Facility and Annualized Cost to Implement the Part 20 Revision

\begin{tabular}{|c|c|c|c|c|}
\hline Facility Category & Number & $\begin{array}{c}\text { Present Value } \\
\text { of Costs, } \\
\$ \text { Millions } \\
\end{array}$ & $\begin{array}{c}\text { Present Value of } \\
\text { Cost Per Facility, } \\
\$ \text { Thousands } \\
\end{array}$ & $\begin{array}{c}\text { Annualized Cost } \\
\text { Per Facility } \\
\$ \text { Thousands/yr(a) }\end{array}$ \\
\hline Fuel Fabrication and Processing & 14 & 75 & 5,400 & 570 \\
\hline Commercial Power Reactors & 109 & 61 & 560 & 59 \\
\hline Medical & 6,506 & 22 & 3.4 & 0.36 \\
\hline Academic/Research Institutions & 1,556 & 4.5 & 2.9 & 0.31 \\
\hline Manufacturing and Distribution & 965 & 2.6 & 2.7 & 0.29 \\
\hline Other Measuring Systems & 5,060 & 0.65 & 0.13 & 0.014 \\
\hline Research and Test Reactors & 80 & 0.62 & 7.8 & 0.82 \\
\hline Industrial Radiography & 851 & 0.45 & 0.53 & 0.056 \\
\hline Well Logging & 454 & 0.39 & 0.86 & 0.091 \\
\hline A11 0thers & 1,752 & 0.50 & 0.29 & 0.030 \\
\hline All Facilities & 17,347 & 168 & 9.68 & 1.03 \\
\hline
\end{tabular}

(a) Annualized cost factor (capital recovery factor) for 30 years at a discount rate of $10 \%=0.106$. 
Reintroduce the provision for long-lived radionuclides. It has previously been reported that the provision present in the proposed rule would eliminate the need for facility modifications at fuel fabrication facilities. In short, this provision allowed some licensees to calculate effective dose equivalent based on annual effective dose equivalent rather than committed effective dose equivalent for intakes of radionuclides having long effective half-lives.

However, it appears that this provision would not eliminate the need for facility modifications even if they were required without the provision. That is because the provision specifically stated that a licensee must operate the facility such that "any individual is unlikely to have an intake from occupational exposure in one year in excess of the ALI value." In effect, the provision would al low licensees to calculate doses differently but not operate the facilities differently.

Another important factor is that it is likely that major facility modifications will not be required in all cases. Currently, most fuel fabrication facilities operate with airborne uranium concentrations at $10 \%$ to $25 \%$ of current Maximum Permissible Concentration (MPC) values; under the revision, licensees would be operating at about $50 \%$ to $125 \%$ of the DAC values. Apparently, licensees feel that this would be unacceptable. Based on the analysis in this report, however, very few workers would exceed the annual whole-body effective dose equivalent limit at these levels. For those who would, an increased use of respirators or appropriate job rotations would eliminate overexposures. Individuals approaching the dose limits would be identified well in advance through air monitoring.

The reason that licensees would likely be unwilling to operate at ambient air concentrations near 1 DAC is that under the present system of dose limitation, MPCs are often considered as limits and it is likely that the new DACs will be incorrectly considered as limits as well. However, ALIs are the principal concern, and if particle size studies, studies on worker stay times in high-concentration areas, or solubility studies would show that workers can work safely under existing conditions, then proper use of the ALARA principle mandates that these studies be done. It is concluded that the provision is inconsistent with the Federal Guidance and would not result in major cost reductions in any case. Costs could be more effectively reduced through promotion of the concept that DACs need not be considered limits in all cases.

Remove the requirement to provide individual dose records to individuals. This modification would reduce the costs of the revision by an estimated $\$ 9.1$ million (present value). Because no significant quantifiable benefits were identified from this requirement, this modification would be cost-beneficial; however, it would be inconsistent with the Federal Guidance.

Revise Section 20.1106, "Records of Individual Monitoring Results." Approximately $12 \%$ of the costs of the revision will be related to this requirement. Licensees will be required to revise recordkeeping procedures to allow the proper assessment and recording of internal doses. Because few workers receive significant internal doses, these costs appear to be excessive. Some 
of these costs could be alleviated by relaxing the requirements for documenting internal exposures on KRC Form 5. However, this would be inconsistent with the recordkeeping requirements in the Federal Guidance.

A]ternative 4: Incorporate Only Those Provisions Necessary for Compliance with the Federal Guidance

This alternative would result in a complete overhaul of the current Part 20 revision. The revision would be rewritten to include only those provisions necessary for compliance with the Federal Guidance. The consequences would essentially be the same as the consequences of Alternative 1 because most of the costs and benefits of the planned revision are associated with provisions necessary for compliance with the Federal Guidance. Considering the costs of the revision that were unquantified, however, especially the costs associated with the revised limits for disposal to sewers, significant cost savings could be realized through this alternative.

\section{DECISION RATIONALE}

Of the four alternatives, only Alternative 2 (no action) appears to be nonviable. Adoption of this alternative would allow the MRC's "Standards for Protection Against Radiation" (10 CFR Part 20) to remain inconsistent with the Federal Radiation Protection Guidance. This would disregard NRC policy and would contradict previous Commission comments to the EPA supporting development of the Federal Guidance.

Alternative 1 (revise Part 20 as planned) would incorporate both the Federal Radiation Protection Guidance and the ICRP and NCRP recommendations on limiting exposure to ionizing radiation. The cost of this alternative to licensees and regulatory agencies is estimated to be approximately $\$ 170$ million (present value). However, adoption of the alternative would benefit society by reducing occupational exposures to both adult workers and the unborn being carried by pregnant workers. It was estimated that this alternative would result in reduced doses to workers of $1200 \mathrm{rem} / \mathrm{yr}$ and reduced doses to enbryos/fetuses of $300 \mathrm{rem} / \mathrm{yr}$. The present value of the benefits of the revision depends on the dollar values assigned to both adult and fetal doses and whether health effects were discounted; based on the assumptions used in this report, the present value was estimated to be $\$ 44$ million. Although the quantified benefits from this alternative do not appear to outweigh the costs, many benefits identified in this analysis were not quantified and their consideration could favor the adoption of this alternative. Also, note that relatively large uncertainties may be associated with the estimates provided in this analysis.

Alternative 3 (modify the revision and proceed with the rulemaking) is viable, provided that the modifications do not compromise the benefits from the revision. Each potential modification identified in the previous section would result in cost savings but would lessen the consistency of the revision with the Federal Guidance. Whether the individual modifications should be adopted depends primarily on subjective considerations of these competing factors. 
Alternative 4 (incorporate only those provisions necessary for compliance with the Federa? Guidance) may be desirable depending on whether the associated delay would be acceptable in view of the reduced costs. Of the costs identified in the analysis of Alternative 1, only a small fraction could be avoided by adoption of this alternative. However, this alternative would avoid many of the potential costs that were not quantified. Essentially all of the primary benefits associated with Alternative 1 would also be realized by adoption of Alternative 4 .

\section{IMPLEMENTATION}

Alternative 1: Revise Part 20 as Planned

Considering that NRC planning has been based on adoption of this alternative, Alternative 1 , if implemented, would probably result in publication of the final rule by December 31,1988 . The NRC would also al low a 5-year implementation period retroactive to the date that the proposed rule was published (January 9,1986$)$. This would effectively allow licensees until January 9, 1991, to implement the provisions of the revision. Granting a longer period of implementation, e.g., 5 years from the date the final rule is published, would allow licensees to defer the costs of implementation. A longer period of implementation would also provide the NRC with more time to develop and publish regulatory guides in support of the revised rule.

\section{Alternative 3: Modify the Revision and Proceed with the Rulemaking}

If implemented, the preferred approach would be to identify the potential modifications and perform a separate cost-benefit analys is for each one. Favorable modifications would be introduced into the revision and unfavorable modifications would be dropped from consideration. Because most of the modifications would result in both reduced costs and reduced consistency with the Federal Guidance, the decisions to include each modification would require a comparison of the cost savings to the perceived importance of consistency with the Federal Guidance. Upon final modification of the rule, the rulemaking would proceed and the final rule would be published. An appropriate implementation period would be granted to licensees, and the NRC would develop and/or revise the regulatory guides required to support the revised rule.

Alternative 4: Incorporate Only Those Provisions Necessary for Compliance with the Federal Guidance

If implemented, this alternative would result in a major interruption to the current schedule for revising Part 20. The preferred approach would be to carefully examine the current revision and eliminate or rewrite the provisions that are not necessary for compliance with the Federal Guidance. Those provisions identified as cost-beneficial but not necessary for compliance with the Federal Guidance should remain in the revision. Once the appropriate changes are made, the revision could be published in the Federal Register. During this period, the NRC could develop and/or revise the regulatory guides required to support the revised rule. 


\section{ACKNOWLEDGMENTS}

The authors would like to thank the following: Jerry B. Martin, Matthew P. Moeller, and Michael J. Scott for their technical contributions; Jim Weber for editing the report; and Claudia H. Burk, Lisa M. Stoetzel, and Marianna Cross for typing the report. The authors would also like to acknowledge the contributions by Darrell R. Fisher and John P. Corley (retired), who provided thorough technical reviews of the report and made many valuable suggestions. 


\section{CONTENTS}

ABSTRACT

EXECUTIVE SUMMARY $\ldots \ldots \ldots \ldots \ldots \ldots \ldots \ldots \ldots \ldots \ldots \ldots \ldots \ldots \ldots \ldots \ldots \ldots$

ACKNONLEDGMENTS $\ldots \ldots \ldots \ldots \ldots \ldots \ldots \ldots \ldots \ldots \ldots \ldots \ldots \ldots \ldots \ldots \ldots \ldots \ldots \ldots \ldots$

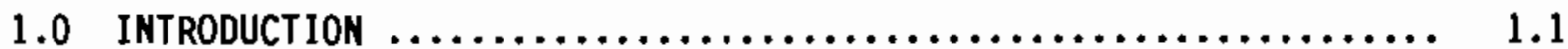

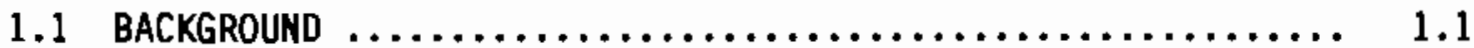

1.2 HISTORY OF PART 20 REVISIONS $\ldots \ldots \ldots \ldots \ldots \ldots \ldots \ldots \ldots \ldots \ldots .1$

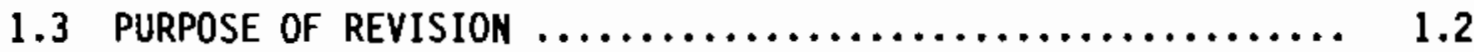

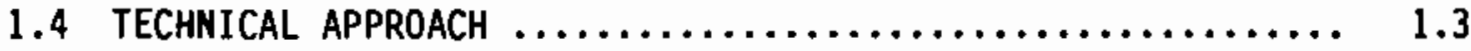

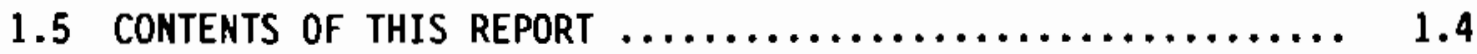

2.0 COMPARISON OF PRESENT PART 20 WITH PART 20 REVISION $\ldots \ldots \ldots \ldots . . .1$

2.1 SUMMARY OF SIGNIFICANT CHANGES REGARDING INTERNAL DOSE

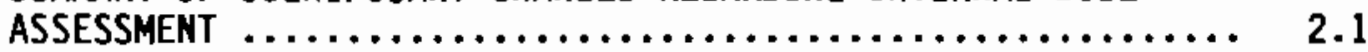

2.1.1 Section 20.202: Compliance with Requirements

for Summation of Internal and Externa] Exposures ... 2.1

2.1.2 Section 20.204: Determination of Internal

Exposure ............................... 2.1

2.1.3 Section 20.502: Conditions Requiring Individual

Monitoring of External and Internal 0ccupational

Dose .................................. 2.2

2.2 SUMMARY OF SIGNIFICANT CHANGES REGARDING OCCUPATIONAL

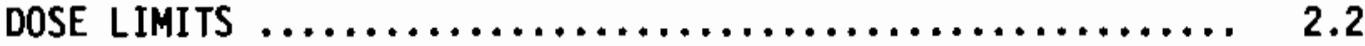

2.2.1 Section 20.201: Occupational Dose Limits for

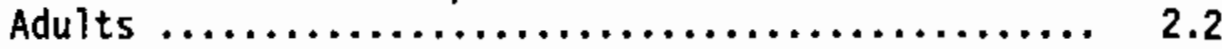

2.2.2 Section 20.206: Planned Special Exposures ....... 2.2

2.2.3 Section 20.208: Dose to an Embryo/Fetus ........ 2.3

2.3 SUMNARY OF SIGNIFICANT CHANGES REGARDING LIMITATION OF

DOSE TO THE PUBLIC ........................... 2.3 
2.3.1 Section 20.301: Dose Limits for Individual Members of the Public ............................... 2.3

2.3.2 Section 20.302: Compliance with Dose Limits for Individual Members of the Public ............... 2.3

2.4 SUMMARY OF SIGNIFICANT CHANGES REGARDING RECORDKEEPING AND REPORTING REQUIREMENTS

2.4.1 Section 20.1106: Records of Individual Monitoring Results $\ldots \ldots \ldots \ldots \ldots \ldots \ldots \ldots \ldots \ldots \ldots \ldots \ldots \ldots, 2.4$

2.4.2 Section 20.1107: Records of Dose to Individual Members of the Public $\ldots \ldots \ldots \ldots \ldots \ldots \ldots \ldots \ldots, 2.4$

2.4.3 Section 20.1206: Reports of Personnel Monitoring .. 2.4 2.5 SUMMARY OF OTHER CHANGES $\ldots \ldots \ldots \ldots \ldots \ldots \ldots \ldots \ldots \ldots \ldots, 2.4$

2.5.1 Changes Regarding Control of Internal Exposure in Restricted Areas $\ldots \ldots \ldots \ldots \ldots \ldots \ldots \ldots \ldots \ldots \ldots, 2.4$

2.5.2 Changes Regarding Precautionary Procedures ........ 2.4

2.5.3 Changes Regarding Waste Disposal .............. 2.5

2.5.4 Changes Regarding Recordkeeping Requirements ...... 2.5

2.5.5 Changes Regarding Reporting Requirements ........ 2.5

3.0 CONSEQUENCES OF REVISED DOSE EVALUATION REQUIREMENTS $\ldots \ldots \ldots \ldots .3 .1$

3.1 EXTERMAL DOSE EVALUATIONS $\ldots \ldots \ldots \ldots \ldots \ldots \ldots \ldots \ldots, 3.1$

3.2 INTERMAL DOSE EVALUATIONS $\ldots \ldots \ldots \ldots \ldots \ldots \ldots \ldots \ldots \ldots \ldots, 3.3$

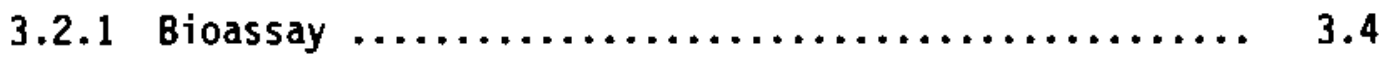

3.2 .2 Air Monitoring $\ldots \ldots \ldots \ldots \ldots \ldots \ldots \ldots \ldots \ldots \ldots \ldots, \quad 3.4$

3.3 DOSE EVALUATION COSTS $\ldots \ldots \ldots \ldots \ldots \ldots \ldots \ldots \ldots \ldots \ldots \ldots, 3.8$

3.4 DISTRIBUTION OF OCCUPATIONAL DOSES $\ldots \ldots \ldots \ldots \ldots \ldots \ldots \ldots .3 .13$

3.4.1 Fuel Fabrication Facilities ................. 3.13

3.4.2 0ther Facilities $\ldots \ldots \ldots \ldots \ldots \ldots \ldots \ldots \ldots \ldots \ldots \ldots, 3.14$

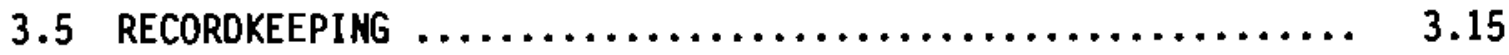

3.6 SUMMARY OF CONSEQUENCES $\ldots \ldots \ldots \ldots \ldots \ldots \ldots \ldots \ldots \ldots \ldots, 3.18$ 
4.0 CONSEQUENCES OF REVISED LIMITS $\ldots \ldots \ldots \ldots \ldots \ldots \ldots \ldots \ldots \ldots \ldots, 4.1$

4.1 OCCUPATIONAL DOSE LIMITS FOR ADULTS $\ldots \ldots \ldots \ldots \ldots \ldots \ldots \ldots, 4.1$

4.1.1 Whole-Body Dose Equivalent Limits ............. 4.1

4.1.2 0ther Limits and Their Consequences ............ 4.8

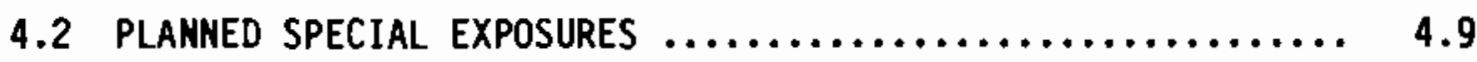

4.2.1 Use of the Planned Special Exposure Provision ..... 4.9

4.2.2 Effect on Distribution of Doses .............. 4.10

4.2.3 Cost Implications ....................... 4.10

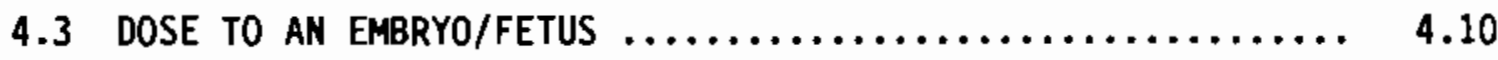

4.3.1 Effect on Distribution of Doses ............... 4.11

4.3.2 Cost Implications $\ldots \ldots \ldots \ldots \ldots \ldots \ldots \ldots \ldots \ldots, 4.12$

4.3.3 Dther Considerations $\ldots \ldots \ldots \ldots \ldots \ldots \ldots \ldots \ldots, 4.12$

4.4 DOSE LIMIT FOR INDIVIDUAL MEMBERS OF THE PUBLIC $\ldots \ldots \ldots \ldots, 4.13$

4.4.1 Effect on Distribution of Doses .............. 4.13

4.4 .2 Cost Implications ........................ 4.14

4.5 SUMMARY OF CONSEQUENCES $\ldots \ldots \ldots \ldots \ldots \ldots \ldots \ldots \ldots \ldots \ldots, 4.14$

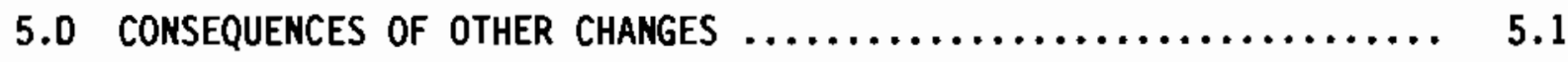

5.1 CONTROL OF INTERNAL EXPOSURE IN RESTRICTED AREAS $\ldots \ldots \ldots \ldots .5 .1$

5.2 PRECAUTIONARY PROCEDURES $\ldots \ldots \ldots \ldots \ldots \ldots \ldots \ldots \ldots \ldots \ldots \ldots \ldots \ldots \ldots \ldots \ldots, 5.3$

5.2.1 Labeling Requirements $\ldots \ldots \ldots \ldots \ldots \ldots \ldots \ldots \ldots \ldots, 5.3$

5.2 .2 Posting Requirements $\ldots \ldots \ldots \ldots \ldots \ldots \ldots \ldots \ldots, 5.4$

5.2.3 Package Handling Requirements $\ldots \ldots \ldots \ldots \ldots \ldots \ldots .5 .4$

5.3 WASTE DISPOSAL $\ldots \ldots \ldots \ldots \ldots \ldots \ldots \ldots \ldots \ldots \ldots \ldots \ldots \ldots, 5.4$

5.4 RECORDKEEPING REQUIREMENTS $\ldots \ldots \ldots \ldots \ldots \ldots \ldots \ldots \ldots \ldots \ldots, 5.5$

5.5 REPORTING REQUIREMENTS $\ldots \ldots \ldots \ldots \ldots \ldots \ldots \ldots \ldots \ldots \ldots \ldots \ldots \ldots \ldots \ldots \ldots \ldots, 5$

5.5.1 Incident Reports $\ldots \ldots \ldots \ldots \ldots \ldots \ldots \ldots \ldots \ldots \ldots, 5.8$ 
5.5.2 Reports of Personnel Monitoring $\ldots \ldots \ldots \ldots \ldots \ldots \ldots, 5.8$

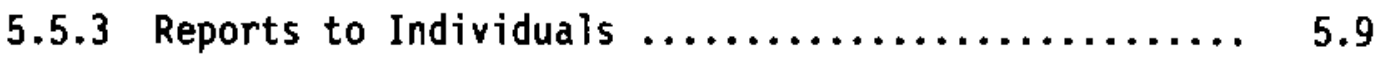

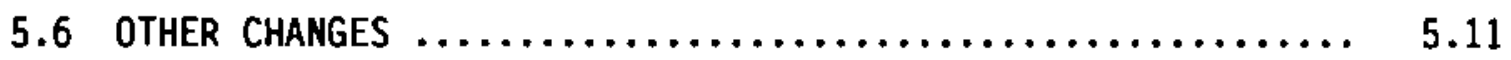

5.6.1 Units of Radiation Dose $\ldots \ldots \ldots \ldots \ldots \ldots \ldots \ldots \ldots, 5.11$

5.6.2 Radiation Protection Programs $\ldots \ldots \ldots \ldots \ldots \ldots \ldots .5 .11$

5.6.3 Control of Access to High Radiation Areas ........ 5.12

5.7 SUMMARY OF CONSEQUENCES $\ldots \ldots \ldots \ldots \ldots \ldots \ldots \ldots \ldots \ldots \ldots, 5.12$

6.0 OTHER CONSEQUENCES OF THE REVISION $\ldots \ldots \ldots \ldots \ldots \ldots \ldots \ldots \ldots \ldots, 6.1$

6.1 Personnel training $\ldots \ldots \ldots \ldots \ldots \ldots \ldots \ldots \ldots \ldots \ldots \ldots \ldots, 6.1$

6.2 PROCEDURE REVISIONS $\ldots \ldots \ldots \ldots \ldots \ldots \ldots \ldots \ldots \ldots \ldots \ldots, 6.3$

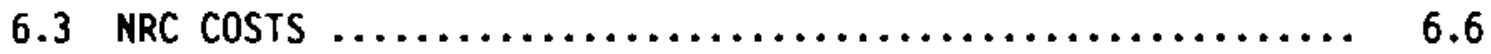

6.3.1 Development $\ldots \ldots \ldots \ldots \ldots \ldots \ldots \ldots \ldots \ldots \ldots \ldots, 6.7$

6.3 .2 Implementation $\ldots \ldots \ldots \ldots \ldots \ldots \ldots \ldots \ldots \ldots \ldots \ldots, 6.7$

6.3 .3 Operation $\ldots \ldots \ldots \ldots \ldots \ldots \ldots \ldots \ldots \ldots \ldots \ldots \ldots \ldots \ldots \ldots \ldots \ldots, 6.8$

6.4 EFFECTS ON SMALL BUSINESSES $\ldots \ldots \ldots \ldots \ldots \ldots \ldots \ldots \ldots \ldots, 6.9$

6.5 SUMMARY OF CONSEQUENCES $\ldots \ldots \ldots \ldots \ldots \ldots \ldots \ldots \ldots \ldots \ldots \ldots, 6.12$

7.0 QUALITATIVE BENEFITS fROM REVISING PART $20 \ldots \ldots \ldots \ldots \ldots \ldots \ldots, 7.1$

7.1 POTENTIAL BENEFITS FROM CONSISTENCY WITH NATIONAL AND
INTERNATIONAL RECOMMENDATIONS $\ldots \ldots \ldots \ldots \ldots \ldots \ldots \ldots \ldots \ldots \ldots \ldots \ldots \ldots \ldots$

7.2 POTENTIAL BENEFITS FROM REVISED MONITORING REQUIREMENTS $\ldots \quad \mathbf{7 . 5}$

7.3 POTENTIAL BENEFITS FROM REVISED RECORDKEEPING/REPORTING

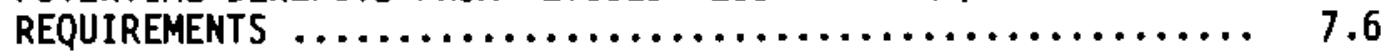

7.4 POTENTIAL BENEFITS FRON ADDITIONS/REVISIONS TO CURRENT 7.8

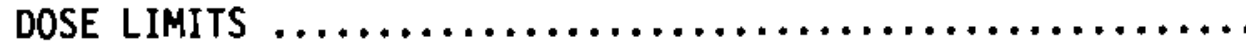

7.5 POTENTIAL BENEFITS FROM SUPPLIED GUIDANCE FOR COMPLYING WITH THE REVISION $\ldots \ldots \ldots \ldots \ldots \ldots \ldots \ldots \ldots \ldots \ldots \ldots \ldots \ldots \ldots, \quad 7.9$

7.6 POTENTIAL BENEFITS FRON DOSE LIMITS FOR PREGNANT HOMEN AND EMBRYOS/FETUSES $\ldots \ldots \ldots \ldots \ldots \ldots \ldots \ldots \ldots \ldots \ldots \ldots \ldots, 7.10$

7.7 POTENTIAL BENEFITS FROM REVISED LABELING REQUIREMENTS $\ldots . .7 .10$ 
8.0 SUMMARY OF COSTS AND BENEFITS $\ldots \ldots \ldots \ldots \ldots \ldots \ldots \ldots \ldots \ldots \ldots, 8.1$

8.1 COMPENDIUM OF MRC AND AGREEMENT STATE LICENSEES $\ldots \ldots \ldots \ldots, 8.1$

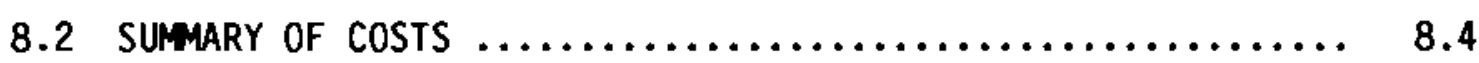

8.2.1 Summary by Facility Type $\ldots \ldots \ldots \ldots \ldots \ldots \ldots \ldots, 8.6$

8.2.2 Sumnary by Part 20 Section $\ldots \ldots \ldots \ldots \ldots \ldots \ldots \ldots, 8.6$

8.2.3 Discussion of Uncertainties $\ldots \ldots \ldots \ldots \ldots \ldots \ldots \ldots, 8.6$

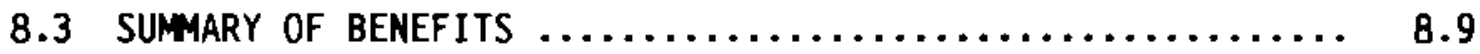

8.3.1 Summary by Part 20 Section $\ldots \ldots \ldots \ldots \ldots \ldots \ldots \ldots .6 .9$

8.3.2 Discussion of Uncertainties $\ldots \ldots \ldots \ldots \ldots \ldots \ldots \ldots, 8.9$

8.4 SENSITIVITY ANALYSIS $\ldots \ldots \ldots \ldots \ldots \ldots \ldots \ldots \ldots \ldots \ldots \ldots, 8.10$

8.5 CONCLUSIONS $\ldots \ldots \ldots \ldots \ldots \ldots \ldots \ldots \ldots \ldots \ldots \ldots \ldots \ldots \ldots \ldots \ldots, 8.11$

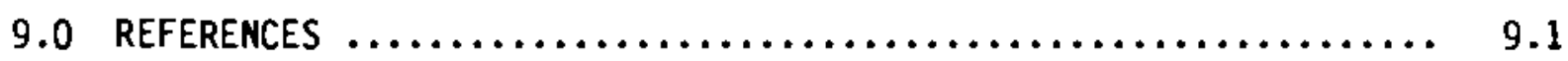




\section{$\underline{T A B L E S}$}

S.1 Costs Incurred by Section of the Final Rule $\ldots \ldots \ldots \ldots \ldots \ldots$ viii

S.2 Implementation Costs of the Part 20 Revision by Facility Type .. $x$

S.3 Cost Per Facility and Annualized Cost to Implement the Part

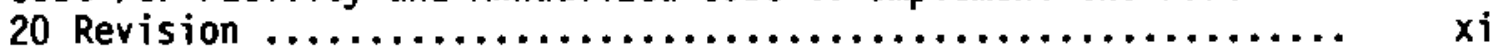

3.1 0ccupational Dose Limits Specified in the Present and

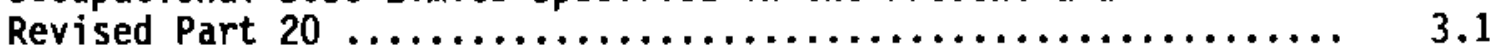

3.2 Annual Limits on Intake of Common Radionuclides Compared to Detection Capabilities for Urinalysis and In Vivo Counting ..... 3.5

3.3 Comparison of Part 20 Current and Revised Air Concentration Limits for Certain Radionuclides ......................... 3.7

3.4 Estimated Costs of Increased Recordkeeping Requirements Resulting from the Revised Dose Evaluation Requirements ....... 3.17

3.5 Summary of Consequences of the Revised Dose Evaluation Requirements

4.1 Doses Received by Licensee Employees in $1984 \ldots \ldots \ldots \ldots \ldots \ldots, 4.2$

4.2 Number of Licensee Employees Reported to Have Received Doses Approaching or Exceeding $5 \mathrm{rem}$ in $1979 \ldots \ldots \ldots \ldots \ldots \ldots \ldots \ldots \ldots$.

4.3 Adjusted Number of Employees who Received Doses >5 rem in 1979 and 1984

4.4 Number of Women Reported to Have Received Doses $>0.5$ rem in 1980

4.5 Sumary of Consequences of the Revised Limits ............. 4.15

5.1 Estimated Collective Dose Equivalent Savings During an Outage Through Reduced Respiratory Usage for Selected Tasks .............

5.2 Current and Revised Average Concentration Limits for Releases

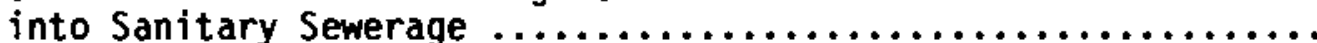

5.3 Cost of Providing Reports to Individuals by Facility Category .. $\quad 5.10$

5.4 Summary of Marginal Cost Increases from 0ther Changes in the

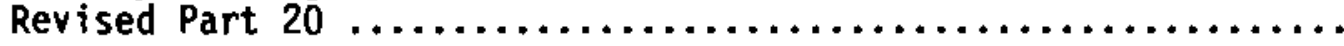

6.1 Fraction of Licensees That May Be Classified as Small Businesses 
6.2 Per-facility Costs from the 10 CFR Part 20 Revision .......... 6.10

6.3 Estimated Total Cost to Small Businesses from the 10 CFR Part 20 Revision $. . . \ldots \ldots \ldots \ldots \ldots \ldots \ldots \ldots \ldots \ldots \ldots, 6.11$

6.4 Summary of Marginal Cost Increases from Other Consequences of

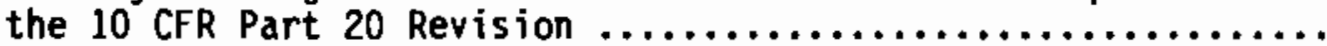

7.1 Comparison of the Revision of Part 20 with National and

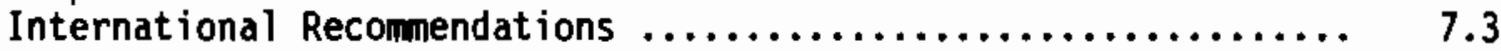

8.1 Categories of Licensees $\ldots \ldots \ldots \ldots \ldots \ldots \ldots \ldots \ldots \ldots \ldots \ldots, 8.3$

8.2 Number of NRC and Agreement State Licensees in $1985 \ldots \ldots \ldots \ldots .8 .4$

8.3 Employee Data for NRC and Agreement State Licensees in $1985 \ldots .8 .8$

8.4 Quantified Costs Incurred from the Revision of Part 20 by Facility Category $\ldots \ldots \ldots \ldots \ldots \ldots \ldots \ldots \ldots \ldots \ldots \ldots \ldots \ldots, \quad 8.7$

8.5 Quantified Costs Incurred from the Revision of Part 20 by Section of the Rule $\ldots \ldots \ldots \ldots \ldots \ldots \ldots \ldots \ldots \ldots \ldots \ldots \ldots \ldots, 8.8$

8.6 Benefits of the Revision of Part 20 by Section of the Rule .... 8.10

8.7 Sensitivity of Net Benefits to Variations in Basic Assumptions . 8.12

8.8 Estimated Net Impact (Present Value) of the Revision

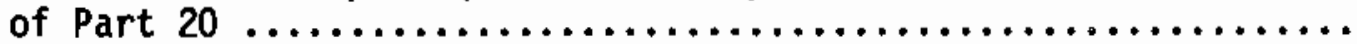




\subsection{INTRODUCTION}

The U.S. Nuclear Regulatory Comission (NRC) plans to promulgate a complete revision of Title 10, Part 20, Code of Federal Regulations, "Standards for Protection Against Radiation." This report presents a cost-benefit analysis of the revision which can be used by regulatory authorities to assess the impact of the revision on society. Groups affected by the revision will be NRC licensees, Agreement State licensees, NRC and Agreement State agencies, the general pubijc, and businesses directly or indirectly related to the nuclear industry. The following four sections provide a historical perspective of Part 20 and describe the methodology used in this report to assess the impact of the revision.

\subsection{BACKGROUND}

Code of Federal Regulations Title 10, Part 20 provides standards for protection of workers and the public against radiation hazards arising out of activities under licenses issued by the NRC. In addition, these standards are used as the basis for the regulations promulgated by the 28 Agreement States.

The current standards are based primarily on the recomendations of the 1nternational Commission on Radiological Protection (ICRP) published in 1959 (ICRP 1959). Since that time, 10 CFR Part 20 has undergone numerous minor revisions, but most of the principles underlying the protection standards remain as they were three decades ago. In 1977, the ICRP published a new set of recomnendations (ICRP 1977). These recommendations were based on a revised concept of total risk limitation and provided methods for normalizing risks from doses received by different parts of the body. This concept was adopted by both the National Council on Radiation Protection and Measurements (NCRP) (NCRP 1987) and the Environmental Protection Agency (EPA) (FR 1987; EPA 1983a; EPA 1983b). If promulgated, the revision of Part 20 would incorporate the ICRP system of dose limitation.

\subsection{HISTORY OF PART 20 REVISIONS}

The NRC's standards for protection against radiation are basically unchanged from those first developed by the Atomic Energy Commission (AEC) approximately 30 years ago. These standards were based on ICRP recommendations (ICRP 1959) and reflected the scientific understanding of the effects of radiation at that time. Since then, Part 20 has undergone numerous minor revisions, but the basic principles underlying the system of dose limitation have not changed.

Soon after the publication of the ICRP recommendations in ICRP Publication 26 (ICRP 1977), the NRC initiated a rulemaking activity to incorporate these recommendations into 10 CFR Part 20. On March 20, 1980, an "Advance Notice of Proposed Rulemaking" was published in the Federal Register. 
In 1982, the NRC prepared a Regulatory Analysis for the most recent version of the planned revision of Part 20 . Subsequently, the revision underwent several iterations until a proposed revision was published in the Federal Register on January 9, 1986 (FR 1986). This was a corrected version of the proposed revision first published on December 20, 1985. Announcement of a 120-day comment period coincided with publication of the proposed revision.

Upon publication of the proposed revision, a draft backfit analysis to comply with Section 50.109 of 10 CFR 50 was requested by the Commission. This analysis was developed and published for public comment on August 29, 1986. Coincident with publication of the backfit analysis, the public comment period on the proposed revision was extended to october 31,1986 . This provided a 250-day comment period on the proposed revision, including a 60-day joint coment period on the proposed revision and the backfit analysis. A total of 813 comments were received during the 250 -day comment period.

Based primarily on analysis of the comments on the proposed rule, the NRC perfomed further iterations of the revision until December 4, 1987, when the final rule language was approved by an NRC Steering Committee. Several changes to the rule were made after that date. The analysis provided in this report is based on the May 19, 1988, wording of the rule. Although further changes to the wording might occur before the Comission decides whether to promulgate the revised rule, any such changes should not affect the conclusions of this report.

\subsection{PURPOSE OF REVISION}

The primary purpose of revising Part 20 is to incorporate the basic principles of ICRP Publication 26, which were endorsed by the EPA in its Federal Radiation Protection Guidance (FR 1987). Under the current Part 20, the quarterly whole-body dose limit applies only to external doses. Internal doses are subject to separate limits based on the dose to critical organs. Under the revised Part 20, external doses and internal doses would be summed to demonstrate compliance with the annual whole-body dose limit. This system of dose limitation is consistent with current ICRP and NCRP recommendations on protection of both workers and the public from ionizing radiation (ICRP 1977; NCRP 1987), and is also consistent with the Radiation Protection Guidance to Federal Agencies for Occupational Exposure, signed by the President (FR 1987).

The revised Part 20 would also incorporate other recommendations of the ICRP, NCRP, and EPA. Under the current Part 20, workers are allowed to receive an external whole-body dose of 3 rem per quarter, provided that their average annual dose after the age of 18 does not exceed 5 rem. Considering that internal doses are not considered in this limit, the potential exists for some workers under the current rule to receive doses significantly more than 12 rem per year. Under the revised Part 20, workers would be 1 imited to 5 rem per year, except under special circumstances when a limit of 10 rem could be applied. 
The revised Part 20 would include, for the first time, a dose limit to the embryo/fetus of pregnant workers. The ICRP, NCRP, and EPA all recommended a limit to the embryo/fetus that is separate and lower than the wholebody dose limit to adult workers. This provision in the revised Part 20 would introduce a limit that is already being applied to most radiation workers in the United States.

The revised Part 20 would correct outdated individual radionuclide intake limits in the current rule. Because the fundamental principles of the current rule are 30 years old, some of the intake limits are no longer consistent with current scientific knowledge and understanding of the behavior of radionuclides in the body. Inconsistencies associated with application of the limits would be corrected by the revision, as well.

In general, the revision of Part 20 represents a complete overhaul of the current rule. The revision would reflect current scientific knowledge of radiation protection principles and would provide a sound technical basis for the dose limits.

\subsection{TECHNICAL APPROACH}

This report documents a regulatory analysis of the impacts of the revision of Part 20. The methods and format of the analysis are consistent with both the regulatory analysis guidelines of the NRC (USNRC 1984) and accepted methods for performing value-impact assessments (Heaberlin et al. 1983). Although this analysis does not provide a backfit analysis consistent with 10 CFR 50.109, the information provided in this report is sufficient for the development of such an analysis.

The analysis provided in this report is a cost-benefit analysis of the revision of Part 20 . Only the marginal costs and benefits are identified; that is, only those costs and benefits that represent additions or reductions compared to those currently being incurred under the present Part 20 are considered. The analysis is based on many sources of information, including a previous regulatory analys is of an earlier version of the revision (USARC 1982), public comments on the regulatory analys is, public comments on the proposed rule and backfit analysis, and numerous publications relevant to specific provisions of the revision.

The current plan for implementing the revision is to allow a 5-year implementation period beginning the day the proposed rule was published (January 9, 1986). Because the final revision is not expected to be published until the end of 1988, licensees will have approximately 2 years after publication of the rule to fully implement its provisions. In this report, all quantified costs and benefits are nomalized to January 1, 1989. For cost estimates obtained from cost information provided in the literature, a 5\% per year increase was applied to account for inflation.

Because publication of the proposed rule in 1986 prompted many licensees to begin "gearing up" for publication of the final rule, implementation costs will be distributed over the 5-year implementation period. In many cases, 
licensees will defer implementation of the rule as long as possible. For this analysis, present value calculations are based on the assumption that $5 \%, 5 \%, 10 \%, 40 \%$, and $40 \%$ of the implementation costs were or will be incurred in 1986, 1987, 1988, 1989, and 1990, respectively.

To be consistent with accepted guidance on performing value-impact assessments (Heaberlin et al. 1983), the resources spent to quantify the costs and benefits identified in this report were comensurate with their expected magnitude. As a result, many of the identified impacts have been labeled "negligible." This is not intended to imply that the impacts are nonexistent or unimportant to individual licensees; rather, impacts labeled "negligible" are assumed to have no significant impact on the results of this analysis.

\subsection{CONTENTS OF THIS REPORT}

The Executive Summary summarizes the analysis in a format consistent with the regulatory analysis guidelines of the MRC (USNRC 1984). Section 2.0 compares the current Part 20 with the Part 20 revision to briefly familiarize the reader with the important changes introduced in the revision. Section 3.0 presents the consequences of the revised dose evaluation requirements, including both external and internal dose evaluation. Section 4.0 presents the consequences of the revised dose limits, and Section 5.0 presents the consequences of other changes to Part 20. In Section 6.0, consequences of the revision that are not related to specific provisions are described, including the costs associated with personnel training and procedure revisions, the costs that will be incurred by NRC to implement and enforce the revision, and the impact of the revision on small businesses. Section 7.0 discusses the important benefits from revising Part 20 . Although most of these benefits cannot be quantified, they are presented in sufficient detail in this report so that the appropriate authorities can evaluate their significance with respect to the associated costs of the revision. Finally, Section 8.0 summarizes the costs and benefits associated with the revision.

As discussed in Section 1.2, the revision of Part 20 has undergone numerous iterations. In this report, the following definitions apply. The proposed rule is defined as the rule published for public comment on January 9. 1986 (FR 1986). It may also be referred to as "the proposed revision" or "the proposed Part 20." The current rule is defined as the rule present in the Code of Federal Regulations as of January 1, 1988. The current rule may also be referred to as "the present rule". "the current (or present) Part 20", or "the current (or present) regulations." The revised rule is defined as the current version of the planned revision, as of May 19, 1988. The revised rule may also be referred to as "the revised Part 20". "the revision of Part $20^{\prime \prime}$, or simply "the revision." 


\subsection{COMPARISON OF PRESENT PART 20 WITH PART 20 REVISION}

The revision of Part 20 will involve changes to most sections of the present rule. Also, the revision will result in either the addition or deletion of certain sections. Some of the changes are major and are expected to impact licensees significantly. Other changes, however, are relatively minor and are expected to have little or no impact. Sections 2.1 through 2.4 below describe changes to the rule that are likely to have significant impacts. Section 2.5, however, describes changes that are expected to have less significant impacts. Changes expected to have little or no impact are not discussed.

\subsection{SUMMARY OF SIGNIFICANT CHANGES REGARDING INTERNAL DOSE ASSESSMENT}

The primary purpose for revising Part 20 is to incorporate the current ICRP system of dose limitation (ICRP 1977) as adopted by the EPA (FR 1987). Basic to this system is the concept that both internal and external doses should be sumed to determine relative risk. As a result, the revised Part 20 requires assessment of internal doses and summation of internal and external doses to determine the total effective dose equivalents, a measure of total health risk, to individuals. The present Part 20 does not require summation of internal and external doses.

An important consideration for this analysis is that under the revised Part 20 , the sumation requirement might result in increased whole-body dose equivalents being recorded compared to the external whole-body doses currently being recorded even though the actual dose (risk) to the worker remains the same. Because this increase in recorded dose would be a result of changing terminology rather than an actual increase in risk, no impact regarding health effects is associated with this change.

\subsubsection{Section 20.202: Compliance with Requirements for Sumation of Internal and External Exposures}

The present Part 20 does not require summation of external and internal doses. In the revised rule, Section 20.202 specifies when and how a licensee must consider intakes of radionuclides in determination of total effective dose equivalent.

\subsubsection{Section 20.204: Determination of Internal Exposure}

This section defines acceptable procedures for determining internal exposures based on air sampling or bioassay measurements. The revised section is more detailed than the analogous section in the present Part 20 because the revised Part 20 requires sumation of internal and external doses. 


\subsubsection{Section 20.502: Conditions Requiring Individual Monitoring of External and Internal 0ccupational Dose}

The present Part 20 requires monitoring at $25 \%$ of the quarterly limits. However, Section 20.502 of the revised rule requires individual monitoring for workers who are likely to receive doses in excess of $10 \%$ of the occupational dose limits. This section mandates, in accordance with Section 20.202, that suitable measurements be performed to allow summation of internal and external doses. Summation is required when internal doses exceed 10\% of the applicable annual limits.

\subsection{SUMMARY OF SIGNIFICANT CHANGES REGARDING OCCUPATIONAL DOSE LIMITS}

This section describes the significant changes in occupational dose limits in the revised Part 20.

\subsubsection{Section 20.201: Occupational Dose Limits for Adults}

The present Part 20 specifies a $1.25 \mathrm{rem} /$ quarter limit to the whole body, head and trunk, active blood-forming organs, lens of eyes, or gonads. If the licensee has a record of a worker's exposure history, the worker may receive up to $3 \mathrm{rem} / q u a r t e r$, provided the worker's lifetime dose does not exceed $5(\mathrm{~N}-18)$ rem, where $N$ is the worker's age in years. The revised occupational dose limits for adults specify a total effective dose equivalent per year of 5 rem and a limit of 50 rem (sum of deep and committed dose equivalents) for organs or tissues other than the lens of the eye.

The present Part 20 specifies limits of $1.25 \mathrm{rem} /$ quarter to the lens of the eye, $7.5 \mathrm{rem} /$ quarter to the skin, and $18.75 \mathrm{rem} /$ quarter to each of the extremities. The revised annual limits are 15 rem to the lens of the eye, 50 rem to the skin, and 50 rem to each of the extremities. The definition of "extremities" in the revision is slightly different than the definition in the present Part 20.

The present Part 20 also specifies limits for exposure of individuals to concentrations of radioactive materials in air. The limit can be calculated from air concentrations listed by radionuclide in Appendix $B$. The revision, on the other hand, does not specify such limits because the total effective dose equivalent limit includes intakes of radionuclides. However, the revision does specify a $10 \mathrm{mg} /$ week limit for intake of soluble uranium because of its chemical toxicity. Limits on intake of other radioactive materials are implied by the $5 \mathrm{rem} / \mathrm{yr}$ limit on total effective dose equivalent for radiation workers.

\subsubsection{Section 20.206: Planned Special Exposures}

This section in the revised rule allows licensees to authorize adult workers to receive doses in excess of the occupational dose limits provided that certain conditions are met. Although there is no analogous provision in the present Part 20, planned special exposures would be similar to the $5(N-18)$ rule in that workers would be allowed to exceed the annual 
occupational dose limits under certain conditions. If the provision is used, individual workers could receive double the annual occupational dose limits for a maximum of 5 years during the worker's lifetime.

\subsubsection{Section 20.208: Dose to an Embryo/Fetus}

A limit to the embryo/fetus is not addressed in the present Part 20. Under this section in the revised rule, however, the dose to an embryo/fetus is limited to 0.5 rem. The new rule effectively limits the total effective dose equivalent of a declared pregnant woman to 0.5 rem during the pregnancy. Most licensees currently practice this limit because it is addressed in both a NRC Regulatory Guide (USNRC 1987a) and a staff position paper.

\subsection{SUMMARY OF SIGNIFICANT CHANGES REGARDING LIMITATION OF DOSE TO THE PUBLIC}

Although the present rule only implies limits on dose to the public, the revised Part 20 would contain explicit limitations on such dose. This section describes the new requirements.

\subsubsection{Section 20.301: Dose Limits for Individual Members of the Public}

In the present Part 20, a whole-body limit of 0.5 rem/yr for each member of the public is implied but is not explicitly stated. This revised section, however, limits the total effective dose equivalent to individual members of the public to $0.1 \mathrm{rem} / \mathrm{yr}$. The limit includes doses from all operations by a licensee, excluding disposal of radioactive material into sanitary sewerage. The revision allows licensees to apply for authorization to operate up to an annual effective dose equivalent of $0.5 \mathrm{rem} / \mathrm{yr}$ for individual members of the public.

\subsubsection{Section 20.302: Compliance with Dose Limits for Individual Members of the Public}

Although the present Part 20 does not include this provision, this section in the revised rule requires licensees to make measurements, as appropriate, to demonstrate compliance with the limits specified in Section 20.301.

\subsection{SUMMARY OF SIGNIF1CANT CHANGES REGARDING RECORDKEEPING AND REPORT1NG REQUUIREMENTS}

Because the revision to Part 20 includes a revised system of dose limitation, the information collected by licensees to assess doses will be more detailed than the information presently collected. As a result, recording and reporting of this information is expected to be more extensive than under the present rule. 


\subsubsection{Section 20.1106: Records of Individual Monitoring Results}

This section specifies the information that will be required on NRC Form 5. Although the present Part 20 also requires individual monitoring results to be recorded on NRC Form 5, more information will be required under the revised rule to denonstrate compliance with occupational dose limits.

\subsubsection{Section 20.1107: Records of Dose to Individual Members of the Public}

Although not required in the present Part 20 , the revised rule requires that records shall be maintained to demonstrate compliance with dose 1 imits for individual members of the public.

\subsubsection{Section 20.1206: Reports of Personnel Monitoring}

The present Part 20 does not require that individual monitoring reports be submitted for each individual for whom monitoring was required, but does require certain licensees to submit an annual statistical summary report. Under Section 20.1206 of the revised rule, however, the same licensees are required to submit an annual report of the results of individual monitoring for each individual for whom monitoring was required. In addition, the revised 10 CFR Part 19 requires that all licensees submit, at least annually, reports to those individuals describing the doses that they received. Currently, licensees are required to submit reports to individuals only upon request.

\subsection{SUMMARY OF OTHER CHANGES}

\subsubsection{Changes Regarding Control of Internal Exposure in Restricted Areas}

Subpart $H$ of the revision contains requirements pertaining to respiratory protection controls to restrict internal exposure in restricted areas. Most of the changes that appear in the revision are either editorial or are insignificant with respect to cost. One exception is Section 20.702, which states that the licensee shall limit intakes so that the total effective dose equivalent is maintained ALARA. The present Part 20 discourages deliberate internal exposures that are a significant fraction of the dose limits and does not require that the total effective dose equivalent be maintained as low as reasonably achievable (ALARA).

\subsubsection{Changes Regarding Precautionary Procedures}

Most of the changes regarding precautionary procedures are expected to have insignificant impacts on licensees with the exception of labeling requirements. In the revised Appendix $C$, quantities of most radioactive materials that will require labeling are higher than the values provided in Appendix $C$ of the present Part 20 . 


\subsubsection{Changes Regarding Haste Disposal}

Most of the changes regarding waste disposal requirements are expected to have insignificant impacts on licensees. One exception is that the amounts of specific radionuclides that can be released into sanitary sewerage have been changed. In most cases, the revised limits are 10-100 times more restrictive than the present limits.

\subsubsection{Changes Regarding Recordkeeping Requirements}

Subpart $L$ of the revision contains sections that describe recordkeeping requirements. The requirements include records of radiation protection programs, records of surveys, records of prior occupational dose, records of planned special exposures, records of doses to both individual workers and individual members of the public, records of waste disposal, and records of testing entry control devices. Except for the sections that require records of doses to individual workers and individual members of the public (discussed in Section 2.4), the changes to the present rule are expected to have only minor impacts on licensees. In several cases, the sections in the revision contain more detail than the relevant sections in the present rule. The impacts of these revised requirenents are expected to be minor because most licensees currently keep records that fulfill the requirements of the revision. In two other cases (records of radiation protection programs and records of testing entry control devices), the requirements are new but are not expected to have a significant cost impact on licensees.

\subsubsection{Changes Regarding Reporting Requirements}

Subpart $M$ of the revision describes reporting requirements. Except for Section 20.1206, which was discussed in Section 2.4 of this report, the reporting requirenents pertain to unusual situations such as thefts and overexposures. In these cases, the requirements in the revision are similar to the requirements in the present Part 20 except for minor changes that either involve editorial changes or revised definitions of reportable events.

Because reporting of incidents is very infrequent, these changes are expected to have minimal cost impacts. 


.




\subsection{CONSEQUENCES OF REVISED DOSE EVALUATION REQUIREMENTS}

The present and proposed dose limits specified in 10 CFR Part 20 are summarized in Table 3.1. In addition to the changes to the limits, the fraction of the annual limit at which monitoring is required was effectively lowered from 25\% to $10 \%$ for both internal and external doses. Also, the revised annual total dose equivalent limit is based on a weighted fraction concept designed to normalize the risk of adverse health effects from a dose delivered nonuniformly to the body to the risk from a uniform whole body dose. The total effective dose equivalent includes the sum of both external doses and weighted internal doses when both individually exceed $10 \%$ of the annual limit. The anticipated impacts of these changes are evaluated in the following sections.

TABLE 3.1. Occupational Dose Limits Specified in the Present and Revised Part 20

\begin{tabular}{|c|c|c|c|}
\hline Present Exposure Category & $\begin{array}{l}\text { Present Dose } \\
\text { Limit, rem }\end{array}$ & $\begin{array}{c}\text { Revised Exposure } \\
\text { Category } \\
\end{array}$ & $\begin{array}{l}\text { Revised } \\
\text { Annual Dose } \\
\text { Limit, rem } \\
\end{array}$ \\
\hline $\begin{array}{l}\text { Whole Body (head and trunk, } \\
\text { act ive blood forming organs, } \\
\text { or gonads) }\end{array}$ & $\begin{array}{l}\text { 3/quarter } \\
5 / \text { yr (avg.) }\end{array}$ & $\begin{array}{l}\text { Total effective } \\
\text { dose equivalent }\end{array}$ & 5 \\
\hline Lens of eyes & $5 / y r$ & Lens of eyes & 15 \\
\hline $\begin{array}{l}\text { Hands, forearms, feet } \\
\text { and ankles }\end{array}$ & $75 / y r$ & Extremities & 50 \\
\hline Skin of the whole body & $30 / y r$ & Skin & 50 \\
\hline Internal Dose & $\begin{array}{l}520 \text { MPC-h } \\
\text { /quarter }\end{array}$ & & \\
\hline $\begin{array}{l}\text { Committed Dose Equivalents } \\
\text { Whole Body } \\
\text { Most Organs } \\
\text { Thyroid }\end{array}$ & $\begin{array}{l}5 / \mathrm{yr} \\
15 / \mathrm{yr} \\
30 / \mathrm{yr}\end{array}$ & $\begin{array}{l}\text { Committed dose } \\
\text { equivalent } \\
\text { (organs) }\end{array}$ & 50 \\
\hline
\end{tabular}

\subsection{EXTERNAL DOSE EVALUATIONS}

The present Part 20 limits external whole-body doses to 3 rem/quarter and to a lifetime average that is less than $5 \mathrm{rem} / \mathrm{yr}$ after the age of 18 . Doses to individual organs are not considered in calculations for compliance with this limit. The revised annual limit of 5 rem includes the summation of external and internal doses if the latter exceed $10 \%$ of the annual effective dose equivalent limit. The annual limit for extremities was lowered from 75 to 50 rem and the limit for the skin was raised from 30 to 50 rem. 
One potential cost associated with reduced external dose limits is the cost associated with improvements in personnel dosimeters. The most restrictive exposure limit regarding the sensitivity of personnel dosimeters is the annual whole body limit of $5 \mathrm{rem} / \mathrm{yr}$. Assuming a 1 -month exchange period, the minimum sensitivity for the dosimeter must be about $40 \mathrm{mrem}$ $(0.1 \times 5000 \mathrm{mrem} / 12$ months per year). Under both the current Part 20 and the revised Part 20, NRC licensees are required to obtain personnel dosimetry from a processor holding accreditation from the National Voluntary Laboratory Accreditation Program (NVLAP). Although NVLAP does not have a provision for lower limit of detection, dosimeters used currently can detect a 40 mrem dose. Therefore, no costs are anticipated regarding improvements in dosimetry methods.

Another potential cost is the cost associated with increased monitoring of workers. Because external doses must be monitored for workers likely to receive $10 \%$ of the revised dose limits in contrast to $25 \%$ of the current limits, it is possible that increased monitoring will be required at some facilities. However, essentially all facilities currently monitor whole-body doses to workers who receive significantly less than $500 \mathrm{mrem} / \mathrm{yr}$. The primary reason for monitoring relatively low doses is not to meet applicable state and federal regulations, but to both detect unsafe working conditions and protect the facility from litigation by documenting individual doses (Kelsey, Lane and Mettler 1984). Therefore, no increased monitoring of whole-body doses is anticipated from the revised monitoring requirements. However, extremity doses are not currently monitored at $10 \%$ of the revised extrenity limits in all cases.

At nuclear power plants, extremity dose monitoring is not nomally performed on a routine bas is because extremity doses received during routine operations are generally well below 25\% of the current limits (Huggins and Watson 1984). However, considering that the revised monitoring requirement is $10 \%$ of the revised extremity limits, and that the revised extremity limits are $50 \mathrm{rem} / \mathrm{yr}$ as opposed to $18.75 \mathrm{rem} /$ quarter, some workers who are not currently monitored will be monitored under the revised requirements. Based on a study of hand doses received during 4 months of routine operations at a typical nuclear power plant (Huggins and Watson 1984), it is estimated that additional extremity monitoring will be required for an average of 60 personmonths during routine operations per nuclear power plant per year. An additional 120 person-months/yr during outages is also anticipated.

Increases in extremity monitoring are expected for some other facilities, as well. Procedures such as implantation of radiotherapy needles at hospitals, elution and activity measurements at nuclear phamacies, and glove box operations at fuel fabrication facilities could result in doses to workers that may require increased extremity monitoring under the revised Part 20 (Thind 1987; Harty, Reece and MacLellan 1986). It is estimated that for $10 \%$ of medical facilities, average additional extremity monitoring of 12 person-months will be required. The remaining $90 \%$ of medical facilities are anticipated to incur no increased extremity monitoring costs. Additional extremity monitoring of 24 person-months per nuclear pharmacy and 60 person-months per fuel fabrication facility are also estimated. For 
other facilities, increases in extremity monitoring are expected to be relatively insignificant.

Based on the estimates provided above and the data presented in Section 8.1, increased extremity monitoring equivalent to 33,600 person-months/yr is anticipated in order to comply with the revised requirements. Assuming a monthly exchange period (Huggins and Watson 1984) and two dosimeters per person (one on a finger of each hand), 67,200 additional dosimeters per year will be processed. Based on an estimated cost of $\$ 5$ per dosimeter, which includes both the cost of evaluation and the cost of recording the evaluated dose information, the impact on NRC and Agreenent State licensees is estimated to be $\$ 340,000$ per year. The present value of these costs is included in the sumaries presented in Sections 3.6 and 8.2 .

\subsection{INTERNAL DOSE EVALUATIONS}

Section 20.103 of the current Part 20 promulgates limits for exposure to concentrations of radioactive materials in air in restricted areas. Internal dose is limited by compliance with maximum permissible concentrations (MPC) of radionuclides in air. These MPC values were established using empirically derived biokinetic models and the calculated dose to critical organs per unit of radioactivity inhaled. The critical organs were defined as those receiving the greatest dose and were specific for each radionuclide.

Compliance with the regulations is currently demonstrated by comparison of the exposure limit with the actual 13-week average air concentration and by appropriate bioassay techniques. Doses do not need to be calculated for time-weighted exposures less than $2 \mathrm{MPC}-\mathrm{h} / \mathrm{d}$ or $10 \mathrm{MPC}-\mathrm{h} / \mathrm{wk}$. The required sensitivity level for monitoring potential internal exposures is, therefore, $25 \%$ of the average weekly intake that would occur during exposure to an air concentration of one MPC.

The revised Part 20 requires 1 icensees to monitor intakes of radioactive material for adults likely to receive, in 1 year, an intake in excess of $10 \%$ of the applicable Annual Limits on Intake (ALIs). Intakes through wounds or oral ingestion will be significant for only a small percentage of the worker population and will almost always be the result of accidents (unplanned exposures). The only mode of entry for which monitoring will be routinely affected by the changes in the revision is intake by inhalation.

In accordance with the revised Part 20, compliance with the limit on intake by inhalation may be demonstrated in any of three ways: 1) limiting the sum of the quotients of intakes divided by ALIs to unity, 2) limiting the DAC-hours of exposure to 2000 , or 3 ) based on calculations from bioassay data, limiting the committed effective dose equivalents to all organs or tissues to the annual limit. Determination of internal exposure, therefore, requires either bioassay measurements to determine the uptake of radionuclides, or air monitoring to determine air concentrations to which workers may be exposed. 


\subsubsection{Bioassay}

Bioassay techniques may be separated into two categories, in vitro and in vivo. In vitro techniques estimate uptakes or intakes through analysis of excreta from potentially exposed individuals and application of biokinetic models to represent the behavior of radionuclides in the body. In vivo techniques estimate uptakes or intakes by direct measurement of photons emitted from radioactive material present in the body. The measurement data are then extrapolated to uptakes using biokinetic models. Because intakes as small as 10\% of an ALI must be included in the total effective dose equivalent under the revised Part 20 requirements, the bioassay technique used to assess internal uptakes must have a minimum detectable activity (MDA) at least as small as the uptake assumed to follow an intake of $10 \%$ of an ALI.

Using published data (Lessard et al. 1987) for excretion and lung retention fractions, the MDA necessary for detecting an intake of one-tenth of an AL1 30 days following the intake was calculated for a number of commonly-used radionuclides (Table 3.2 ). Thirty days was assumed to be the minimum measurement interval for a routine program, even though longer intervals are typical for many radionuclides. The calculated MDAs were then compared to acceptable MDAs (AMDAs) listed in draft ANSI Standard N13.30 Performance Criteria for Radiobioassay (see note "b" to Table 3.2). The AMDAs were established as the level expected to be obtainable by a competent counting laboratory and are not necessarily "acceptable" to meet health physics needs in all situations.

Table 3.2 indicates that for most radionuclides, an intake of $10 \%$ of an ALI is detectable 30 days following the intake by either in vitro or in vivo techniques. However, detection at this level may not pe possible at current levels of sensitivity for a few radionuclides (e.g., ${ }^{\mathrm{Sr}}$ and $\mathrm{Pu}$ isotopes). If the nuclide-specific MDAs are within the present capabilities of a bioassay laboratory, implementation of the proposed regulations will incur no additional costs due to sensitivity requirements. If the required MDA is below the present sensitivity of the bioassay system, costs will be incurred either to improve the system sensitivity, increase the frequency of bioassay measurements, or implement an alternate monitoring system for internal exposure (air monitoring).

\subsubsection{Air Monitoring}

Airborne radioactive material can be measured by air sampling and analysis. A volume of air is drawn through a detection device that measures the radioactivity directly, or through a collection device such as a filter or impactor, which removes the radioactive material from the air for counting.

Two general types of air samples can be collected: breathing zone and general area. Breathing zone samplers provide a relatively representative sample of the concentration of radioactive material in air breathed by an individual, but suffer from limitations regarding sampling rate. Although 
TABLE 3.2. Annual Limits on Intake of Common Radionuclides Compared to Detection Capabilities for Urinalysis and In Vivo Counting

\begin{tabular}{|c|c|c|c|c|c|c|}
\hline & & & $\begin{array}{r}\text { MDAla } \\
\text { Detect A } \\
30 \text { Days } \\
\end{array}$ & $\begin{array}{l}\text { Required To } \\
10 \% \text { ALI Intake } \\
\text { Post Exposure } \\
\end{array}$ & $\frac{\text { Required }}{\text { Urine }}$ & MDACAMDA (b) \\
\hline Nuclide & Class & $\mathrm{ALI}, \mu \mathrm{Ci}$ & Urine & In Vivo & Urine & In Vivo \\
\hline $3 \mathrm{H}$ & Vapor & $8 E 4$ & 2.5E4 & $-(c)$ & No & - \\
\hline${ }^{14} \mathrm{C}$ & D & 2E5 & $1.4 \mathrm{E} 6$ & - & No & - \\
\hline $32 p$ & D & $\begin{array}{l}9 \mathrm{E} 2 \\
4 \mathrm{E} 2\end{array}$ & $\begin{array}{l}4.2 \mathrm{E} 1 \\
1.9 \mathrm{E} 1\end{array}$ & $\overline{-}$ & $\begin{array}{l}\text { No } \\
\text { No }\end{array}$ & - \\
\hline${ }^{35} \mathrm{~s}$ & $\underset{W}{D}$ & $\begin{array}{l}2 \mathrm{E} 4 \\
2 \mathrm{E} 3\end{array}$ & $\begin{array}{l}1.2 \mathrm{E} 3 \\
1.8 \mathrm{E} 2\end{array}$ & - & $\begin{array}{l}\text { No } \\
\text { No }\end{array}$ & - \\
\hline${ }^{45} \mathrm{Ca}$ & $W$ & 8E2 & $3.0 \mathrm{E} 4$ & - & No & - \\
\hline${ }^{51} \mathrm{Cr}$ & $\begin{array}{l}D \\
W \\
Y\end{array}$ & $\begin{array}{l}5 \mathrm{E} 4 \\
2 \mathrm{E} 4 \\
2 \mathrm{E} 4\end{array}$ & $\begin{array}{l}2.8 \mathrm{E} 6 \\
5.1 \mathrm{E} 5 \\
1.4 \mathrm{E} 5\end{array}$ & $\begin{array}{l}\overline{9} .7 \mathrm{E4} \\
1.4 \mathrm{E} 5\end{array}$ & $\begin{array}{l}\text { No } \\
\text { No } \\
\text { No }\end{array}$ & $\begin{array}{l}\text { No } \\
\text { No }\end{array}$ \\
\hline${ }^{54} \mathrm{Mn}$ & $\underset{H}{D}$ & $\begin{array}{l}9 \mathrm{E} 2 \\
8 \mathrm{E} 2\end{array}$ & $\begin{array}{l}2.0 \mathrm{E} 2 \\
2.0 \mathrm{E} 1\end{array}$ & $\begin{array}{c}<1 \mathrm{E}-3 \\
7.6 \mathrm{E} 3\end{array}$ & $\begin{array}{l}\text { No } \\
\text { No }\end{array}$ & $\begin{array}{l}\text { Yes } \\
\text { No }\end{array}$ \\
\hline${ }^{59} \mathrm{Fe}$ & $\underset{H}{D}$ & $\begin{array}{l}3 \mathrm{E} 2 \\
5 \mathrm{E} 2\end{array}$ & $\begin{array}{l}2.3 \mathrm{E} 3 \\
1.0 \mathrm{E} 3\end{array}$ & $\overline{3} .2 \mathrm{E} 3$ & $\begin{array}{l}\text { No } \\
\text { No }\end{array}$ & No \\
\hline${ }^{60} \mathrm{Co}$ & $\begin{array}{l}H \\
Y\end{array}$ & $\begin{array}{l}\text { 2E2 } \\
3 \mathrm{E} 1\end{array}$ & - & $\begin{array}{l}2.0 \mathrm{E} 3 \\
4.3 \mathrm{E} 2\end{array}$ & $\overline{-}$ & $\begin{array}{l}\text { No } \\
\text { No }\end{array}$ \\
\hline${ }^{65} \mathrm{Zn}$ & $Y$ & 3E2 & $5.3 \mathrm{E} 3$ & $4.0 \mathrm{E} 3$ & No & No \\
\hline${ }^{86} \mathrm{Rb}$ & D & $8 \mathrm{E} 2$ & $9.1 \mathrm{E} 3$ & - & No & - \\
\hline${ }^{90} \mathrm{Sr}$ & $\begin{array}{l}D \\
Y\end{array}$ & $\begin{array}{l}\text { 2E1 } \\
4 E 0\end{array}$ & $\begin{array}{l}9.0 \mathrm{E}-1 \\
6.6 \mathrm{E}-3\end{array}$ & - & $\begin{array}{l}\text { No } \\
\text { Yes }\end{array}$ & - \\
\hline${ }^{99}$ Mo & $\begin{array}{l}\mathrm{D} \\
\mathrm{Y}\end{array}$ & $\begin{array}{l}3 \mathrm{E} 3 \\
1 \mathrm{E} 3\end{array}$ & $\begin{array}{l}1.1 \mathrm{E6} 6 \\
1.8 \mathrm{E} 4\end{array}$ & $\overline{1} .5 \mathrm{E} 4$ & $\begin{array}{l}\text { No } \\
\text { No }\end{array}$ & $\overline{\text { No }}$ \\
\hline${ }^{99 m} \mathrm{Tc}$ & D & $2 \mathrm{E} 5$ & - & - & - & - \\
\hline${ }^{125} \mathrm{I}$ & D & $6 \mathrm{El}$ & $2.6 \mathrm{E} 3$ & $1.1 \mathrm{E} 3$ & No & No \\
\hline${ }^{129} \mathrm{I}$ & D & 9E0 & 5.5E2 & 2.2E2 & No & No \\
\hline $131_{1}$ & D & $5 \mathrm{E} 1$ & $2.7 \mathrm{E}-1$ & $2.4 \mathrm{E} 1$ & No & No \\
\hline${ }^{137} \mathrm{Cs}$ & D & 2E2 & - & $4.8 \mathrm{El}$ & - & No \\
\hline
\end{tabular}




\section{TABLE 3.2 (contd)}

\begin{tabular}{|c|c|c|c|c|c|c|}
\hline Nuclide & Class & $A L I, \mu C i$ & $\begin{array}{r}\text { MDAla } \\
\text { Detect A } \\
30 \text { Days } \\
\text { Urine } \\
\end{array}$ & $\begin{array}{l}\text { Required To } \\
10 \% \text { ALI Intake } \\
\text { Post Exposure } \\
\text { In Vivo }\end{array}$ & $\frac{\text { Required }}{\text { Urine }}$ & $\frac{M D A<A M O A(b)}{\operatorname{In} V i v o}$ \\
\hline${ }^{144} \mathrm{Ce}$ & $\begin{array}{l}W \\
Y\end{array}$ & $\begin{array}{l}3 \mathrm{E} 1 \\
1 \mathrm{El}\end{array}$ & $\begin{array}{l}-(c) \\
-\end{array}$ & $\begin{array}{l}2.9 \mathrm{E} 2 \\
6.7 \mathrm{E} 1\end{array}$ & - & $\begin{array}{l}\text { No } \\
\text { No }\end{array}$ \\
\hline${ }^{235} U$ & $\begin{array}{l}D \\
W \\
Y\end{array}$ & $\begin{array}{l}1 E 0 \\
8 E-1 \\
4 E-2\end{array}$ & $\begin{array}{l}1.0 \mathrm{E} 1 \\
5.0 \mathrm{EO} \\
2.5 \mathrm{E}-1\end{array}$ & $\begin{array}{l}<1 \mathrm{E}-3 \\
8.2 \mathrm{EO} \\
5.8 \mathrm{E}-1\end{array}$ & $\begin{array}{l}\text { No } \\
\text { No } \\
\text { No }\end{array}$ & $\begin{array}{l}\text { Yes } \\
\text { No } \\
\text { No }\end{array}$ \\
\hline $\begin{array}{l}\text { Nat U(by } \\
234 \mathrm{Th} \text { ) }\end{array}$ & $\begin{array}{l}D \\
W \\
Y\end{array}$ & $\begin{array}{l}1 E 0 \\
8 E-1 \\
5 E-2\end{array}$ & $\begin{array}{l}1.0 \mathrm{E} 1 \\
5.0 \mathrm{EO} \\
2.5 \mathrm{E}-1\end{array}$ & $\begin{array}{l}1.5 \mathrm{E} 1 \\
8.2 \mathrm{EO} \\
7.2 \mathrm{E}-1\end{array}$ & $\begin{array}{l}\text { No } \\
\text { No } \\
\text { No }\end{array}$ & $\begin{array}{l}\text { No } \\
\text { No } \\
\text { Yes }\end{array}$ \\
\hline${ }^{238} 8_{\mathrm{Pu}}$ & $\begin{array}{l}W \\
Y\end{array}$ & $\begin{array}{l}6 \mathrm{E}-3 \\
2 \mathrm{E}-2\end{array}$ & $\begin{array}{l}8.0 \mathrm{E}-6 \\
1.0 \mathrm{E}-6\end{array}$ & $\begin{array}{l}6.1 \mathrm{E}-2 \\
2.9 \mathrm{E}-1\end{array}$ & $\begin{array}{l}\text { Yes } \\
\text { Yes }\end{array}$ & $\begin{array}{l}\text { Yes } \\
\text { Yes }\end{array}$ \\
\hline $241_{\text {Am }}$ & $W$ & $5 E-3$ & $5.0 \mathrm{EO}$ & $5.1 \mathrm{E}-2$ & No & No \\
\hline
\end{tabular}

(a) Units are $\mathrm{nCi}$ for in vivo bioassay and $\mathrm{nCi} / \mathrm{L}$ for all urinalyses except natural uranium urinalyses $(\mu \mathrm{g} / \mathrm{L})$.

(b) AMDAs specified in draft ANSI Standard N13.30, Performance Criteria for Radiobioassay. Draft ANSI Standard N13.30 is available from the Executive Secretary, Health Physics Society, 8000 Westpark Drive, Suite 400, McLean, VA 22102.

(c) Not applicable.

area air samplers can collect larger air samples, general area air concentrations may differ appreciably from the concentration in the breathing zone of the individual. Uptakes estimated from air samples have an estimated total uncertainty factor of 5 or more for breathing zone samplers and 20 or more for area air samplers (Booth, Bronson and Groth 1985).

Table 3.3 sumarizes the revised changes in air concentration limits for a number of common radionuclides. For those radionuclides not detectable with current bioassay technology, increased sensitivity is most easily obtainable through dir monitoring. The costs of implementing the revised limits will, therefore, involve procuring and maintaining additional air monitoring equipment, increasing labor costs for collecting and analyzing air samples, and establishing an appropriate personnel monitoring records system. These costs are detailed in Sections 3.3, 3.4, and 3.5. 
TABLE 3.3. Comparison of Part 20 Current and Revised Air Concentration Limits for Certain Radionuclides

\begin{tabular}{|c|c|c|c|c|}
\hline Nuclide & Class & $\begin{array}{c}\mathrm{DAC} \\
\mu \mathrm{C} \mathrm{i} / \mathrm{mL}\end{array}$ & $\frac{M P C(a j r)}{\mu \mathrm{Ci} / \mathrm{mL}(\mathrm{a})}$ & $\mathrm{DAC} / \mathrm{MPC}$ (air) \\
\hline $3 \mathrm{H}$ & Vapor & $2 \mathrm{E}-5$ & $5 E-6(S)$ & 4 \\
\hline${ }^{14} \mathrm{C}$ & D & $1 E-6$ & $4 E-6(S)$ & 0.3 \\
\hline $32 p$ & $\underset{W}{D}$ & $\begin{array}{l}4 \mathrm{E}-7 \\
2 \mathrm{E}-7\end{array}$ & $\begin{array}{l}7 \mathrm{E}-8(\mathrm{~S}) \\
8 \mathrm{E}-8(\mathrm{I})\end{array}$ & $\begin{array}{l}6 \\
3\end{array}$ \\
\hline${ }^{35} \mathrm{~s}$ & $\stackrel{D}{W}$ & $\begin{array}{l}7 \mathrm{E}-6 \\
9 \mathrm{E}-7\end{array}$ & $\begin{array}{l}3 \mathrm{E}-7(\mathrm{~S}) \\
3 \mathrm{E}-7(\mathrm{I})\end{array}$ & $\begin{array}{r}20 \\
3\end{array}$ \\
\hline${ }^{45} \mathrm{Ca}$ & $W$ & $4 E-7$ & $1 E-7(I)$ & 4 \\
\hline${ }^{51} \mathrm{Cr}$ & $\begin{array}{l}D \\
W \\
Y\end{array}$ & $\begin{array}{l}2 E-5 \\
1 E-5 \\
8 E-6\end{array}$ & $\begin{array}{l}1 \mathrm{E}-5(\mathrm{~S}) \\
1 \mathrm{E}-5(\mathrm{~S}) \\
2 \mathrm{E}-6(\mathrm{I})\end{array}$ & $\begin{array}{l}2 \\
1 \\
4\end{array}$ \\
\hline${ }^{54} \mathrm{Mn}$ & $\underset{W}{D}$ & $\begin{array}{l}4 \mathrm{E}-7 \\
3 \mathrm{E}-7\end{array}$ & $\begin{array}{l}4 \mathrm{E}-7(\mathrm{~S}) \\
4 \mathrm{E}-8(\mathrm{I})\end{array}$ & $\begin{array}{l}1 \\
8\end{array}$ \\
\hline${ }^{59} \mathrm{Fe}$ & $\underset{W}{D}$ & $\begin{array}{l}1 \mathrm{E}-7 \\
2 \mathrm{E}-7\end{array}$ & $\begin{array}{l}1 \mathrm{E}-7(\mathrm{~S}) \\
5 \mathrm{E}-8(\mathrm{I})\end{array}$ & $\begin{array}{l}1 \\
4\end{array}$ \\
\hline${ }^{60} \mathrm{Co}$ & $\begin{array}{l}W \\
Y\end{array}$ & $\begin{array}{l}7 \mathrm{E}-8 \\
1 \mathrm{E}-8\end{array}$ & $\begin{array}{l}3 \mathrm{E}-7(\mathrm{~S}) \\
9 \mathrm{E}-9(\mathrm{I})\end{array}$ & $\begin{array}{l}0.2 \\
1\end{array}$ \\
\hline${ }^{65} \mathrm{Zn}$ & $Y$ & $1 \mathrm{E}-7$ & $6 E-8(I)$ & 2 \\
\hline${ }^{86}{ }_{R b}$ & D & $3 \mathrm{E}-7$ & $3 E-7(S)$ & 1 \\
\hline${ }^{90} \mathrm{Sr}$ & $\begin{array}{l}0 \\
Y\end{array}$ & $\begin{array}{l}8 \mathrm{E}-9 \\
2 \mathrm{E}-9\end{array}$ & $\begin{array}{l}1 \mathrm{E}-9(\mathrm{~S}) \\
5 \mathrm{E}-9 \text { (I) }\end{array}$ & $\begin{array}{l}8 \\
0.4\end{array}$ \\
\hline${ }^{99} \mathrm{Mo}_{\mathrm{O}}$ & $\begin{array}{l}D \\
Y\end{array}$ & $\begin{array}{l}1 \mathrm{E}-6 \\
6 \mathrm{E}-7\end{array}$ & $\begin{array}{l}7 \mathrm{E}-7(\mathrm{~S}) \\
2 \mathrm{E}-7(\mathrm{I})\end{array}$ & $\frac{1}{3}$ \\
\hline${ }^{99 m} \mathrm{Tc}$ & D & $6 \mathrm{E}-5$ & $4 \mathrm{E}-5(\mathrm{~S})$ & 2 \\
\hline $125_{I}$ & D & $3 E-8$ & $5 E-9(S)$ & 6 \\
\hline${ }^{129} \mathrm{I}$ & D & $4 E-9$ & $2 E-9(S)$ & 2 \\
\hline${ }^{131} 1_{I}$ & D & $2 E-8$ & $9 E-9(S)$ & 2 \\
\hline${ }^{137} \mathrm{Cs}$ & D & $6 \mathrm{E}-8$ & $6 E-8(S)$ & 1 \\
\hline
\end{tabular}


TABLE 3.3 (contd)

\begin{tabular}{|c|c|c|c|c|}
\hline Nuclide & Class & $\begin{array}{c}\mathrm{DAC}, \\
\mu \mathrm{Ci} / \mathrm{mL}\end{array}$ & $\frac{\mathrm{MPC}(\mathrm{air})}{\mu \mathrm{Ci} / \mathrm{mL}(\mathrm{a})}$ & DAC/MPC(air) \\
\hline${ }^{144} \mathrm{Ce}$ & $\begin{array}{l}W \\
Y\end{array}$ & $\begin{array}{l}1 \mathrm{E}-8 \\
6 \mathrm{E}-9\end{array}$ & $\begin{array}{l}1 \mathrm{E}-8(\mathrm{~S}) \\
1 \mathrm{E}-9(\mathrm{I})\end{array}$ & $\begin{array}{l}1 \\
6\end{array}$ \\
\hline $235_{U}$ & $\begin{array}{l}D \\
W \\
Y\end{array}$ & $\begin{array}{l}6 \mathrm{E}-10 \\
3 \mathrm{E}-10 \\
2 \mathrm{E}-11\end{array}$ & $\begin{array}{l}5 \mathrm{E}-10(\mathrm{~S}) \\
5 \mathrm{E}-10(\mathrm{~S}) \\
1 \mathrm{E}-10(\mathrm{I})\end{array}$ & $\begin{array}{l}1 \\
0.6 \\
0.2\end{array}$ \\
\hline $\begin{array}{l}\text { Natural } \\
\text { Uranium }\end{array}$ & $\begin{array}{l}D \\
W \\
Y\end{array}$ & $\begin{array}{l}5 E-10 \\
3 E-10 \\
2 E-11\end{array}$ & $\begin{array}{l}1 \mathrm{E}-10(\mathrm{~S}) \\
1 \mathrm{E}-10(\mathrm{~S}) \\
1 \mathrm{E}-10(\mathrm{I})\end{array}$ & $\begin{array}{l}5 \\
3 \\
0.2\end{array}$ \\
\hline${ }^{238} \mathrm{Pu}$ & $\begin{array}{l}W \\
Y\end{array}$ & $\begin{array}{l}3 \mathrm{E}-12 \\
7 \mathrm{E}-12\end{array}$ & $\begin{array}{l}2 \mathrm{E}-12(\mathrm{~S}) \\
4 \mathrm{E}-11(\mathrm{I})\end{array}$ & $\begin{array}{l}2 \\
0.2\end{array}$ \\
\hline $241_{A m}$ & $W$ & $2 E-12$ & $6 \mathrm{E}-12(\mathrm{~S})$ & 0.3 \\
\hline
\end{tabular}

(a) $S=$ soluble, 1 = insoluble

\subsection{DOSE EVALUATION COSTS}

The principal components of cost-benefit evaluations (value-impact assessments) of proposed regulatory actions are the attributes that are used to characterize the consequences of the proposed action. There are twelve attributes normally used for NRC value impact assessments (Heaberlin et al. 1983). These attributes may be categorized as factors affecting public heaith, accidental occupational exposure, routine occupational exposure, offsite property, onsite property, regulatory efficiency, improvements in knowledge, industry implementation, industry operations, NRC development, NRC implementation, and NRC operations.

Changes in dose evaluation requirements will not affect actual doses received by the public, nor the frequency of accidents which could affect occupational exposure, nor property damage. The effect of the revised dose evaluation requirements on routine occupational exposures will be discussed in Section 3.4. Changes in dose evaluation requirements may affect regulatory efficiency through changes in reporting requirements. This is discussed in Section 7.3. The changes will not improve knowledge of accident probabilities or consequences. The NRC development costs are sunken costs and are not considered in the regulatory analys is. The NRC implementation and operations costs will not be specific for dose evaluation requirements and are discussed in Section 6.3. Discussions in this section will therefore be limited to the effect of the revised dose evaluation requirements on industry implementation and operations costs. 
In this section, costs are summarized by facility type according to the facility categories 1 isted in Table 8.1 of this report. For each affected facility type, the industry implementation and operations costs expected to be incurred from the revised dose evaluation requirements are estimated. Costs associated with recordkeeping are discussed separately in Section 3.5. Cost estimates are not provided for five facility categories (well logging, industrial radiography, other measuring systems, research and test reactors, and other facilities) because the associated costs are anticipated to be either zero or insignificant. Costs for these five facility types will be minima) because significant internal doses are rare and it is not anticipated that changes to existing procedures will be required from the revised dose evaluation requirements.

Medical Facilities. Potential internal exposures to workers in a hospital are primarily limited to the nuclear medicine department. By far the most common radionuclide used in nuclear medicine is ${ }^{2} \mathrm{TC}$. In one study it was estimated that $80 \%$ of the patient procedures involve ${ }^{\circ}$ Tc (Wiatrowski et al. 1984).

The radiopharmaceuticals of ${ }^{00}$ Tc are stable in solution and are nonvolatile. If there are $30 \mathrm{mCi}$ per patient and 8 patients per day per room of $10 \times 15 \times 8$ feet with one air change per hour, 188 of the total dose could be volatilized without exceeding $10 \%$ of the $O A C$ value. With no air changes (total recirculation), $0.8 \%$ of the total dose could be volatilized without exceeding 10\% of the DAC value. The intakes of these radiopharmaceuticals by workers, therefore, are expected to be less than the 10\% threshold for monitoring.

Radioiodine compounds comprise most of the remaining radionuclides that are potentially inhaled at nuclear medicine departments. For all of these compounds, the OAC values in the revision are at least two times higher than the current MPC values. Therefore, monitoring will not be required at lower levels of intake than are currently required even though monitoring will be required if intakes are likely to exceed $10 \%$ of the applicable ALIs. It is anticipated, however, that some of these licensees will respond to the revised Part 20 by performing additional monitoring for 1 year to demonstrate compliance. This monitoring will consist of a self-monitoring program by researchers who handle iodine (USNRC 1982). Associated cost estimates for one-third of the approximately 4800 nuclear medicine departments (i.e.. 1600 departments) are $\$ 400$ each for instrument calibration services and $\$ 550$ each for equipment purchases, for a total one-time cost of $\$ 1,500,000$ (USNRC 1982). The remaining two-thirds of the facilities are not anticipated to incur costs because they currently do not have quantitative internal exposure monitoring programs and are not expected to require one based on the revised regulations.

A similar response is anticipated from the research hospitals possessing a broad license. There are approximately 200 broad-scope research hospitals with 52,000 potentially exposed employees, two-thirds of whom are monitored for internal exposures (USNRC 1982). Assuming a 1-year program of quarterly internal monitoring to demonstrate that intakes are less than $10 \%$ of the applicable ALIs, that most researchers handle $\mathrm{H}-3$ or $\mathrm{P}-32$ which can be 
evaluated using urinalysis, and that $20 \%$ of the researchers would be sampled at a cost of $\$ 18$ per urinalys is (USNRC 1982), the one-time cost would be $52,000 \times 0.67 \times 0.2 \times \$ 18 \times 4$, or $\$ 500,000$. One whole-body count is also expected to be needed for $10 \%$ of the researchers who received urinalys is in order to evaluate internal deposition of ganma-emitters. The associated cost est imate, assuming $\$ 200$ per whole-body count, is $\$ 140,000$ (that is, $52,000 \mathrm{X}$ $0.67 \times 0.2 \times 0.1 \times \$ 200)$.

The costs to private practitioners of nuclear medicine will be similar to those of nonresearch hospitals. Of the approximately 1000 private practice licensees, one-third were assumed to have quantitative internal exposure monitoring programs (USNRC 1982). If these 330 facilities undergo a selfmonitoring program for 1 year at a cost of $\$ 1000$ each, the total cost estimate is $\$ 330,000$.

The current level of monitoring in nuclear pharmacies is sufficient to satisfy the provisions of the revised regulation. The only additional efforts would be the conversion of organ burden to dose, which falls under the category of recordkeeping (see Section 3.5).

Manufacturing and Distribution Facilities. It was assumed that the facilities involved in the manufacture and distribution of large sources currently have limited routine monitoring programs for internal exposures. Although exposures are probably less than $10 \%$ of the limits, monitoring would have to be performed for a year to demonstrate this to the inspectors (USNRC 1982). 1t is estimated that 100 workers in the industry would have to be monitored at a cost estimated to be $\$ 200$ per whole-body count. With an initial count and four quarterly counts the cost for the demonstration program would be about $\$ 100,000$.

Facilities involved in the manufacture and distribution of small sources utilize extensive routine bioassay and air monitoring at numerous locations. The programs are considerably more extensive than those expected to be required under the provisions of the revised Part 20 and should not need to be upgraded in response to the revision.

Academic/Research Institutions. There are currently about 1500 academic and research institutions employing 692,000 workers, 14\% of whom are monitored for ionizing radiation (Table 8.3) . The radionuclides connonly used at these institutions are ${ }^{3} \mathrm{H},{ }^{14} \mathrm{C},{ }^{32} \mathrm{P},{ }^{38} \mathrm{Cl},{ }^{46} \mathrm{Ca},{ }^{56} \mathrm{Fe},{ }^{6} \mathrm{Co},{ }^{215} \mathrm{I},{ }^{131} \mathrm{I}$, and ${ }^{137} \mathrm{Cs}$, among others. The DAC values in the revision for these radionuclides are an average of 2.4 times higher than the current MPC values. Considering that the revised requirement for monitoring intakes is effectively lower by a factor of 2.5 than the current requirement, no significant changes in longterm monitoring practices are expected to be necessary at these facilities.

Even though long-term changes are not anticipated, it is expected that some of these licensees will incur initial costs required to demonstrate compliance to inspectors (USNRC 1982). Although these costs may not be necessary based on strict interpretation of the revision, they are included in this analysis because they are based on anticipated actual responses by licensees regardless of the necessity of their responses. Based on similar 
assumptions used to estimate these costs for broad-scope medical facilities, the total initial costs for academic/research institutions are estimated to be $\$ 940,000$ for urinalysis (i.e., $692,000 \times 0.14 \times 0.67 \times 0.2 \times \$ 18 \times 4$ ) and $\$ 260,000$ for whole-body counts (i.e., $692,000 \times 0.14 \times 0.67 \times 0.2 \times 0.1$ $x \$ 200)$. Increases in long-term operation costs are estimated to be negligible.

Fuel Fabrication and Processing Facilities. As will be discussed in Section 3.4.1, the effective dose equivalent to workers at fuel fabrication facilities from radioactive material deposited in the body may currently equal or, at least at one facility, exceed the effective dose equivalent from external radiation. The internal exposures at these facilities are thought to be chronic exposures to Class $Y$ materials.

If the proposed DACs are implemented, if chronic exposures continue to exist at fuel fabrication plants, and, if the margin between the DACs and actual plant air concentrations will be equal to the present margin between MPCs and plant conditions, then it may be assumed that the chronic lung burdens of the average worker will decrease by a factor of 5 , which is the difference between the revised DAC and current MPC for insoluble (Class $Y$ ) uranium. Since the lung burdens at one facility are near the detection limits of currently available lung counting equipment, a reduction of the lung burdens by a factor of 5 would result in lung burdens that are below the detection limits of currently available lung counting equipment (Booth, Bronson and Groth 1985; Palmer et al. 1987; Robinson et al. 1986). Booth, Bronson and Groth (1985) concluded that adequate estimates of intake can be accomplished with currently available air monitoring equipment, much of which should be already in place. They also concluded that procedural changes would be required for changing the method of compliance from one based on lung counting to one based on air monitoring, and estimated these costs to be about $\$ 24,000$ per facility (in 1989 dollars). Based on recent information on operating fuel fabrication facilities, these costs are anticipated to be incurred by five facilities in this category for a total of $\$ 120,000$. Although other facilities in this category may incur related costs, they are assumed to be relatively insignificant for this analysis. Annual operation costs of $\$ 43,000$ per facility (Booth. Bronson and Groth 1985) for a total of $\$ 215,000$ are also anticipated for additional air sampling equipment.

The primary costs in these facilities will involve facility modifications to reduce existing airborne levels to below the applicable DACs for uranium. Booth, Bronson and Groth (1985) stated that fuel fabrication facilities may have areas where airborne activities are routinely $25 \%$ to $50 \%$ of current MPCS. More recently, it appears that existing fuel fabrication facilities operate with airborne levels that range from $10 \%$ to $25 \%$ of the MPCs. Considering that the revised DAC value for Class $Y$ uranium is one-fifth of the current MPC value, facility modifications might be necessary to provide adequate safety margins.

Two courses of action are being considered by these facilities: ventilation changes and extensive use of glove boxes. One facility has estimated these costs to be $\$ 11.5 \mathrm{milli}$ ion for the ventilation change option and $\$ 42$ million for the glove box option; the ventilation change option will also 
require an annual maintenance cost of $\$ 2$ million. Nilson and Malody (1982) did not quantify the costs but did estimate that it would be millions of dollars. Although apparently not yet evaluated, it might be possible to collect air samples to determine the actual particle size distribution at these facilities; the observed particle size distributions may allow operation at current activity levels. There is evidence that such studies would show that some engineering modifications may not be necessary (West, Scott and Schultz 1979). Licensees may choose not to exercise such an option even if it is offered due to the difficulties in explaining to the public why air activity concentrations above those published in Part 20 do not pose a hazard to the workers. In consideration of these factors and assuming that five facilities will be most affected, the total cost estimate is $\$ 30,000,000$ initially ( $\$ 6$ million per facility) and $\$ 5,000,000$ in annual operation costs ( $\$ 1$ million per facility). These estimates are based on the assumption that particle size studies will render some modifications unnecessary.

It may be asked whether reductions of air concentration levels would be required at fuel fabrication plants if it were permissible to base dose equivalent limits for long-lived radionuclides on the annual effective dose equivalent rather than the committed effective dose equivalent. Even with the exemption described in Section 20.205 of the proposed revision, it appears that the facilities would be required to maintain the average air concentration less than the DAC [see 20.205(b)(2)]. Since the external contribution to the committed effective dose equivalent is small, on the average, and even the maximum external dose equivalents do not exceed approximately $1 \mathrm{rem}$ (which would decrease the allowable air concentration by $\sim 20 \%$ ), it seems that fuel fabrication plants will be required to reduce their uranium air concentrations irrespective of whether the dose equivalent is based on annual effective dose equivalent or comitted effective dose equivalent. The major question seems to be how much below the DAC the licensee would be required to maintain air concentrations. If the average air concentration is I DAC and a worker were to inhale 1 ALI (the apparent maximum in either case), the comitted effective dose equivalent received is 5 rem, which does not allow for external doses to be accrued. If external doses were received by the worker, then air concentrations would need to be reduced below the DAC by corresponding amounts. In the case of fuel fabrication plants, it appears that 99\% of the workers would not exceed the revised total effective dose equivalent limit if they inhaled $0.8 \mathrm{ALI}$. For those few who would, procedures such as increased local ventilation or the use of respirators would serve as sufficient countermeasures.

Commercial Power Reactors. Revised internal exposure provisions are not expected to alter internal monitoring programs already in existence at these plants. These prograns greatly exceed the requirements of both the current and revised Part 20 . Those utilities that use air monitoring as the surrogate for internal dose will continue to do so, and the calculated doses are so low that it is unlikely that any utility will refine their methods by measuring particle size, solubility fraction, etc. The few facilities that use bioassay data for compliance will probably not alter their procedures. Less than $0.03 \%$ of the individuals counted at nuclear power plants between 1978 and 1983 had measured body burdens in excess of $10 \%$ of the relevant ALIs (Booth, Bronson and Groth 1985) and it is unlikely that any utility will 
discontinue its existing monitoring program. The revised regulation does not require breathing zone monitoring for intake monitoring and allows general area sampling. The significant costs associated with the revised dose evaluation requirements are related to recordkeeping (see Section 3.5).

\subsection{DISTRIBUTION OF OCCUPATIONAL DOSES}

The revised dose evaluation requirements will result in internal and external doses being summed to demonstrate compliance with the dose limits. An important distinction between the current and revised rule is that the latter requires control of internal exposures as long as the controls are consistent with maintaining the total effective dose equivalent ALARA. In contrast, the current rule strongly discourages intakes of radioactive material by mandating both quarterly and weekly control measures. As a result, intakes of radioactive material are currently rare at most facilities. For those facilities where internal doses are significant compared to the revised annual dose limit, e.g., fuel fabrication facilities, added control measures should result in decreased internal doses.

\subsubsection{Fuel Fabrication Facilities}

In 1984, there were 9379 workers at 11 uranium fuel fabrication plants, 5947 of whom received measurable external radiation doses. In 1984, the average measurable dose was about $140 \mathrm{mrem} ;$ in 1983 and 1982, the average measurable radiation doses were $160 \mathrm{mrem}$ and $140 \mathrm{mrem}$, respectively (Brooks 1986). These numbers agree well with the measurable average of 170 mrem for 1980 that was reported by Kumazawa, Nelson and Richardson (1984), and the average annual dose equivalent reported by Booth, Bronson and Groth (1985) at a single facility. Brooks (1986) reported that for fuel fabrication plants, 99\% of the external dose equivalents were less than 1.5 rem in 1982 and 1983, and that 99\% were less than 0.95 rem in 1984.

Regarding internal doses, the workers at the facility studied by Booth, Bronson and Groth (1985) were found to have measurable lung burdens ranging from 60 to $200 \mu g{ }^{236} \mathrm{U}$. The average of all workers (including those with burdens less than measurable) was found to be $47 \mu 9$. The average body burden of $47 \mathrm{\mu g}$ of ${ }^{235} \mathrm{U}$ will result in an annual effective dose equivalent of 460 mrem and an estimated annual lung dose equivalent of 3900 mrem, based on the assumption that the body burdens resulted from chronic exposures to $\mathrm{Class} Y$ aerosols. The maximum observed lung burdens $\left(200 \mu \mathrm{g}{ }^{295} \mathrm{U}\right.$ ) result in annual lung dose equivalents of approximately $17 \mathrm{rem} / \mathrm{yr}$ and annual effective dose equivalents of about $2 \mathrm{rem} / \mathrm{yr}$. Thus, for at least one facility, the average annual effective dose equivalent from internal radiation exceeded that from external radiation. Because these are values for only one facility, extrapolation to the entire industry is tenuous.

Lessard et al. (1987) have published tables that indicate the lung burden at various times after inhalation of uranium. These tables can be combined with a continuous inhalation model in order to compute the cumulative lung burden following chronic inhalation of uranium. Calculations indicate that during chronic inhalation, the lung burden quickly builds and 
essentially levels off at about 15 years; the lung burden increases at a rate of only about $1 \%$ per year at 15 years.

Kumazawa, Nelson and Richardson (1984) found that the median age of a nuclear fuel cycle worker was 35 years. For purposes of this analys is it was assumed that the average worker began work at 25 years of age, which results jn a total work time of about 10 years. The average lung burden of $47 \mu 9$ ${ }^{236} \mathrm{U}$ found by Booth, Bronson and Groth (1985) will be achieved in 10 years if the chronic inhalation rate is about $102 \mu \mathrm{g}\left({ }^{236} \mathrm{U}\right)$ per year. This annual intake will result in a committed dose equivalent to the lung of about 5.5 rem and a committed effective dose equivalent of 0.65 rem. This indicates that the average worker at fuel fabrication facilities receives committed effective dose equivalents well below $5 \mathrm{rem} / \mathrm{yr}$.

Considering external doses, it appears that the average worker receives about 0.8 rem combined external and committed effective dose equivalent; the internal component is about four times the external component. The only instance in which fuel fabrication facilities appear not to be already in compliance with the revised requirements is for those individuals who receive the maximal doses, and even then it appears to be a problem only if the individuals who have the largest lung burdens have been exposed for less than 5 years. For a chronic exposure over 5 years, 99\% of the workers would have a total of external radiation dose equivalent and committed effective dose equivalent that is $<5$ rem. For those $1 \%$ who currently receive doses that would be unacceptable under the revised Part 20, steps would need to be taken to reduce intakes, e.g., through the use of respirators.

Although the air concentrations in certain areas of fuel fabrication facilities exceed the revised DACs, it appears that few individuals would exceed the revised dose limits. Thus, it appears that one or more of the following may be true: 1) workers do not spend all of their time in the high air concentration areas of the facility, 2) the particle size distribution of the dust precludes lung deposition of much of the material, or 3) some of the material is more soluble than anticipated and is removed from the lung with a biological half-life less than 500 days.

Calculations based on the data presented above indicate that a reduction in airborne levels in all areas of a facility by a factor of 5 would result in a decreased effective dose equivalent of $520 \mathrm{mrem}(650 \mathrm{mrem} \times 0.8$ ) for an average worker. Based on five facilities and assuming that 414 workers receive measurable doses at each of these facilities (see Section 8.1), the annual reduction in effective dose equivalent would be $1080 \mathrm{rem}$. However, in Section 3.3 as well as in this section it was determined that airborne levels in some areas of these facilities need not be reduced by a factor of five. It is assumed that an average reduction of 2.5 will be observed, for a total effective dose equivalent savings of $540 \mathrm{rem} / \mathrm{yr}$.

\subsubsection{0ther Facilities}

Significant internal doses are rare at facilities other than fuel fabrication facilities. For nuclear power plant workers, average annual internal doses are negligible and maximum annual internal doses are a small 
fraction of the revised annual total dose equivalent limit (Booth, Bronson and Groth 1985). As a result, it is not expected that summation of internal and external doses will result in added control measures to ensure that workers do not exceed the revised total effective dose equivalent limit or corresponding administrative limits. This assumption is thought to be valid for all facilities (except fuel fabrication facilities) because currently most of the significant intakes of radioactive material result from accidental, not planned, exposures.

Under the current Part 20, most licensees attempt to avoid intakes of radionuclides by workers. The current rule emphasizes the limitation of internal exposures and many licensees feel that compliance is assured if intakes are avoided altogether. Unfortunately, the avoidance of intakes of radionuclides often leads to increased external doses that exceed the internal doses avoided. This practice may or may not be consistent with the ALARA principle, depending on both the magnitude of the increase in total collective dose equivalent and the costs saved by avoiding the assessment and recording of intakes of radioactive material (Merwin, Brown and Martin 1987).

It is likely that the revised dose evaluation requirements will affect the distribution of doses to some workers who currently receive negligible internal doses. Because the DACs for most radionuclides are higher than the corresponding MPCS, it is anticipated that intakes of radionuclides will generally be more common under the revised Part 20 than under the current Part 20. This increase will result from both decreased controls on airborne activity and more consistent use of the ALARA philosophy regarding tradeoffs between internal and external doses.

In summary, the revised dose evaluation requirements may result in increased internal doses for some workers at facilities other than fuel fabrication facilities. However, these doses would be justified by a concomitant decrease in external doses and/or a cost savings, e.g.. a reduction in the use of respirators. In other words, the fact that the revised requirements will likely result in improved implementation of the ALARA principle virtually assures a positive impact. Otherwise, licensees could not justify allowing increased internal doses. This potential impact is discussed further in Section 5.1 .

\subsection{RECORDKEEPING}

The revised dose evaluation requirements, in combination with the revised recordkeeping requirements, will result in substantial costs to licensees who have extensive internal dosimetry programs. These costs are estimated in this section. Recordkeeping costs not associated with the revised dose evaluation requirements are estimated in Section 5.4.

The current Part 20 requires that individual dose records be kept for a]1 personnel for whom monitoring is required. The records are required to be kept on NRC Form 5 (or equivalent) and at least four separate entries per 
year are required because the current rule promulgates quarterly dose limits. Records of surveys and individual monitoring are also required to be maintained.

The revision of Part 20 also requires that individual dose records be kept for all personnel for whom monitoring was required. However, because individual doses will include internal doses when intakes greater than 10\% of applicable ALIs occurred, more information will be required to evaluate doses. Thus, NRC Form 5 will require more information under the revised rule. For facilities with comprehensive internal dosimetry programs, such as nuclear power plants and fuel fabrication facilities, extensive modifications to existing dose evaluation procedures will be required. For facilities where internal doses are normally insignificant, increased effort to complete NRC Form 5 should not be required (USNRC 1982).

An extensive study on the dosimetry and recordkeeping implications of the revision of Part 20 was performed by the Atomic Industrial Forum (AIF) (Booth, Bronson and Groth 1985). Additional information on recordkeeping costs anticipated from the revised dose evaluation requirements were available from public comments on the proposed revision and a report prepared for the NRC (SEA 1986).

Costs are anticipated to be incurred by some licensees to develop revised recordkeeping procedures and to implement and operate revised recordkeeping programs. Development costs may include development and approval of revised procedures. Implementation costs may include modification of computer programs and data bases and acquisition of additional computer-related equipment. Operation costs may include equipment replacement and maintenance, labor, and data review (Booth, Bronson and Groth 1985). These costs are expected to be incurred at some facilities even though there exists an extremely low frequency of significant internal exposures at the facilities. Some of the costs, therefore, will not be necessary for compliance with the revised Part 20; rather, the costs will be incurred voluntarily as options for demonstrating compliance.

An extensive study of these costs for nuclear power plants and fuel fabrication facilities was performed (Booth, Bronson and Groth 1985). Upon review of this study and other applicable information, the cost estimates from this study were adopted for this analysis. Table 3.4 lists the appropriate cost estimates in 1989 dollars.

Assuming that 109 nuclear power plants will be operating in the beginning of 1989 (ANS 1988), the total development and implementation costs incurred by nuclear power plant facilities is estimated to be $\$ 2,700,000$ and $\$ 9,900,000$, respectively. The annual operation costs are estimated to be $\$ 2,300,000$. It was assumed for this analysis that the number of nuclear power plants operating after January 1, 1989, would remain constant at 109. 
TABLE 3.4. Estimated Costs of Increased Recordkeeping Requirements Resulting From the Revised Oose Evaluation Requirements

\section{Cost Category}

Oevelopment (initial cost)

Implementation (initial cost)

Operation (annual cost)

Present Value ${ }^{(a)}$
Cost per Facility (1989 dollars)

Nuclear Power Plants Fuel Fabrication

\begin{tabular}{rr}
25,000 & 13,900 \\
91,000 & 67,200 \\
21,000 & 9,700 \\
\hline 290,000 & 157,000
\end{tabular}

(a) Calculated using methods described in Section 8.2 of this report.

Based on five fuel fabrication facilities that will incur most of the costs of the revision, the total costs for development and implementation are estimated to be $\$ 70,000$ and $\$ 336,000$, respectively. Total annual operation costs for these facilities are estimated to be $\$ 49,000$.

Although significant internal doses are relatively rare at other facilities, they do exist and health physicists at these facilities will be required to evaluate and record the appropriate comitted and total dose equivalents. Because these instances will be rare, it is assumed that internal doses will be recorded manually at these facilities when appropriate. It is estimated that at academic and research facilities and at medical facilities, responsible personnel will spend an average of 8 person-hours developing and implementing revised recordkeeping procedures that pertain to dose evaluation. Average operation costs of 4 person-hours/yr are anticipated for manual evaluation and recording of information on NRC Form 5. Based on an hourly rate of $\$ 25$ per health physicist in 1989 dollars (SEA 1986), the development costs per facility are expected to be $\$ 200$. Annual operation costs are expected to be $\$ 100$ per facility. Based on the number of academic/research and medical facilities estimated in Section 8.1, academic/ research facilities are anticipated to incur $\$ 310,000$ in development costs and $\$ 160,000$ in annual operation costs. Medical facilities are anticipated to incur development costs of $\$ 1,300,000$ and annual operation costs of $\$ 650,000$. These estimates include both NRC and Agreement State licensees.

Most other licensees have limited or nonexistent internal dosimetry programs. Internal doses at these facilities will rarely exceed levels that must be included in the evaluation of total effective dose equivalent. Thus, no significant recordkeeping costs related to the revised dose evaluation requirements are anticipated for these facilities.

Because licensees will be required to monitor both external doses and intakes of radioactive material likely to exceed $10 \%$ of the applicable annual limits under the revised monitoring requirements, licensees that currently do not record doses over $10 \%$ of the current limits will have to record external doses under the revised requirements and might have to record internal doses 
depending on the radionuclide. Because the applicable DACs are higher for most radionuclides than the current MPCs, and considering that most licensees currently record all measured external and internal doses, the impact on recordkeeping with regard to an increased number of workers for whom records will be kept is considered to be negligible for this analysis.

\subsection{SUMMARY OF CONSEQUERCES}

This section sumnarizes the consequences of the revised dose evaluation requirements described in Sections 3.1-3.5. In Table 3.5, the costs are summarized by facility category in terms of both initial and annual costs. Initial costs include development and implementation costs; annual costs consist of operational costs. Table 3.5 also sumnarizes the annual benefits (reduced doses) from the revised dose evaluation requirements. The impacts from the revised dose evaluation requirements are anticipated to be negligible for facility categories not listed in Table 3.5.

TABLE 3.5. Summary of Consequences of the Revised Dose Evaluation Requirements

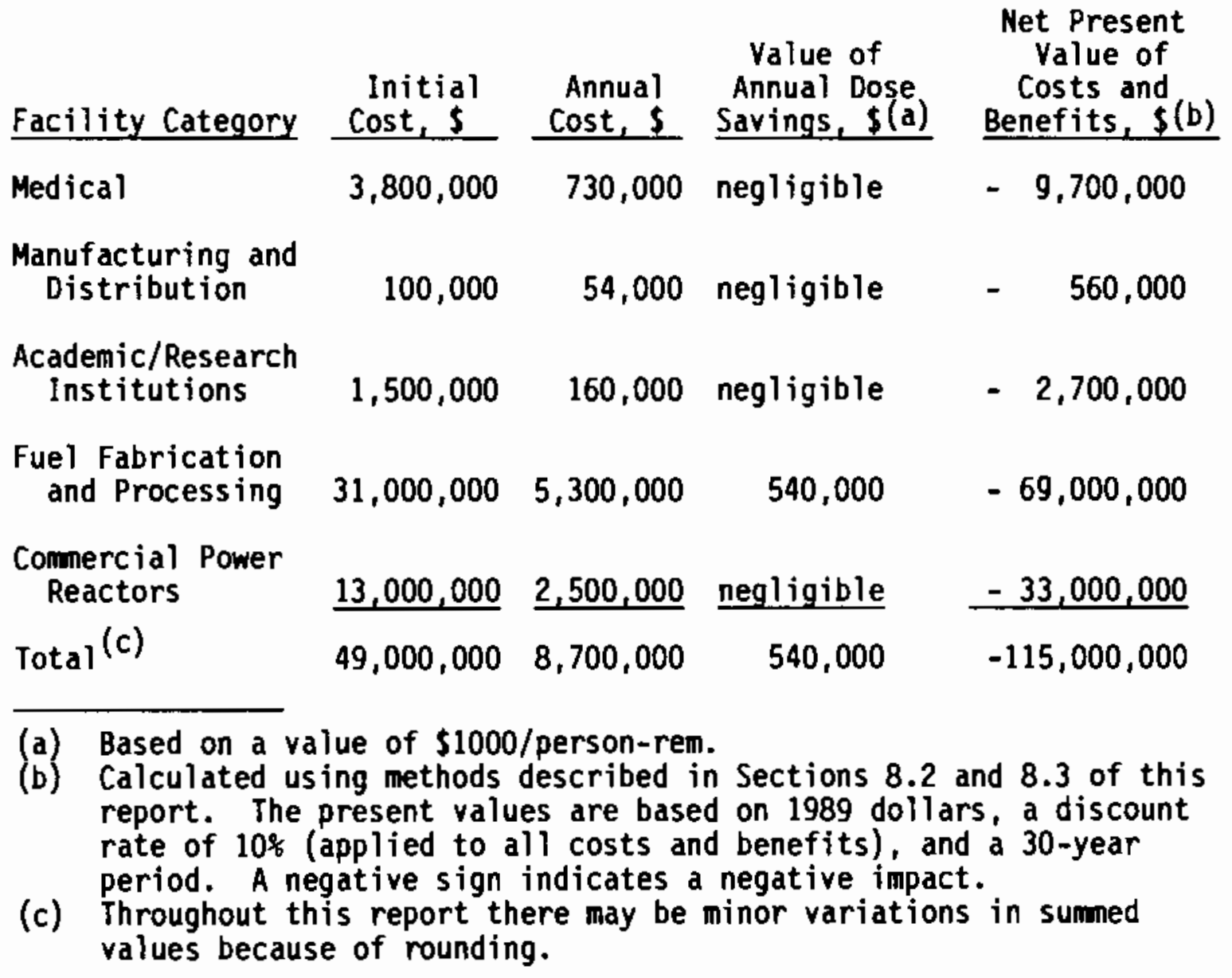


It is probable that some of the costs that will be incurred by licensees in response to the promulgation of 10 CFR Part 20 will not be necessary for compliance with the revision. For example, because few workers at nuclear power plants currently receive doses greater than 10\% of the applicable DACs, summation of external and internal doses will be required in only a small number of cases. It follows that some of the estimated costs of increased recordkeeping requirements resulting from the revised dose evaluation requirements (see Table 3.4) could be avoided if optimal compliance with the revision is achieved. An estimate of the costs of the revision based on optimal compliance is included in the sensitivity analysis provided in Section 8.4 . 


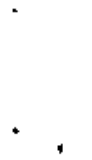

"

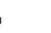




\subsection{CONSEQUENCES OF REVISED LIMITS}

The revision of Part 20 contains changes to most of the current dose limits. These include occupational whole-body dose 1 imits and separate limits for the eyes, extremities, skin, and individual organs. In addition, the revised Part 20 contains dose limits for the embryo/fetus and for individual members of the public; neither of these limits exists in the current Part 20. The consequences of the revised limits are presented below.

\subsection{OCCUPATIONAL DOSE LIMITS FOR AOULTS}

The present occupational dose limits for adults are $1.25 \mathrm{rem} /$ quarter to the whole-body, head and trunk, active blood-forming organs, lens of eyes, or gonads; $18.75 \mathrm{rem} /$ quarter for hands and forearms or feet and ankles; and $7.5 \mathrm{rem} /$ quarter for skin of the whole body. A licensee may, however, permit a worker to receive whole-body doses up to $3 \mathrm{rem} /$ quarter, provided that the worker's average dose to the whole body after the age of eighteen does not exceed $5 \mathrm{rem} / \mathrm{yr}$. Inhalations of radioactive material per quarter are limited to the amount that would be inhaled by a worker present for 520 hours at the air concentrations listed in Appendix B, Table 1 .

The revised occupational dose limits are a total effective dose equivalent of $5 \mathrm{rem} / \mathrm{yr}$, a dose to any organ or tissue other than the lens of the eye of $50 \mathrm{rem} / \mathrm{yr}$, an eye dose equivalent of $15 \mathrm{rem} / \mathrm{yr}$, and a shallow dose equivalent of $50 \mathrm{rem} / \mathrm{yr}$ to each of the extremities and to the skin. Planned special exposures exceeding the annual limits are allowed, providing there is justification (see Section 4.2). A comparison of the current and revised limits was presented in Table 3.1 .

\subsubsection{Whole-Body Dose Equivalent Limits}

As discussed in Section 3.0, there are significant differences in the dosimetric principles that form the basis for the two sets of limits. Under the present Part 20, whole-body dose limits are based only on external doses. Internal doses are subject to separate controls on intake. Under the revised limits, however, external and internal doses are sumned to determine the total effective dose equivalent. Weighting factors are applied to internal doses depending on the critical organ(s) for the radionuclides of concern to equate the risk to that from a whole-body exposure.

In this section, the costs and benefits associated with revising the whole-body dose limits are presented. Although it is difficult to compare the two dose limits because they are based on different methodologies for evaluating doses, very few workers currently receive both internai and external doses that approach the separate limits under the current Part 20. (It is assumed in this section that workers who were reported to receive whole-body doses approaching or exceeding 5 rem did not receive significant internal doses. The few cases where this assumption does not apply were discussed in Section 3.4). 


\section{Number of Workers Who Receive High Doses}

Certain licensees are currently required under Part 20.407 to submit an annual statistical summary report of whole-body doses received by individuals for whom monitoring was required. The reports list the number of individuals who received doses in any of eighteen dose ranges. The data in these reports are periodically compiled and analyzed by the NRC. To assess the impact of the revision, summary information on the relatively high doses received by individuals at NRC-licensed facilities was reviewed. Table 4.1 lists selected data for the year 1984 for the seven categories of licensees required to submit annual summary reports (Brooks 1986).

\section{TABLE 4.1. Doses Received by Licensee Employees in 1984}

\begin{tabular}{|c|c|c|c|c|c|}
\hline Facility Type & $\begin{array}{c}\text { No. of } \\
\text { Licensees }\end{array}$ & $\begin{array}{l}\text { No of } \\
\text { Employees } \\
\text { Monitored }\end{array}$ & $\begin{array}{c}\text { Average Dose } \\
\text { Equivalent per } \\
\text { Employee } \\
\text { Monitored rem }\end{array}$ & $\begin{array}{l}\text { No. of } \\
\text { Receivir } \\
4 \text { rem or } \\
4-5 \text { rem }\end{array}$ & $\begin{array}{l}\text { ployees } \\
\text { Doses } \\
\text { Greater } \\
>5 \text { rem }\end{array}$ \\
\hline Industrial & & & & 0 & \\
\hline & & & & & \\
\hline $\begin{array}{l}\text { Manufacturing and } \\
\text { 0istribution }\end{array}$ & 38 & 5,009 & 0.13 & 1 & 0 \\
\hline $\begin{array}{l}\text { High-Level Waste } \\
\text { Repository }\end{array}$ & 0 & 0 & ---- & 0 & 0 \\
\hline $\begin{array}{l}\text { Low-Level Waste } \\
\text { Disposal }\end{array}$ & 2 & 925 & 0.08 & 0 & 0 \\
\hline $\begin{array}{l}\text { Independent } \\
\text { Fuel Storage }\end{array}$ & 1 & 32 & 0.41 & 0 & 0 \\
\hline $\begin{array}{l}\text { Fuel Fabrication } \\
\text { and Processing }\end{array}$ & 14 & 9,488 & 0.09 & 0 & 0 \\
\hline $\begin{array}{l}\text { Commercial Power } \\
\text { Reactors }\end{array}$ & $\underline{88}$ & $\underline{170,928}$ & $\underline{0.32}$ & 380 & $\underline{11}$ \\
\hline Total & 504 & 194,840 & 0.30 & 405 & 24 \\
\hline
\end{tabular}

Similar data for licensee categories other than the seven presented in Table 4.1 were not available for the year 1984 because licensees in other categories were not required to submit annual reports of occupational exposures. However, data for other categories of licensees were compiled for exposures occurring in 1979 (Brooks. McDonald and Richardson 1982). Selected data from that report are presented in Table 4.2. 
TABLE 4.2. Number of Licensee Employees Reported to Have Received Doses Approaching or Exceeding 5 rem in 1979

\section{Facility Category}

Academic

Medical

Marketing

Industrial Radiography

Research and Development

Other Byproduct Material(a)

Uranium Milling/Production

Fuel Fabrication and Processing

Other Special Nuclear Material

Research and Test Reactors

Power Reactors

Total
No. of Employees

Monitored

24,639

64,057

11,037

11,969

18,663

27,335

3,508

9,946

7,562

3,003

$\underline{106,445}$

288,164
No. of Employees Receiving Doses of 4 rem or Greater $4-5 \mathrm{rem} \geq 5 \mathrm{rem}$ 1 1

21 29

31 21

34 24

4 1

9

22

0

0

0

0

477

577

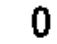

0

0

0

130

(a) Includes well logging.

Although in some cases the facility categories are not consistent between Tables 4.1 to 4.2 , analysis of the data from which the tables were derived provides an indication of trends in dose distributions. Of the 577 individuals reported to have received occupational doses between 4 and $5 \mathrm{rem}$ in 1979, only 35 (6\%) were not employed by licensees categorized as facilities belonging to one of the seven types listed in Table 4.1. Of these 35 individuals, 30 were employed at either a medical facility or a well logging facility. The remaining 5 individuals were employed at other types of facilities. Similarly, of the 228 individuals reported to have received occupational doses greater than 5 rem in 1979, 53 (23\%) were not employed by licensees categorized as facilities belonging to one of the types listed in Table 4.1. Of these 53 individuals, 46 were employed at either a medical facility or a well logging facility. The remaining 7 individuals were employed at other types of facilities.

The number of workers reported by licensees to have received doses in the various dose ranges does not reflect the actual distribution of doses received because of multiple reporting of transient (temporary) workers who worked at more than one facility during a year. Transient workers are often employed at nuclear power facilities for relatively brief periods, principally during plant outages or during special maintenance activities (Lawrence et al. 1984). Because a facility is required to report only those doses 
received at that facility, a sumation of these reports results in transient workers being counted two or more times in relatively low dose ranges; such a practice does not reflect the doses actually received by these individuals during the year. However, their actual annual doses can be determined by compiling termination reports. When a transient worker terminates employment at a facility, a termination report indicating the dose received by that worker during employment at that facility is reported to the NRC as required under the present Part 20. Although termination reports are required to be submitted by all seven categories of licensees listed in Table 4.1, more than 95\% of termination reports are filed by commercial nuclear power facilities (Brooks 1986).

Analysis of the termination reports submitted by nuclear power facilities indicates that from 1977 through 1984, multiple reporting of transient workers accounted for an underestimate of the number of workers who were reported to have received annual doses greater than 5 rem. The actual total was from 50 to 80 workers per year higher (Brooks 1986). Although this number applies only to transient workers employed at nuclear power plants, it was assumed that relatively few transient workers at other facilities received doses $>5$ rem during this period because more than 95\% of transient worker reports were filed by nuclear power plants. In addition, the nature of the work performed during outages at nuclear power plants suggests that doses $>5 \mathrm{rem} / \mathrm{yr}$ are most likely to be incurred by transient workers employed at nuclear power plants rather than transient workers employed elsewhere.

Using these adjusted dose estimates for transient workers at commercial power reactors, the actual number of workers who received annual doses $>5$ rem was derived for the years 1979 and 1984. The results are presented in Table 4.3. For 1984, the data for well logging, medical, and other facilities were extrapolated from the 1979 data assuming a reduction in numbers consistent with the reduction observed for industrial radiography facilities. Extrapolation was necessary because 1979 was the last year that data were compiled for facilities other than those required to submit annual summary reports.

The data in Table 4.3 suggest that the number of licensee workers who received annual doses $>5$ rem dropped significantly from 1979 to 1984 . In 1979, 180 nuclear power plant workers received doses $>5$ rem, 130 (72\%) of whom were reported by facilities on the annual statistical summary report form. The remaining $28 \%$ were transient workers reported by two or more facilities during the year. In 1984, 110 workers received $>5$ rem, none of whom were reported on the annual statistical sumnary report forms, i.e., all of whom were transient workers.

Exposure data for the years 1985 and 1986 suggest that doses received by workers in the nuclear power plant industry dropped dramatically during those two years. In 1985, collective doses received by nuclear power plant workers were $20 \%$ lower than the collective doses received in 1984 (Ryan 1986). Compared to the reduction in collective doses observed in previous years, the 20\% reduction in collective doses in 1985 was unprecedented. Since 1973, the greatest single-year reduction in collective dose equivalent received by 
TABLE 4.3. Adjusted Number of Employees Who Received Doses $>5$ rem in 1979 and 1984

\begin{tabular}{|c|c|c|}
\hline Facility Type & \multicolumn{2}{|c|}{ Received $>5$ rem } \\
\hline & 1979 & 1984 \\
\hline Industrial Radiography & 24 & 13 \\
\hline Medical & 29 & 16 \\
\hline Well Logging & 17 & 9 \\
\hline Commercial Power Reactors & 180 & $110(a)$ \\
\hline All 0thers & 7 & 5 \\
\hline Total & 257 & 153 \\
\hline
\end{tabular}

(a) Estimate based on discussions with firms providing contract personnel (Brooks 1986).

nuclear power plant employees had been 4\%. As in 1984, no worker at any one nuclear power facility received $>5$ rem in 1985 .

In 1986, the total collective dose equivalent was lower than the 1985 level. Also in 1986, the average dose per worker reached the lowest level ever reported for the U.S. nuclear power industry (USNRC 1987b). For the third consecutive year, no worker received a dose $>5$ rem while at any one facility.

The recent dramatic decreases in collective dose equivalents, average individual dose equivalents, and number of workers who received $>5$ rem per year is not likely to be a short-lived phenomenon. Some of this change is attributable to an increased emphasis by the Institute of Nuclear Power 0perations (INPO) on keeping doses low (Ryan 1985). INPO, an organization established in 1979 to promote the highest levels of safety and excellence in the nuclear industry, has recognized low personnel radiation exposures as one indicator of high plant performance (Pate 1986). Combined with NRC efforts to promote the ALARA concept, efforts by INPO to reduce individual and collective radiation doses throughout the nuclear industry have been successful.

Several other factors may have contributed to the recent reduction in doses to workers at both nuclear power plants and other NRC-licensed facilities. First, for most of this decade, NRC has been moving toward a revision of Part 20 that includes a 5-rem annual limit. Second, the concept of ALARA has been emphasized by essentially all influential organizations, including the NRC. Many facilities have responded by both reducing the collective doses incurred at the facilities and by reducing the number of workers to zero who are receiving an annual dose $>5$ rem. These two factors have contributed to the practice by all nuclear power plants to establish administrative 
limits that are $<5 \mathrm{rem} / \mathrm{yr}$. Finally, post-Three Mile Island modifications that involved high doses have now been completed (Ryan 1985).

\section{Direct Implications of Revised Occupational Limits}

It is evident from the data presented in the preceding section that the number of licensee workers who receive annual doses $>5$ rem is small and is continually decreasing. Based on the trends indicated by recent exposure data, it is estimated that the revised whole-body dose limit will reduce from 50 to zero the number of workers at nuclear power plants who will receive planned annual doses $>5$ rem. This estimate does not consider the use of the planned special exposure provision, which is discussed in Section 4.2; nor does it consider gradual implementation of the revision.

Because the workers affected by the revised limits will primarily be temporary workers, licensees will selectively hire temporary workers whose total annual doses from all employers are not approaching the dose limits. This is not expected to result in a change in the total collective dose equivalents received at the facilities, nor is it expected that significant costs will be incurred by licensees, because only 50 workers per year would be expected to receive annual doses $>5$ rem if the revised Part 20 were not promulgated. This is a very small percentage of the contractor work force, and licensees are not anticipated to experience a shortage of qualified workers in the foreseeable future (NESP 1980). The only significant cost associated with nuclear power plant facilities is that some workers will not be eligible for some jobs within the nuclear industry for portions of a year because their total annual doses from all employers will be near administrative or NRC dose limits. No attempt was made in this analysis to quantify these costs.

No impact from the revised limit is anticipated with regard to reducing annual doses below 5 rem to workers at facilities other than nuclear power plants. Table 4.3 indicated that in 1984, 43 non-power-plant workers were exposed to doses $>5$ rem. Of these, 16 were employed at medical facilities (hospitals) and it is likely that similar exposures in 1989 would not be planned, with or without promulgation of the revised Part 20. Twenty-two of the 43 workers were employed by either well logging or industrial radiography facilities. It is estimated that by 1989, only a few such workers per year would receive annual doses $>5$ rem if the revised Part 20 were not promulgated. This estimate considers the continuing overall reduction in relatively high doses throughout the nuclear industry as a result of emphasis on ALARA practices. For similar reasons, the five individual doses $>5$ rem in 1984 that were reported by other facifities would not be expected to occur in 1989 .

\section{1ndirect Implications of Revised 0ccupational Limits}

An important effect of the revised occupational whole-body dose limit will be to reduce the administrative limits at some facilities. An administrative limit is a self-imposed limit set by a facility to provide a safety margin to ensure that the NRC limits are not exceeded. As stated previousiy in this section, nuclear power plants currently do not intentionally allow 
workers to receive whole-body doses greater than $5 \mathrm{rem} / \mathrm{yr}$. To assure this, the administrative limits at the plants are set lower than $5 \mathrm{rem} / \mathrm{yr}$. Annual administrative limits are common at many plants, as are quarterly and/or weekly administrative limits (either in addition to or instead of annual administrative limits) (Pelletier and Voilleque 1979). It is expected that a minor reduction in administrative limits will occur at some nuclear power plants in response to the revision of Part 20, resulting in hiring about 20 permanent workers for radiation areas who will lessen the burden on similar workers approaching the plant administrative limits. Although this will likely result in a decrease in efficiency for performance of some work, the anticipated slight increase in collective dose equivalent is considered negligible for this analysis.

It is likely that other facilities will reduce their administrative dose limits in response to the revised whole-body dose limits in Part 20. However, Table 4.1 indicated that few employees other than those at nuclear power plants receive doses $>4$ rem. Therefore, the impact of the revised whole-body dose limit with regard to lowered administrative limits is estimated to be negligible for facilities other than nuclear power plants.

Before the estimated impact of the revised whole-body dose limits can be quantified, two important factors must be considered. First, as stated previously, the number of workers who have received doses approaching or exceeding $5 \mathrm{rem} / \mathrm{yr}$ has decreased dramatically in recent years. It is likely that this trend will continue regardless of the limits specified in Part 20 . However, because of the difficulty in estimating the rate of decrease, it is estimated that the work force in the nuclear industry will be permanently increased by 20 workers to ensure that administrative dose limits are not exceeded. This consideration partially accounts for the probability that some of the decrease in individual doses already observed may be directly attributable to licensee pre-planning in anticipation of the revised limits.

The second important consideration in assessing the impact of the revised limits is that the implementation period for the revision is 5 years from the date the proposed revision was published (January 9, 1986). If licensees make use of this implementation period, costs could be deferred, resulting in a reduced present value of the costs of the revision. The method used in this report for calculating present values is described in Section 8.2.

\section{Statement of Impact}

The estimated impact of the revised whole-body occupational dose limit on NRC licensees is expected to be limited to the costs associated with hiring additional permanent workers at nuclear power plants. These workers will be hired in order to reduce annual doses to members of the existing workforce who currently receive doses approaching or exceeding $5 \mathrm{rem} / \mathrm{yr}$. Based on data presented in this report and an annual cost of $\$ 60,000 /$ worker (SEA 1986), which includes all costs (labor and overhead) associated with the employment of the worker, the estimated annual impact of the revised whole-body dose limits is $\$ 1,200,000$ in 1989 dollars. A one-time marginal cost of \$280,000 is also estimated for hiring 20 workers at a cost of $\$ 14,000 /$ worker in 1989 
dollars (Vallario et al. 1985). No other attributes are expected to be significantly affected by the revised whole-body dose limit.

\subsubsection{Other Limits and Their Consequences}

In addition to the revised whole-body dose limit, the revision of Part 20 includes revised dose limits for the eyes, extremities, skin, and individual organs. The revised limits for the eyes and skin allow higher annual doses than are allowed by the present limits. The revised limit for the extremities is lower than the present limit; however, the revised rule clearly states that the limit is applicable to individual extremities. In contrast, the current rule does not specify that the limit is applicable to individual extremities. Finally, the dose limit to individual organs is essentially unchanged. However, the use of DACS and ALIs to limit the doses to individual organs will indirectly change the limit on intake of certain radionuclides. This consequence of the revised dose evaluation requirements was discussed in Section 3.4.

Dose limits for the eyes, skin and extremities are intended to prevent nonstochastic effects to those parts of the body (ICRP 1977. NCRP 1987). When the dose limit to an individual organ is not determined by the 5-rem annual limit for the whole-body, the limit to that organ (50 rem/yr) is also intended to prevent nonstochastic effects.

Because nonstochastic effects have a dose threshold, workers should not suffer from these effects, providing that their doses are kept below the limits. Under the current dose limits, no nonstochastic effects have been observed except when doses much greater than the limits were received from accidental overexposures. Assuming that the revised dose limits will not affect the probability of an accidental overexposure, no impact regarding occupational health is anticipated from the revised i imits.

The revised limits could result in slight impacts on operations costs. For example, an increased annual eye dose limit could result in a decreased use of protective goggles (McGuire, Baker and Vandergrift 1983). Also, a decreased extremity limit could result in an increased use of shielding and gloves. Depending on the current interpretation of the dose limit to the skin, however, some individual licensees currently choose to adopt the limit to the skin for limiting dose to the extremities. Although the most recent guidance by NRC states that the dose limit to the skin of the whole body does not apply to the skin of the hand and forearm (USNRC 1983), licensees do not use consistent methods to determine doses to the skin. Therefore, an increased dose limit for skin could result in increased extremity doses.

Although there will likely be slight impacts on operations costs from the revised limits, the net impact is estimated to be negligible. Because the revised limits to the eyes and skin are less restrictive than the current limits, the costs saved are expected to approximately offset the costs incurred from the more restrictive extremity limits. In addition, previous case studies have indicated that, except for a few workers, eye, skin, and extremity doses have been maintained well below both the current and revised limits (USNRC 1982). Increased costs for extremity monitoring, which will 
result from both reduced limits and reduced doses that require monitoring, were discussed in Section 3.1.

\subsection{PLANNED SPECIAL EXPOSURES}

Under the planned special exposure provision in the revised Part 20, a licensee may authorize an adult worker under certain conditions to receive doses in excess of the prescribed annual limits. This provision may only be used in an exceptional situation, and the dose received by an individual from all planned special exposures in a year must not exceed one times the annual limit. In order to authorize a planned special exposure, a licensee must first ascertain the doses received from all previous planned special exposures and unplanned exposures in excess of the annual limits for each individual involved. The total lifetime dose from all planned special exposures and all doses in excess of the annual limits must not exceed 5 times the annual limits.

Although the present Part 20 does not include a planned special exposure provision, the present "5(N-18)" rule is somewhat similar because, under the rule, annual doses $>5 \mathrm{rem} / \mathrm{yr}$ are permitted. An important difference, however, is that planned special exposures are limited to "exceptional" situations, whereas the "5(N-18)" rule was essentially unconditional. As a result, it is expected that fewer individuals will receive annual doses $>5$ rem under the revised Part 20 than under the present Part 20.

\subsubsection{Use of the Planned Special Exposure Provision}

Use of the planned special exposure provision for whole-body doses will be limited primarily to conmercial nuclear power facilities. This is because, as demonstrated in Section 4.1.1, temporary workers at nuclear power plants are the only workers at NRC-licensed facilities who currently receive planned annual doses $>5$ rem. It is assumed that this would continue in the future even without implementation of the revised Part 20 . As a result, facilities other than nuclear power plants would have no reason or justification for using the planned special exposure provision for whole-body doses. The few exceptions that might occur were assumed for this analys is to be negligible.

It was estimated that reduced administrative limits based on the revised Part 20 would result in the hiring of 20 additional permanent workers at all nuclear power plants combined (Section 4.1.1). In addition, it was estimated that annual individual doses $>5$ rem would be reduced from 50 to zero once the revised Part 20 is implemented. This reduction would be realized primarily through selective hiring of temporary workers. These estimates were made without consideration of the planned special exposure provision.

Instead of reducing individual doses through increased or selective hiring, it is possible that licensees will use the planned special exposure provision to authorize annual doses $>5$ rem in order to reduce expenses. However, this possibility is remote because of the conditions of the provision. The condition likely to limit the use of the planned special 
exposure provision is 20.206 (a), which states that the provision can on iy be used when other alternatives are either "unavailable or impractical." Because the term "cost-effective" is not included in this condition, licensees will be likely to use the planned special exposure provision only when no other reasonable alternative exists.

It is estimated that an average of one nuclear power plant facility per year will use the planned special exposure provision. One reason for using the provision could be to avoid a safety hazard that may occur if repairs to a vital piece of equipment are delayed. Another reason could be to avoid substantial costs that would be incurred if vital work is delayed. In either case, the benefits would outweigh the costs. Otherwise, the licensee could not justify using the planned special exposure provision.

\subsubsection{Effect on Distribution of Doses}

Use of the planned special exposure provision should result in a decrease in collective dose equivalent because alternatives to use of the provision, such as performance of a job using more workers than are needed, would be less efficient. Therefore, use of the provision should partially offset the slight increase in collective dose equivalent anticipated from the revised whole-body dose equivalent limit. However, because the planned special exposure provision is anticipated to be used about once per year, the effect on doses to workers is assumed to be negligible.

\subsubsection{Cost Implications}

When the planned special exposure provision is used, a cost savings associated with its use is virtually assured because of the conditions that must be met before the rule can be implemented. Licensees will be unlikely to use the provision unless alternatives to its use are significantly less cost-effective. The associated cost savings could be significant if, for example, the down time at a nuclear power plant is reduced (the cost of replacement power averages $\$ 400,000$ - \$500,000 per day during a nuclear power plant outage). Because the planned special exposure provision is anticipated to be used infrequently, no attempt was made in this analys is to quantify the associated net cost savings. It is assumed, however, that these savings will partially offset the cost increases associated with the revised whole-body dose limit.

\subsection{DOSE TO AN EMBRYO/FETUS}

The current Part 20 does not provide a limit on dose to the embryo/ fetus of a pregnant worker. Rather, pregnant workers are subject to the same occupational dose limits as all other adult workers. A 0.5 -rem limit is practiced at many facilities because of a NRC Regulatory Guide (USNRC 1987a) and a staff position paper that address this subject. The revised Part 20 explicitly states that the dose to an embryo/fetus due to occupational exposure of a declared pregnant worker shall be limited to 0.5 rem during the entire pregnancy. The rule also states that efforts shall be made to avoid substantial variation above a uniform monthly rate that would satisfy 
the 0.5 -rem limit. By comparison, the NCRP recommends a limit of 0.5 rem to the fetus during the entire pregnancy, and also recommends a limit of $0.05 \mathrm{rem} / \mathrm{month}$ once a pregnancy becomes known (NCRP 1987). Essentially, the revised Part 20 rule is consistent with the NCRP recomendations; however, the rule is worded less strongly.

\subsubsection{Effect on Distribution of Doses}

Because licensees are currently not required to submit detailed annual reports of doses received by individuals, it is not possible to precisely determine the number of female workers at licensee facilities who currently receive doses $>0.5 \mathrm{rem} / \mathrm{yr}$. However, based on a comprehensive review of occupational exposure to ionizing radiation in the United States in the year 1980 (Kumazawa, Melson and Richardson 1984), it is possible to estimate the effect of the embryo/fetus limit on occupational exposures. In 1980, an estimated $80 \%$ of female workers monitored for exposure to ionizing radiation were between the ages of 18 and 40 . The median age of these women was 27 , 28, and 32 for workers in medicine, the nuclear fuel cycle, and industry, respectively. Approximately 10,000 women were reported to have received doses $>0.5$ rem in 1980. A distribution of these women by dose range and industry is presented in Table 4.4, where the data indicate that approximately $90 \%$ of the women who received doses $>0.5$ rem were employed in medicine.

There is evidence, however, that the number of pregnant women who receive annual doses $>0.5 \mathrm{rem}$ is small and is decreasing (USNRC 1982). Several factors could account for this trend. First, the NRC published a revised regulatory guide on prenatal radiation exposure in 1975 (USNRC 1975) which specifies that women assigned to work in a restricted area should be given specific instruction regarding prenatal exposure risks to the developing embryo and fetus. Women were instructed that they could request reassignment to nonradiation work if they were pregnant or expected to be soon. Currently, most licensees either comply with or go beyond the recommendations in this regulatory guide. Two other factors that may contribute to this trend are the emphas is by ICRP (ICRP 1977) and NCRP (NCRP 1987) on limitation of dose to the unborn, and the trend toward reduced individual doses throughout the nuclear industry (see Section 4.1.1).

Although few pregnant wonen currently receive doses $>0.5$ rem, the embryo/fetus dose limit in the revised Part 20 and the recent revision of Regulatory Guide 8.13 (USNRC 1987a) will result in a further reduction in the number of pregnant women who receive doses $>0.5$ rem. For the reasons discussed in the paragraph above, it is assumed in this report that essentially all pregnant women who currently receive doses $>0.5$ rem do so voluntarily.

It was estimated that about $7 \%$ of female radiation workers in the U.S. become pregnant in a given year (NCRP 1977). Based on the data in Table 4.4 and the recent trend toward decreased individual doses, and assuming that declared pregnant wonen will not receive doses $>0.5$ ren under the new limit, it is estimated that the doses to 200 pregnant women per year will be reduced below 0.5 rem due to the embryo/fetus limit. It is also estimated that an additional 1000 pregnant wonen per year will receive reduced doses even 
TABLE 4.4. Number of Women Reported to have Received Doses $>0.5 \mathrm{rem}$ in 1980

\begin{tabular}{|c|c|c|c|c|}
\hline \multirow[b]{2}{*}{$\begin{array}{c}\begin{array}{c}\text { Dose Range, } \\
\text { rem }\end{array} \\
\end{array}$} & \multicolumn{4}{|c|}{ Number of Women Employed } \\
\hline & Medicine & $\begin{array}{c}\text { Nuclear Fuel } \\
\text { Cycle } \\
\end{array}$ & $\begin{array}{c}\text { 0ther } \\
\text { Industries }\end{array}$ & Total \\
\hline $0.5-1.0$ & 5,902 & 82 & 560 & 6,544 \\
\hline $1.0-2.0$ & 2,191 & 111 & 236 & 2,538 \\
\hline $2.0-3.0$ & 587 & 33 & 68 & 688 \\
\hline $3.0-4.0$ & 188 & 19 & 0 & 207 \\
\hline $4.0-5.0$ & 100 & 0 & 0 & 100 \\
\hline Total & 8,968 & 245 & 864 & 10,077 \\
\hline
\end{tabular}

though they would not have received doses $>0.5 \mathrm{rem}$ had the limit not been promulgated. This estimate is based on the assumption that licensees will be more cautious regarding the exposure of pregnant women to ionizing radiation once the limit is promulgated. The total dose reduction for the 1200 pregnant women is estimated to be $300 \mathrm{rem}$. Because these doses will likely be distributed to nompregnant replacement workers in most cases, the net savings in collective dose is anticipated to be insignificant for workers at licensee facilities. However, it is estimated that $300 \mathrm{rem} / \mathrm{yr}$ to fetuses will be saved by the dose limit. It is assumed that $90 \%$ of this dose reduction will occur at medical facilities and $10 \%$ will occur at nuclear power plants.

\subsubsection{Cost 1mplications}

Because most licensees voluntarily keep doses to pregnant women below the limit specified in the Part 20 revision, they have experience in ensuring that declared pregnant workers do not receive doses $>0.5$ rem. Most licensees simply remove pregnant workers from work involving high radiation doses (USNRC 1982). The costs, therefore, are expected to be administrative costs required to either hire a replacement worker or reassign a present worker to the job vacated by the pregnant woman. The average estimated cost per pregnant worker who is removed from her work is $\$ 500$. Based on the estimates in Section 4.3.1, the total cost to licensees is expected to be $\$ 600,000$ per year, $90 \%$ and $10 \%$ of which will be incurred by medical facilities and nuclear power plants, respectively.

\subsubsection{Other Considerations}

Because it will be difficult for licensees to determine in advance which women will become pregnant during their employment, it is possible that some licensees will selectively hire either men or older women for jobs that involve relatively high doses. This will limit the career opportunities for certain women. This phenomenon has already been observed at some facilities, especially nuclear power plants (USNRC 1982), and it is likely that promulgation of the limit will further affect the employment opportunities to some 
degree for a small number of women. This topic is discussed further in Section 7.6.

\subsection{DOSE LIMIT FOR INDIVIDUAL MEMBERS OF THE PUBLIC}

The current Part 20 does not explicitly state a dose limit for individual members of the public, but does state limits of 2 mrem in 1 hour and 100 mrem in 7 days, based on continuous presence of an individual in an unrestricted area. An annual limit of 500 mren is implied, however, by wording in the current rule regarding license applications. A limit of $500 \mathrm{mrem} / \mathrm{yr}$ is also implied by the limit on releases of radioactive material to unrestricted areas. The present Part 20 also refers to 40 CFR Part 190 (EPA 1986a), which specifies much lower dose limits to the public from nuclear fuel cycle operations. Even though a $500 \mathrm{mrem} / \mathrm{yr}$ limit is not explicitly stated in the present Part 20 , the NRC would not allow licensees to operate such that this annual dose is exceeded.

The Part 20 revision explicitly states an annual dose limit of 0.1 rem to individual members of the public from continuing operations by a licensee. A licensee may apply for authorization to operate temporarily up to an annual limit of 0.5 rem. In addition to the annual limit, the dose in any unrestricted area is limited to $2 \mathrm{mrem} / \mathrm{h}$ (there is no 7-day limit). An additional rule requires demonstration of compliance with the dose limits by either measurement or calculation using approved methods.

\subsubsection{Effect on Distribution of Doses}

All licensees in the nuclear fuel cycle are constrained by 40 CFR Part 190 (EPA 1986a) to operate such that whole-body doses to individual members of the public are less than $25 \mathrm{mrem} / \mathrm{yr}$; 40 CFR Part 61 (EPA 1986b) contains a similar limit for air emissions for most other NRC licensees. Nuclear power plants are subject to further release limits in 10 CFR Part 50, Appendix 1. Because of the nature of operations of licensees not affected by 40 CFR Part 190 or 40 CFR Part 61 , it is extremely unlikely that any licensee (NRC or Agreement State) currently exceeds the revised 100-mrem annual effective dose equivalent limit, except for some medical facilities (see below). For those licensees in the future who can justify exceeding this limit, the revised rule allows for application to operate up to $500 \mathrm{mrem} / \mathrm{yr}$, which is the limit implied in the present Part 20.

It is possible that medical facilities where brachytherapy or radioimmunotherapy procedures are performed will be affected by the revised limits. Many hospitals performing brachytherapy have radiation levels outside a patient's room exceeding $2 \mathrm{mrem} / \mathrm{h}$ (Thomadsen et al. 1983). In some cases, these facilities must provide shielding or control patient admissions to ensure that dose rates to neighboring patients do not exceed the limits in Part 20. In many cases, the 100-mrem/7-day limit is the more restrictive limit because the wording of the rule requires limitation based on continuous presence of an individual in an unrestricted area (Thomadsen et al. 1983; Gitterman and Webster 1984). 
The revised limits could be both costly and beneficial to these facilities. The 100-mrem annual limit could be restrictive for patients who would otherwise remain at the facility for an extended period near a brachytherapy room. Conversely, the absence of the 100-mrem/7-day limit could allow facilities to control dose rates based on the less-restrictive $2-\mathrm{mrem} / \mathrm{h}$ limit. Based on these opposing factors and detailed descriptions of the ramifications of the current dose limits (Gitterman and Webster 1984), the net impact from the revised limits is anticipated to be insignificant for this analysis.

\subsubsection{Cost Implications}

Because licensee operations are not expected to be impacted by the revised limit, no operations costs are anticipated. However, the rule requiring demonstration of compliance may involve some added costs. The magnitude of these costs depends on the interpretation of the rule, which does not provide detailed procedures for how compliance must be demonstrated, nor does it provide details on which licensees are affected by the rule. Discussions with NRC personnel indicate that the intent of the rule is not to require increased monitoring of the environment, but to require licensees to maintain records showing compliance. Therefore, no significant costs other than recordkeeping costs are anticipated from promulgation of both the revised limits and the requirement to demonstrate compliance. The associated recordkeeping costs are discussed in Section 5.4 of this report.

\subsection{SUMMARY OF CONSEQUENCES}

In this section, the consequences of the revised limits are summarized. Table 4.5 summarizes these consequences by facility category (as defined in Section 8.1 ) and is a compendium of the consequences identified in Sections 4.1 to 4.4 in this report. The impacts from the revised 1 imits are anticipated to be negligible for facility categories not listed in Table 4.5. The positive present value of $\$ 10 \mathrm{million}$ listed in the table indicates that the expected benefit from the dose savings to the embryo/fetus exceeds the costs that will be incurred by licensees to comply with the revised dose 1 imits. 
TABLE 4.5. Summary of Consequences of the Revised Limits

\begin{tabular}{|c|c|c|c|c|}
\hline Facility Category & $\begin{array}{l}\text { Initial } \\
\text { Cost, \$ }\end{array}$ & $\begin{array}{r}\text { Annual } \\
\text { Cost, } \$ \\
\end{array}$ & $\begin{array}{r}\text { Value of } \\
\text { Annual Dose } \\
\text { Savings, } \$(a) \\
\end{array}$ & $\begin{array}{l}\text { Net Present Value } \\
\text { of Costs and } \\
\text { Benefits, } \$(\text { b) }\end{array}$ \\
\hline \multirow{2}{*}{$\begin{array}{l}\text { Medical } \\
\text { Commercial Power } \\
\text { Reactors }\end{array}$} & 0 & 540,000 & $2,700,000$ & $+19,000,000$ \\
\hline & 280,000 & $1,300,000$ & 300,000 & $-9,000,000$ \\
\hline Total & 280,000 & $1,800,000$ & $3,000,000$ & $+10,000,000$ \\
\hline
\end{tabular}

(a) Based on a value of $\$ 10,000 /$ fetus-rem.

(b) Calculated using method's described in Sections 8.2 and 8.3 of this report. The present values are based on 1989 dollars, a discount rate of $10 \%$ (applied to all costs and benefits), and a 30-year period. A positive sign indicates a positive impact and a negative sign indicates a negative impact. 
.

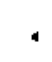




\subsection{CONSEQUENCES OF OTHER CHANGES}

In this section, the consequences of other changes in the revision are discussed. These include changes regarding control of internal exposure in restricted areas, precautionary procedures, waste disposal, recordkeeping requirements not discussed in Section 3.5, reporting requirements, and others. These consequences are summarized in Section 5.7.

\subsection{CONTROL OF INTERNAL EXPOSURE IN RESTRICTED AREAS}

Under the present Part 20, in areas of airborne contamination, licensees are required to maintain intakes of radioactive material as low as is reasonably achievable without regard to external exposures. In many circumstances this mandates the use of respiratory protective equipment. Under the revised Part 20, internal exposures are considered a part of the worker's total radiation exposure and the licensee is required to keep the total effective dose equivalent ALARA. This permits the licensee to base ALARA decisions on both internal and external exposure rates, and could lead to a long-term net benefit in both collective dose and program costs.

Informal studies at Three Mile Island Unit 2 (TMI-2) indicated an overall dose savings of up to $50 \%$ (internal plus external dose) when the use of a respirator was discontinued (Cardarelli et al. 1986). The higher doses with a respirator were due to loss of productivity and consequent lengthened work times. It is well known that wearing respirators can lead to anxiety, which is associated with increased breathing resistance, increased body temperatures, decreased communication capabilities, limited vision, and general discomfort, all of which reduce work efficiency. A controlled experiment (Cardarelli et al. 1986) failed to show a statistically significant change in work time for a selected task with and without a respirator. It was observed that due to the discomfort of the respirator the workers operated faster, but this would probably not be true during longer, more complex tasks.

Information on accumulated doses is readily available for the various jobs involving respirator usage; however, information on present respirator usage, job frequency, and air concentrations by job is not readily available. Clearly, both cost savings and dose savings are likely, but the magnitude was difficult to assess accurately without additional information. If there were a $25 \%$ decrease in collective dose due to the greater efficiency from not using respirators in high-external, low-internal dose rate fields, this could result in an annual savings of over 600 person-rem during outages (Table 5.1). This is based on collective doses for selected jobs (Dionne and Baum 1985) and assumes a 25\% decrease in collective doses for $10 \%$ of the outage tasks.

The costs associated with the use of respiratory protection equipment (i.e., costs of canisters and additional personnel to process respirators and track stay times in airborne radioactivity areas) were estimated at over $\$ 30,000$ per outage week (Hendrixson, Wagner and Morris 1986). With a typical plant outage lasting 8 weeks (ANS 1988), the annual cost savings for the 
IABLE 5.1. Estimated Collective Dose Equivalent Savings During an Outage Through Reduced Respiratory Usage for Selected Tasks(a)

\begin{tabular}{|c|c|c|c|c|}
\hline Task & $\begin{array}{c}\text { Typical } \\
\text { Collective Dose } \\
\text { Equivalent } \\
\text { person-rem(b) }\end{array}$ & $\begin{array}{c}\text { Annual } \\
\text { Frequency (c) }\end{array}$ & $\begin{array}{l}\text { No. of } \\
\text { Reactors } \\
\text { Affected }\end{array}$ & $\begin{array}{l}\text { Savings in } \\
\text { Collective Dose } \\
\text { Equivalent } \\
\text { person-rem (d) }\end{array}$ \\
\hline $\begin{array}{l}\text { Assembly/Disassembly Fuel } \\
\text { Shuffle }\end{array}$ & 56 & 0.67 & 107 & 100 \\
\hline Snubber Inspection and Repair & 75 & 0.6 & 107 & 120 \\
\hline $\begin{array}{l}\text { Torus Inspection/Modification } \\
\text { Repair }\end{array}$ & 280 & 0.6 & 36 & 151 \\
\hline In-Service Inspection & 68 & 0.6 & 107 & 109 \\
\hline Steam Generator(Test/Plug) & 76 & 0.5 & 71 & 67 \\
\hline Decontamination & 33 & 0.5 & 107 & 44 \\
\hline $\begin{array}{l}\text { Reactor Coolant/Circulation } \\
\text { Pump Seal Repair }\end{array}$ & 14 & 0.47 & 107 & 18 \\
\hline Total & & & & 609 \\
\hline
\end{tabular}

(a) Data derived from Dionne and Baum (1985).

(b) Collective dose for typical plant based on $\frac{1}{\mathrm{~N}_{T}}\left(\Sigma \mathrm{N}_{i} \times 0\right)$ where $\mathrm{Ni}$ is the number of plants of Type $i$ and 0 is the average collective dose for type $i$.

(c) (Estimated frequency of task per outage) $X$ (annual frequency of outage [0.67]).

(d) Assumes a 25\% reduction in collective dose due to efficiency increases through reduced respiratory usage for $10 \%$ of the outage tasks. 
utility industry would be $\$ 1.75$ million, counting 0.67 outages per reactor per year, 109 reactors (ANS 1988), and a $10 \%$ reduction in the overall use of respirators during outages. However, a decrease in the frequency of respirator use will likely result in increased costs for air monitoring, health physics support, and bioassay measurements (Merwin, Brown and Martin 1987). Therefore, the net annual cost savings are estimated to be one half of $\$ 1,750,000$ or $\$ 880,000$.

There are large uncertainties in these estimates, and benefits realized on other jobs or during routine operation were ignored. The impact on the non-power reactor segments of the industry were felt to be relatively insignificant and were not considered further.

\subsection{PRECAUTIONARY PROCEOURES}

Precautionary procedures are set forth in Subpart $J$ of the Part 20 revision. These include procedures for labeling containers of radioactive material, posting caution signs, and handling packages containing radioactive material.

\subsubsection{Labeling Requirements}

The revised rules that address container labeling are essentially the same as the present rules. In both cases, containers of radioactive material must be labeled with caution signs, and the labels must provide information on the radioactive material present in the containers. Containers are exempt from the labeling requirement if they contain concentrations or quantities of radioactive material less than the values tabulated in Appendixes $B$ and $C$.

The significant differences between the revised and present requirements are the exempt quantities provided in Appendix $C$. The present Appendix $C$ lists the exempt quantities of 180 separate radionuclides, whereas the revised Appendix $C$ lists the exempt quantities of 761 separate radionuclides. of the 180 radionuclides listed in the revised Appendix $C$ that are also listed in the present Appendix $C$, the exempt quantities in the revision are unchanged for 93 radionuclides, higher for 79 radionuclides, and lower for 8 radionuclides. Of the 87 exempt quantities that were changed, 76 were changed by a factor of ten and 11 were changed by a factor of 100 .

The current exempt quantities of the radionuclides not listed in the present Appendix $C$ are equal to one of two default values, depending on whether or not the radionuclide is an alpha emitter. Of the 581 radionuclides listed in the revised Appendix $C$ that are not listed in the present Appendix $C, 557$ of the revised exempt quantities are equal to, or in most cases higher than the current default quantities. Only 24 revised quantities are lower than the relevant default values listed in the present Appendix $C$.

Because the Part 20 revision relaxes the requirement for labeling for most radionuclides, there could be a net cost savings from the revised labeling requirements. However, most of the radionuclides listed in the revised Appendix $C$ are not commonly found in licensee facilities. For most 
of the radionuclides that are common, the revised exempt quantities are only one order of magnitude higher than the present exempt quantities. Also, it is common practice to label containers of radioactive material with appropriate labels regardless of the quantity. The main exception to this practice occurs for packages containing naturally-occurring radionuclides, such as thorium and uranium, for which the exempt quantities in Appendix $C$ are unchanged. As a result, the net benefit from the revised labeling requirements is anticipated to be positive but small. No attempt was made in this report to quantify the potential benefits nor the potential for increased doses to the public. However, a qualitative discussion of the potential benefits from the revised labeling requirements is presented in Section 7.7 .

\subsubsection{Posting Requirements}

The revised posting requirements, which address the types of posting required for rooms containing radioactive material or having specified radiation dose rates, are essentially equivalent to the current requirements. The minor changes are not expected to result in significant cost impacts.

\subsubsection{Package Handling Requirements}

These requirements address the receiving, monitoring, and opening of packages containing radioactive material. The changes are relatively minor and no significant impacts from the revision are anticipated.

\subsection{HASTE DISPOSAL}

The revision of Part 20 explicitly permits onsite storage of radioactive wastes to allow the radioactivity to decay. The expense of radioactive waste disposal and the lack of facilities has forced licensees to segregate, recycle, and compact wastes in an attempt to reduce waste volume and, thus, costs (Bunker 1985). More significant than cost is the possible exclusion from commercial low-level waste disposal facilities which the Low-Level Radioactive Waste Policy Act of 1990 (P.L. 96-573) portends. This has led to the building of onsite radwaste storage facilities as an alternative to immediate disposal. The NRC issued a generic letter (USNRC 1981) that provides guidance for temporary (5-yr) onsite radwaste storage at power reactors. Temporary onsite storage is regarded as a contingency that would become legalized by the new Part 20 . This change will have little impact on the industry since facilities are already being built at medical research institutions (Masse 1984) and nuclear power plants (Rutland and Tuohy 1984; Kemper, Kohlerand and Scholz 1984). The NRC encourages medical licensees to modify their license to store wastes with half-lives up to 100 days for decay and disposal by conventional means. The value of this change is already being realized and the cost impact is already being borne by NRC licensees.

The only changes regarding waste disposal requirements that are expected to have a significant impact are the revised requirements for disposal by release into sanitary sewerage. Although there are some changes in the wording of the rule, they are relatively insignificant compared to the 
changes in the concentration limits listed in Appendix B. Under the current Part 20, releases to sewers must be in concentrations lower than the values listed in Appendix B, Table I, Column 2. The limiting concentrations in the revised Part 20 are listed in Appendix $B$. Table 3 . A comparison of the current and revised average concentration limits for sewage disposal is presented in Table 5.2 .

Table 5.2 indicates that for the radionuclides listed, the revised concentration limits are generally one to two orders of magnitude lower than the current values. For alpha enitters, the disparity is often greater than two orders of magnitude.

It is anticipated that some licensees will be required to take action to reduce the concentrations of radionuclides that are released to the sanitary sewerage system. Based on a review of published data on releases of radionuclides by licensees (Tichler and Norden 1986; Cook 1981) and on a review of numerous NRC inspection reports, it is concluded that some medical, academic/ research, manufacturing and distribution, and nuclear laundry licensees could be affected by the revised release limits. Because of the large volumes of water released by most major medical and academic/research licensees, the impact on these licensees should be relatively small. It is likely, however, that some manufacturing and distribution and nuclear laundry licensees could be required to improve filtration systems, increase holdup times, and/or increase the amount of water released to sewers in order to comply with the revised limits. Nuclear power plants should not be affected because releases from these facilities are currently very low in accordance with the requirements in 10 CFR 50. Appendix I. Nilson and Malody (1982) suggested that some fuel fabrication facilities might be impacted by the revised limit for ${ }^{295} \mathrm{U}$; however, the magnitude of this potential impact is uncertain, and may be smaller than originally anticipated. Because the available data are not sufficient for a complete evaluation of these potential impacts, the impact of the revised limits for releases into sanitary sewerage was not quantified in this analysis: however, the impact on some licensee operations could be significant.

\subsection{RECORDKEEPING REQUIREMENTS}

Subpart $L$ of the revision describes the records required to be kept by licensees. As discussed in Section 3.5 of this report, the requirements for recording individual monitoring results will be costly to licensees because more information must be evaluated and recorded than under the present Part 20 . The requirement to maintain records of radiation protection programs is included in the discussion presented in Section 5.6. Changes regarding other recordkeeping requirements will have relatively insignificant impacts, as described below:

Records of Surveys. Although the revised requirements are more detailed than the present requirements, essentially all licensees currently keep records required by the revised Part 20 . Therefore, no significant impact is anticipated. 
TABLE 5.2. Current and Revised Average Concentration Limits for Releases into Sanitary Sewerage

\begin{tabular}{|c|c|c|c|}
\hline Radionuclide & $\begin{array}{c}\text { Current } \\
\text { Limit, } \mu \mathrm{Ci} / \mathrm{mL}\end{array}$ & $\begin{array}{c}\text { Revised } \\
\text { Limit, } \mu \mathrm{Ci} / \mathrm{mL}\end{array}$ & $\begin{array}{l}\text { Reduction Factor, } \\
\text { Current/Revised }\end{array}$ \\
\hline${ }^{3} \mathrm{H}$ & $1 E-1$ & $1 E-2$ & 10 \\
\hline${ }^{14} \mathrm{C}$ & $2 E-2$ & $3 E-4$ & 70 \\
\hline $32 p$ & $5 E-4$ & $9 \mathrm{E}-5$ & 60 \\
\hline${ }^{35} \mathrm{~s}$ & $2 E-3$ & $1 E-3$ & 2 \\
\hline${ }^{45} \mathrm{Ca}$ & $3 E-4$ & $2 E-4$ & 2 \\
\hline${ }^{51} \mathrm{Cr}$ & $5 \mathrm{E}-2$ & $5 E-3$ & 10 \\
\hline${ }^{54}{ }_{\mathrm{Mn}}$ & $4 E-3$ & $3 \mathrm{E}-4$ & 10 \\
\hline${ }^{59} \mathrm{Fe}$ & $2 E-3$ & $1 E-4$ & 20 \\
\hline${ }^{60} \mathrm{Co}$ & $1 E-3$ & $3 E-5$ & 30 \\
\hline${ }^{65} \mathrm{Zn}$ & $3 E-3$ & $5 E-5$ & 60 \\
\hline${ }^{86} \mathrm{Rb}$ & $2 E-3$ & $7 \mathrm{E}-5$ & 30 \\
\hline${ }^{90} \mathrm{Sr}$ & $1 E-5$ & $4 E-6$ & 2 \\
\hline${ }^{99} 9_{\text {Mo }}$ & $5 E-3$ & $1 E-4$ & 50 \\
\hline $99 m_{T c}$ & $2 \mathrm{E}-1$ & $1 \mathrm{E}-2$ & 20 \\
\hline${ }^{125} \mathrm{I}$ & $4 E-5$ & $2 E-5$ & 2 \\
\hline${ }^{129} \mathrm{I}$ & $1 E-5$ & $3 E-6$ & 3 \\
\hline $131_{I}$ & $6 \mathrm{E}-5$ & $1 E-5$ & 6 \\
\hline${ }^{137} \mathrm{Cs}$ & $4 E-4$ & $1 E-5$ & 40 \\
\hline${ }^{144} \mathrm{Ce}$ & $3 E-4$ & $3 E-5$ & 10 \\
\hline $235_{U}$ & $8 E-4$ & $3 E-6$ & 300 \\
\hline${ }^{238} \mathrm{Pu}$ & $1 E-4$ & $2 E-6$ & 50 \\
\hline $241_{\mathrm{Am}}$ & $1 E-4$ & $3 \mathrm{E}-7$ & 300 \\
\hline
\end{tabular}


Determination of Prior Occupational Dose. The primary change regarding requirements for determining prior occupational dose is that licensees must "attempt" to obtain lifetime records of dose before permitting individuals who will require monitoring to enter the licensee's restricted or controlled areas. Under the current Part 20, licensees must obtain record of prior doses only for the current calendar quarter, unless they plan to use the $5(N-18)$ dose-averaging provision. Only then are licensees required to determine lifetime cumulative doses.

There could be both costs and benefits from the revised requirements. Because licensees will be required to determine lifetime cumulative doses for more workers, additional costs will be incurred. On the other hand, the revised requirements will result in better tracking of individual doses and licensees will expend less effort per worker to determine prior doses. The latter point is especially important for tracking transient worker doses, where under the current recordkeeping requirements time is often lost waiting for and verifying exposure histories (Hageman, Artz and Humphress 1982). Because the revised requirements will result in both costs and benefits that are difficult to quantify, the net impact was not estimated in this analysis.

Records of Planned Special Exposures. As discussed in Section 4.2, the planned special exposure provision will not be used frequently. Therefore, the associated recordkeeping costs are assumed to be insignificant for this analysis.

Records of Dose to Individual Hembers of the Public. Under this new requirement, licensees must maintain records sufficient to demonstrate compliance with the dose limit for individual members of the public. Although not explicitly required under the present Part 20, records currently being maintained by most licensees should be sufficient to demonstrate compliance. The only licensees that are likely to be affected by the new requirement are some medical facilities, academic/research institutions, and manufacturing and distribution facilities, where health physicists or radiation safety officers will maintain more detailed records of radioactive releases and inventories of radioactive materials. It is estimated that for facilities in these categories, a health physicist or other appropriate professional will devote an average of 2 hours per year to these tasks. Based on a cost of $\$ 25$ per hour for health physicists (SEA 1986) and 9027 iicensees in these categories (see Section 8.1), the estimated annual cost is $\$ 450,000$.

Records of Haste Disposal. The changes that appear in the revised Part 20 are relatively minor and are expected to have an insignificant impact on licensees.

Records of Testing Entry Control Devices for Very High Radiation Areas. Although licensees are currently required to test entry control devices, they are not required to maintain test records. Although this requirement in the revision is new, most licensees voluntarily keep records to demonstrate compliance with the current testing requirements. Therefore, no significant impact is anticipated. 


\subsection{REPORTING REQUIREMENTS}

The NRC currently requires that licensees report the theft or loss of licensed material and incidents involving radiation exposures that exceed the annual limits. Certain licensees are also required to submit an annual summary report of radiation exposures received by workers (Brooks 1986). However, the revision contains three significant changes regarding reporting requirements. First, planned special exposures must be reported to the NRC within 15 days after the exposure occurs. A similar requirement is not included in the current Part 20 because planned special exposures are not currently allowed. Second, licensees that are currently required to submit annual exposure data will be required to submit separate reports for each individual for whom monitoring was required rather than one report containing summarized information. Third, all licensees will be required to, submit reports, at least annually, to all individuals for whom monitoring was required, indicating the doses that they received in the workplace. Although the latter requirement will actually be included in the revised 10 CFR Part 19, Section 19.13, it is included in the analysis provided in this report.

\subsubsection{Incident Reports}

Some incidents that are not reportable under the current requirements will be reportable under the revised requirements. Such incidents, including planned special exposures, are expected to be rare. Also, the cost of reporting an incident to the $N R C$ is relatively insignificant. As a result, no significant impact is anticipated from the revised incident reporting requirements.

\subsubsection{Reports of Personnel Monitoring}

Under the current Part 20 , certain licensees are required to submit an annual statistical summary report containing information on doses received by personnel. Under the revised requirements, individual reports rather than a summary report must be submitted. As a result, the affected licensees will annually submit one NRC Form 5 (or equivalent) for each individual for whom monitoring was required, rather than one report that summarizes all of the individual exposure information.

Because licensees are required to record individual dose information on NRC Form 5 (or equivalent) under a separate section of Part 20, the revised reporting requirement is not anticipated to result in significant costs regarding collection of information. The affected licensee will simply submit copies of forms they are required to maintain under the recordkeeping requirements. The amount of time required to assemble and submit these forms is anticipated to be equivalent to the amount of time expended under the current requirements to prepare a statistical sumary report. Additional mailing costs will be incurred under the revised requirements, but these costs are assumed to be negligible for this analysis. Costs associated with updating computer programs and data bases so that licensees can process the reportable exposure information were included under the category of recordkeeping requirements (Section 3.5 ). 
The significant costs from the revised requirements for reporting personnel exposures to the NRC will be incurred by the NRC itself. The NRC personnel responsible for processing licensee exposure data estimate that the marginal annual cost increase for processing exposure data could range from zero to $\$ 300,000$ per year, depending on the format of the reports submitted by the licensees. If all licensees provide computer disks containing exposure information in NRC Form 5 format, no additional annual costs would be needed to process the data. However, the revised rule only requires that the reports contain all information required in NRC Form 5; the revised rule does not require that NRC Form 5 be used. Personnel at NRC estimate that approximately $30 \%$ of licensees will submit computer disks containing exposure information in NRC Form 5 format. Therefore, the estimated marginal cost increase is $70 \%$ of $\$ 300,000$, or $\$ 210,000$ per year. The NRC personnel also anticipate a one-time cost of $\$ 20,000$ to upgrade software for processing the new data.

\subsubsection{Reports to Individuals}

Under the revised 10 CFR Part 19, all NRC licensees will be required to submit individual dose reports to all individuals for whom monitoring was required. As a minimum, licensees will be required to provide the reports at least annually. Three factors were considered in estimating the impact on licensees: 1) some licensees currently provide these reports voluntarily; 2) some licensees may choose to provide these reports more than once per year; and 3 ) under the current requirements, 1 icensees must provide these reports to individuals who request them. Based on discussions with licensees and former licensee health physicists and radiation safety officers, it is assumed for this report that 1) 25\% of licensees currently comply with the revised requirement, 2) licensees who choose to provide reports more frequently than once per year perceive a benefit from doing so (thus, the marginal cost can be estimated by assuming all licensees provide reports annualiy), and 3 ) the fraction of workers who currently request these reports is insignificant.

Based on the data provided in Section 8.1 and the assumptions listed above, it is estimated that an additional 583,000 reports per year (one each for $75 \%$ of monitored employees, see Table 8.3 ) will be submitted to individual workers. This estimate is also based on the assumption that for convenience, licensees will provide reports to all individuals actually monitored, not only to those individuals for whom monitoring is required.

Licensees will have three primary options for providing reports to individuals. First, larger facilities may maintain a database of personnel exposures and simply print the information on a form that is provided to the individuals. Second, smaller facilities that record personnel exposure data by hand will probably prepare annual individual reports by hand. Third, licensees who use the services of a dosimetry processor may pay the processor to prepare the annual sumary reports.

It is estimated that no matter which of these three options is used, the cost per individual report will range from $\$ 1$ to $\$ 2$. For this analysis, 
an average value of $\$ 1.50$ per report is assumed. Based on 583,000 additional reports per year, the marginal annual cost would be $\$ 870,000$. In addition, licensees that choose to maintain a database will be required to modify existing software. It is estimated that $25 \%$ of all medical, academic/ research, and manufacturing and distribution licensees will select this option. This option will also be selected by an estimated $90 \%$ of all commercial power reactor and fuel fabrication facilities. A relatively insignificant fraction of other licensees will choose this option. A cost estimate for software modification is based on several factors: an estimated 1 person-week of effort by a computer programer per licensee, as well as hourly costs of $\$ 33$ for programmers at nuclear power plants (SEA 1986) and fuel fabrication facilities and $\$ 23$ for programers at other facilities. It is further assumed that 25\% of the licensees currently provide reports voluntarily. Based on these factors, the estimated one-time cost for software modifications is $\$ 1,700,000$. Table 5.3 presents the estimated costs by facility category. The present values provided in the table were calculated using methods described in Section 8.2 of this report.

TABLE 5.3. Cost of Providing Reports to Individuals by Facility Category

\begin{tabular}{|c|c|c|c|}
\hline Facility Category & $\begin{array}{l}\text { Initial } \\
\text { Cost, } \$\end{array}$ & $\begin{array}{l}\text { Annual } \\
\text { Cost, } \$ / y r\end{array}$ & $\begin{array}{l}\text { Present Value } \\
\text { of Costs, } 5\end{array}$ \\
\hline Medical & $1,100,000$ & 220,000 & $2,900,000$ \\
\hline Well Logging & negligible & 44,000 & 380,000 \\
\hline $\begin{array}{l}\text { Industrial } \\
\text { Radiography }\end{array}$ & negligible & 22,000 & 190,000 \\
\hline $\begin{array}{l}\text { Manufacturing and } \\
\text { Distribution }\end{array}$ & 170,000 & 140,000 & $1,400,000$ \\
\hline $\begin{array}{l}\text { Academic/Research } \\
\text { lnstitutions }\end{array}$ & 270,000 & 110,000 & $1,200,000$ \\
\hline $\begin{array}{l}\text { Other Measuring } \\
\text { Systems }\end{array}$ & negligible & 43,000 & 370,000 \\
\hline $\begin{array}{l}\text { Fuel Fabrication } \\
\text { and Processing }\end{array}$ & 12,000 & 11,000 & 110,000 \\
\hline $\begin{array}{l}\text { Research and Test } \\
\text { Reactors }\end{array}$ & negligible & 4,000 & 34,000 \\
\hline $\begin{array}{l}\text { Commercial Power } \\
\text { Reactors }\end{array}$ & 97,000 & 240,000 & $2,100,000$ \\
\hline All others & negligible & 49,000 & 420,000 \\
\hline Totals & $1,700,000$ & 880,000 & $9,100,000$ \\
\hline
\end{tabular}




\subsection{OTHER CHANGES}

Miscellaneous changes in the revision that do not fall under one of the categories discussed previously in this report are discussed in this section. In general, these changes are expected to have minimal impacts on licensees. Changes in the revision that are editorial changes only are not discussed in this report.

\subsubsection{Units of Radiation Dose}

Although the revision references the International System of Units (SI), it presents the conventional units found in the present Part 20 . Thus, licensees will not be required to use the SI system for purposes of recordkeeping or reporting. In addition, the default quality factor (Q) for neutrons remains at 10 and it is unlikely that licensees will be impacted by the slight changes in the table that presents factors for converting neutron fluence to dose.

\subsubsection{Radiation Protection Programs}

The revised Part 20 states that 1 icensees must develop and document a radiation protection program that is "commensurate with the scope and extent of licensed activities...." In addition, licensees are required to use, "to the extent practicable," procedures and controls to maintain doses ALARA. In comparison, the present Part 20 does not specifically require a radiation protection program to be maintained, but does require that doses be maintained ALARA. An important point here is that the revision does not require a documented ALARA program, a requirement that was present in the proposed Part 20 .

Although the new requirement to develop a radiation protection program may appear to place a substantial burden on some licensees, the marginal impact will not be severe because most licensees currently maintain a radiation protection program that is commensurate with the scope of their licensed activities. These programs are in place because of either license conditions, or regulatory guides, or both. For example, all nuclear power plants maintain both radiation protection programs and ALARA programs that greatly exceed the requirements in the revised Part 20 . Also, most medical licensees maintain programs commensurate with Regulatory Guide B.18 and a supporting publication (Brodsky 1982).

The only marginal costs anticipated from this requirement will be increased program documentation for a few licensees. For those licensees that have radiation protection manuais, the manuals should serve as acceptable documentation. (See Section 6.2 for cost estimates pertaining to revisions of these manuals.) For licensees that do not have radiation protection manuals, the limited scope of their activities should be sufficient to prevent the need for development of a program. Thus, for this analysis, it is assumed that the associated costs are negligible. However, the costs could be significant depending on the interpretation of the requirement by both licensees and the NRC. The NRC plans to publish several regulatory 
guides that will provide information on acceptable radiation protection programs for specific categories of licensees.

\subsubsection{Control of Access to High Radiation Areas}

The revised Part 20 provides more detailed requirements than the present Part 20 for controlling access to high and very high radiation areas. Although the changes will affect some licensees, the associated costs are assumed to be negligible in this analysis.

\subsection{SUMMARY OF CONSEQUENCES}

In this section, the estimated impacts from other changes in the revised Part 20 are summarized. Table 5.4 summarizes these impacts by licensee facility category. It is a compendium of the costs and benefits identified in Sections 5.1 through 5.6 of this report. 
IABLE 5.4. Summary of Marginal Cost Increases from Other Changes in the Revised Part 20

\begin{tabular}{|c|c|c|c|c|}
\hline Facility Category & $\begin{array}{l}\text { Initial } \\
\text { Cost, }\end{array}$ & $\begin{array}{l}\text { Annual } \\
\text { Cost, } \$\end{array}$ & $\begin{array}{l}\text { Value of } \\
\text { Annual Dose } \\
\text { Savings, } \$(a) \\
\end{array}$ & \begin{tabular}{l}
\multicolumn{1}{c}{ Net } \\
Present Value \\
of Costs and \\
Benefits, $\$(b)$ \\
\end{tabular} \\
\hline Medical & $1,100,000(c)$ & $540,000(c)$ & negligible & $-5,600,000(c)$ \\
\hline Well Logging & negligible & 44,000 & negligible & $-380,000$ \\
\hline $\begin{array}{l}\text { Industrial } \\
\text { Radiography }\end{array}$ & negligible & 22,000 & negligible & $-190,000$ \\
\hline $\begin{array}{l}\text { Manufacturing and } \\
\text { Distribution }\end{array}$ & $170,000(c)$ & 190,000 (c) & negligible & $-1,800,000(c)$ \\
\hline $\begin{array}{l}\text { Academic/Research } \\
\text { Institutions }\end{array}$ & 270,000 (c) & 180,000 (c) & negligible & $-1,800,000(c)$ \\
\hline $\begin{array}{l}\text { Other Measuring } \\
\text { Systems }\end{array}$ & negligible & 43,000 & negligible & $-370,000$ \\
\hline $\begin{array}{l}\text { Fuel Fabrication } \\
\text { and Processing }\end{array}$ & $12,000(c)$ & $11,000(c)$ & negligible & $-110,000(c)$ \\
\hline $\begin{array}{l}\text { Research and Test } \\
\text { Reactors }\end{array}$ & negligible & 4,000 & negligible & $-34,000$ \\
\hline $\begin{array}{l}\text { Commercial Power } \\
\text { Reactors }\end{array}$ & 97,000 & $(640,000)(d)$ & 610,000 & $+11,000,000$ \\
\hline All others & negligible(c) & $50,000(c)$ & negligible & $-430,000(c)$ \\
\hline NRC & 20,000 & 210,000 & negligible & $-1,800,000$ \\
\hline Total & $1,700,000(c)$ & $650,000(c)$ & 610,000 & $-2,000,000(c)$ \\
\hline
\end{tabular}
(a) Based on a value of $\$ 1000 /$ person-rem.
(b) Calculated using methods described in Sections 8.2 and 8.3 of this report. The present values are based on 1989 dollars, a discount rate of 10\% (applied to all costs and benefits), and a 30-year period. A positive sign indicates a positive impact and a negative sign indicates a negative impact.
(c) Not including potential costs from revised concentration limits for releases into sanitary sewerage.
(d) Number in parentheses indicates a cost savings. 


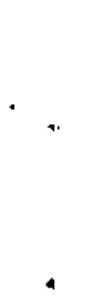

.

1 


\subsection{OTHER CONSEQUENCES OF THE REVISION}

Some of the costs associated with the revision of Part 20 cannot be attributed to specific sections of the rule. These costs include training of personnel and revision of procedures, and are discussed in Sections 6.1 and 6.2 , respectively. Impacts on the NRC and small businesses are discussed in Sections 6.3 and 6.4 , respectively. These consequences are sumarized in Section 6.5.

Many of the costs identified in this section were calculated using published labor rates (including overhead costs) for nuclear power plant workers (SEA 1986). Because labor rates for non-power-reactor workers are generally lower, these costs were estimated by applying a factor of 0.7 to the rates for power reactor workers where applicable. All costs were adjusted to 1989 dollars.

\subsection{PERSONNEL TRAINING}

Some licensees will incur significant costs associated with training of personnel. Supervisory, health physics, and other professional personnel as well as general employees might require training depending on the facility. In the subsections below, cost estimates are provided for the ten categories of facilities defined in this report (see Section 8.1). In most cases, the costs per facility have a wide range with in each category. Where appropriate, cost estimates are provided for separate classes of facilities within a category.

An important consideration in developing these cost estimates was that personnel training is performed routinely at most facilities. Personnel are often required to attend periodic training sessions conducted or sponsored by the licensees. The content and level of training with regard to radiation protection depends on the work performed by the employee.

To eliminate nonmarginal costs from this analysis, a factor of 0.75 has been applied to some of the cost estimates to account for the increased training or retraining in response to the revised Part 20 that can be incorporated into routine training programs. In addition, intensive training immediately following promulgation of the revision will result in a decreased need for training in the short term. In some cases, the marginal cost factor should be higher or lower than 0.75 . Where applicable, the appropriate factor is provided in the sections below.

Some of the costs estimated in this section (and other sections) are considered to be marginal even though it is likely that in many cases, the costs will be absorbed during the normal daily activities of the relevant personne1. For radiation protection personnel whose primary function is to ensure that operations by the facility are in compliance with radiation protection regulations, part of their responsibility is to be familiar with the regulations and familiarization with new regulations would not result in increased actual costs to the facilities. 
Medical. It is anticipated that nuclear physicians and nuclear medicine technologists would use their allotted time for continuing education to inform themselves of the content of the revised regulations and the ICRP Publication 26 recommendations (USNRC 1982). For this analys is, however, some of these costs are considered to be marginal and must be included in the assessment of the impact of the revision. It is estimated that $5 \%$ of the workers monitored for radiation exposure at these facilities will commit 2 hours each to studying the revised regulations and their implications. At a cost of \$14 per technician hour (SEA 1986) and applying the data in Tables 8.2 and 8.3, the cost estimate for these workers is $193,000 \times 0.05 \times$ $2 \times \$ 14$, or $\$ 270,000$. Applying the marginal cost factor of 0.75 , the marginal costs are estimated to be $\$ 200,000$. Costs for professionals to study the regulations are included in the cost estimates provided in Section 6.2.

Well Logging. No significant retraining of workers or managers is anticipated for these facilities (USNRC 1982). All costs associated with studying the revision are accounted for in Section 6.2.

Industrial Radiography. In a survey of several of these facilities, none envisioned a need for retraining personnel (USNRC 1982). Thus, no significant costs are anticipated. All costs associated with studying the revision by responsible management are accounted for in Section 6.2.

Manufacturing and Distribution. It has been estimated that for facilities in this category, supervisors, health physicists, and other professionals will commit 250 person-hours, 200 person-hours, and 150 person-hours, respectively, to retraining (USNRC 1982). Other costs associated with retraining are assumed to be insignificant for this facility category. Assuming \$31 per professional hour (SEA 1986), the total cost is estimated to be $\$ 19,000$. The associated marginal cost estimate is $\$ 19,000 \times 0.75$, or $\$ 14,000$.

Academic/Research Institutions. It is anticipated that users of radioactive material at these institutions will learn of the Part 20 revision and its implications through routine training and information programs. All of these costs are considered to be nonmarginal. Costs incurred by radiation safety officers to understand and implement the revised requirements are included in the cost estimates provided in Section 3.5 .

Other Measuring Systems. No significant costs regarding personnel training will be required for these facilities. However, responsible personnel at most of the facilities will need to become familiar with the revision. An average of 2 person-hours for each facility is estimated. At a cost of $\$ 31$ per professional hour (SEA 1986) and 5060 facilities (see Section 8.1), the marginal cost estimate is $\$ 310,000$.

Fuel Fabrication and Processing. Booth, Bronson and Groth (1985) estimated that the revision would result in training costs of $\$ 145,000$ (in 1989 dollars) at a typical fuel fabrication facility. For this analysis, it is estimated that of the 14 facilities in this category (see Section 8.1 ), five will incur marginal costs of $\$ 145,000$ and nine will incur one-fourth of those 
costs, or $\$ 36,000$. The total cost estimate for fuel fabrication facilities is $\$ 1,000,000$.

Research and Test Reactors. For these facilities, retraining of personnel will be absorbed in the nomal training cycles (USNRC 1982). However, health physics personnel will need to become familiar with the revision. It is estimated that 8 hours will be comitted per facility to become familiar with the revision and its ramifications. Assuming a cost of $\$ 31$ per professional hour (SEA 1986) and 80 facilities (see Section 8.1), the total cost would be $\$ 20,000$.

Comercial Power Reactors. Published cost estimates for training and retraining of personnel at commercial power reactors in response to the revision of 10 CFR 20 are available (Booth, Bronson, and Groth 1985; USNRC 1986) and are given in the public comments on the proposed revision. It appears that training for a new employee under the revised Part 20 will be comparable to current training for new employees. However, most employees will need to be retrained to becone familiar with the revised regulations and the relevant revisions to plant procedures. In addition, health physics and dosimetry personnel will need to be retrained in the areas of their work affected by the revision.

It has been estimated that at a typical nuclear power plant, total costs associated with training are $\$ 175,000$ (in 1989 dollars) (Booth, Bronson and Groth 1985). For this analysis, it is estimated that two-thirds of these costs are marginal. Further, a factor of 0.75 is applied to these costs to account for the fact that some nuclear power stations have multiple units, i.e., the training costs per unit at these sites will be less than at a typical one-unit station. For 109 nuclear power plants expected to be operating in 1989 (ANS 1988), the marginal cost estimate is $\$ 175,000 \times 0.67 \times$ $0.75 \times 109$, or $\$ 9,500,000$.

Al] 0thers. In general, the licensees in this category do not have extensive radiation protection programs and general employee training will not be required. However, radiation protection personnel responsible for compliance with NRC regulations will probably read the revised Part 20 to become

familiar with its provisions. It is estimated that an average of 2 hours per facility will be spent reading the revision and associated documents. Assuming a cost of \$31 per professional hour (SEA 1986) and 1752 facilities in this category (see Section 8.1), the total cost would be $\$ 110,000$. Applying the marginal cost factor of 0.75 , the marginal cost estimate for this category of licensees is $\$ 81,000$.

\subsection{PROCEDURE REVISIONS}

Some licensees will incur significant costs to incorporate the revised requirements into existing procedures and related documents. The magnitude of the impact on individual licensees is related to the magnitude of the licensee's radiation protection program. The affected documents could include operating procedures, radiation protection manuals, and policy statements (training manual revisions were included in the estimates provided in 
Section 6.1). In this section, the costs associated with revising recordkeeping procedures are not included because they were included in the recordkeeping costs discussed in Section 3.5 .

In the subsections below, cost estimates are provided for the ten categories of facilities defined for this analysis (see Section 8.1). In most cases, the costs per facility have a wide range within each category. Where appropriate, cost estimates are provided for separate classes of facilities within a category.

An important consideration in developing these cost estimates was that many procedures and related documents are routinely revised by licensees. Therefore, all of the costs associated with procedure revisions will not be marginal and should not be considered in this analysis. Several competing factors exist in separating the marginal costs from the nonmarginal costs: 1) considering the implementation period permitted by the HRC, some revisions can be incorporated without interrupting the usual schedule; 2) considering both the implementation period and the magnitude of the revised Part 20, some revisions cannot be incorporated without interrupting the usual schedule; 3) some revisions will be much more extensive than they would have been without a revised Part 20; and 4) extensive procedure revisions in response to the revised Part 20 will decrease the need for further revisions in the short term. In consideration of these factors, for this analysis the marginal costs of revising procedures are estimated to be $75 \%$ of the total costs, unless otherwise noted.

Medical. For these facilities, the cost of required procedure changes depends greatly on the type of facility. Of the 6506 facilities in this category (see Section 8.1 ), an estimated 4735 are classified as medical institutions (Hendrickson et al. 1987). The remaining facilities include private practice of nuclear medicine, in vitro labs, veterinary medicine, and others (see Table 8.1).

It is anticipated that a radiation protection manual at each medical institution will need to be revised. In addition to the procedure changes regarding recordkeeping that were estimated in Section 3.5, an estimated 8 person-hours will be committed to this task (USHRC 1982). At a cost of $\$ 31$ per professional hour (SEA 1986), and assuming that $\$ 400$ in printing and duplicating costs will be required per facility, the total cost estimate is $\$ 3,100,000$.

It is expected that the costs of required procedure changes at other medical facilities will be limited to recordkeeping changes associated with the recording of infrequent internal exposures. (These costs were estimated in Section 3.5.) The marginal cost estimate for procedure revisions for all medical facilities is $\$ 3,100,000 \times 0.75$, or $\$ 2,300,000$.

Well Logging. It is estimated that only five of the licensees in this category have radiation protection programs extensive enough to warrant procedure revisions in radiation protection manuals (USNRC 1982). It is estimated that for each of these firms, 80 person-hours of management time will be devoted to this work, and an additional $\$ 800$ per firm will be spent to produce 
revised manuals. At a cost of $\$ 31$ per hour for management personnel (SEA 1986), the total cost for the five firms is estimated to be $\$ 16,000$. The other firms in the industry are not expected to incur significant costs. Therefore, the marginal cost of procedure revisions is estimated to be $\$ 16,000 \times 0.75$, or $\$ 12,000$.

Industrial Radiography. Most of the facilities in this industry have an in-house document that serves as a radiation protection manual (USNRC 1982). Because internal exposures are not a problem in this segment of the nuclear industry, it is not anticipated that extensive revisions to the existing manuals would be required in response to the revised Part 20 . It is estimated that at a typical facility, one professional will spend 8 hours revising the radiation protection manual. Also, $\$ 200$ will be spent to prepare and print the manual. At an hourly cost of $\$ 31$ (SEA 1986) and assuming 851 industrial radiography facilities currently in operation (see Section 8.1 ). the total cost to these facilities would be $\$ 380,000$. The marginal costs are estimated to be $\$ 380,000 \times 0.75$, or $\$ 290,000$.

Manufacturing and Distribution. Of the facilities in these categories, required procedure revisions would be insignificant except for some source manufacturing firms and most nuclear pharmacies. 1t is anticipated that ten source manufacturing firms will require extensive procedure revisions, at a cost of 16 person-weeks of professional time per facility. At a cost of $\$ 31$ per professional hour (SEA 1986) and $\$ 500$ in printing and duplicating costs per facility, the total cost would be $\$ 200,000$.

For nuclear pharmacies, it is expected that minor revisions of radiation safety manuals will be necessary, requiring $B$ hours of professional time per facility. Printing costs of about $\$ 300$ per facility will also be required. At a cost of $\$ 31$ per professional hour and with 221 facilities in this category (Hendrickson et al. 1987), the total cost for these facilities would be $\$ 120,000$.

Costs of required procedure changes at other facilities in this category are expected to be relatively insignificant. Therefore, the marginal cost estimate is $(\$ 200,000+\$ 120,000) \times 0.75$, or $\$ 240,000$.

Academic/Research Institutions. Most of the facilities in this category have a radiation protection manual that provides guidance to users of radioactive material. In general, these manuals will not require revisions based on the revised Part 20.

As discussed in Section 3.5, radiation safety officers or other personnel at these facilities will be required to revise recordkeeping procedures to allow calculation of internal doses should significant intakes occur. No additional costs related to procedure revisions have been identified for these licensees.

0ther Measuring Systems. Few of these licensees have radiation protection manuals or procedures that would require revisions based on the revised Part 20 (USNRC 1982). For those that do, the costs associated with the revisions are assumed to be insignificant for this analysis. 
Fuel Fabrication and Processing. These facilities will require extensive revisions to air sampling and bioassay procedures in response to the revised dose evaluation requirements. Detailed cost estimates by Booth, Bronson, and Groth (1985) suggest that the associated costs at a typical facility are $\$ 86,000$ (in 1989 dollars). For this analysis, it is estimated that of the 14 facilities in this category, five will incur marginal costs of $\$ 86,000$ and nine will incur one-fourth of those costs, or $\$ 22,000$. The total cost estimate for fuel fabrication facilities is $\$ 630,000$.

Research and Test Reactors. It has been suggested that revisions will be required to safety guides for approximately $70 \%$ of the facilities in this category (USNRC 1982). The associated costs per facility will be 2 personmonths of a professional, and $\$ 5000$ in preparation, printing and duplicating costs (USNRC 1982). At a cost of $\$ 31$ per professional hour (SEA 1986), the total cost based on 80 facilities in this category is $\$ 840,000$. The marginal cost estimate is $\$ 840,000 \times 0.75$, or $\$ 630,000$.

Commercial Power Reactors. Commercial power reactors have extensive radiation protection programs that include detailed procedures for external dosimetry, internal dosimetry, recordkeeping, contamination control, etc.

Detailed cost estimates for revising these procedures based on the revised Part 20 are available in the literature (Booth, Bronson and Groth 1985). Other than recordkeeping procedures, which were discussed in Section 3.5, licensees will be required to revise procedures related to external and internal dosimetry. Because of the magnitude of the radiation protection programs at these facilities, much of the time associated with these revisions will be spent studying the impact of the revised regulations and designing programs and procedures to comply with the regulations. It is estimated that the associated development costs at a typical nuclear power plant will be $\$ 124,000$ in 1989 dollars (Booth, Bronson and Groth 1985). For this analysis, a factor of 0.7 is applied to this estimate to account for the fact that multiple units at some sites share some of the procedure development activities, and as a result the costs of evaluating Part 20 and developing revised procedures will be smaller per facility than at a typical one-unit site. Assuming 109 operating units in 1989 (ANS 1988), the associated marginal cost estimate is $\$ 124,000 \times 109 \times 0.75 \times 0.7$, or $\$ 7,100,000$.

All Others. In general, the licensees in this category do not have extensive radiation protection programs and do not have procedures that would require revisions based on the revised Part 20. Thus, the associated costs are assumed to be negligible for this analysis.

\section{$6.3 \mathrm{NRC} \operatorname{COSTS}$}

The NRC will incur costs related to the development, implementation, and operation of the revised rule. Development costs include the costs incurred by the NRC to prepare the revised rule for implementation. Implementation costs include the costs incurred to place the revised rule into operation. These costs include preparation and publication of the final rule. Costs associated with preparing and revising regulatory guides in support of the revised rule are also included in this category. Operation costs include 
those costs incurred by the NRC after the proposed action takes effect. They primarily consist of the costs of enforcing the requirements.

Because this regulatory analysis pertains to both NRC licensees and Agreement State licensees, costs incurred by state regulatory agencies must also be considered. These cost estimates are included in the applicable sections below.

\subsubsection{Development}

The NRC has incurred substantial costs required to research and develop numerous versions of the revision of Part 20 over the past 7 years. More costs are anticipated for further reviews and revisions. However, because this analysis includes only those costs and benefits that will be incurred after the decision is made whether or not to publish the rule, the costs incurred by NRC before that date are not considered. In this report, the assumed decision date is 0ctober 1, 1988. No significant NRC development costs after that date are anticipated.

\subsubsection{Implementation}

The NRC has estimated that nine new regulatory guides will be necessary to support the revised Part 20 . In addition, ten existing regulatory guides will require major revisions. It is estimated that 1.D person-years per new guide and 0.5 person-year per revised guide will be comitted. An additional 0.25 person-year is estimated to be required for minor revisions to a number of other existing regulatory guides. Based on a mean hourly rate of $\$ 51$ per hour (SEA 1986) and 28,500 total hours of effort, the NRC is expected to incur implementation costs of $\$ 1,500,000$ for developing and revising regulatory guides in support of the Part 20 revision.

Because only a few of the new and revised regulatory guides will be crucial to successful implementation of the revision by 1 icensees, it is estimated that $30 \%$ of the costs estimated above will be incurred during the 2 years following publication of the revision (1989 and 1990). The remaining $70 \%$ of the costs are estimated to be distributed evenly over the following 5 years. In addition, only one-half of the latter are assumed to be marginal costs, because it is thought that the development and revision of similar regulatory guides would have occurred even without the revision of Part 20 . As a result, the marginal costs associated with the development and revision of regulatory guides in response to the revision are estimated to be $\$ 220,000$ per year in 1989 and 1990 and $\$ 100,000$ per year from 1991 through 1995 .

The NRC will also incur implementation costs related to the final preparation and publication of the rule. A total of 1 person-year of effort is anticipated to be required at a cost of $\$ 100,00 \mathrm{D}$. Finally, the NRC will be required to revise the various forms associated with Part 20, such as NRC Form 4 and NRC Form 5. The associated cost estimate for these revisions is $\$ 25,000$. 


\subsubsection{Operation}

Once the Part 20 revision is implemented, the NRC and Agreement States may incur costs related to additional inspection activities and additional training of inspectors. These cost estimates are provided below.

\section{Additional Inspection Activities}

Currently, power reactors are inspected an average of two or three times per year. Most other licensees are inspected anywhere from one to five times per year, depending on past performance and the type of license.

No increase in inspection activities at power reactors is anticipated from promulgation of the revision. Although inspectors will use the revision as the basis for the inspections, the frequency of inspections and the person-hours per inspection are not expected to change.

For other types of licensees, some may require additional inspections to ensure compliance with the revision. However, in consideration of the limited resources that will be available for carrying out additional inspections, it is anticipated that the NRC will reschedule inspections so that the problem facilities receive additional attention and the facilities with satisfactory performance will receive less attention than usual. Problem facilities will be identified through response to a letter-writing campaign. After several years, it is anticipated that inspection scheduling will be unaffected by the presence of the revised Part 20 .

In summary, only those costs associated with communication with nonreactor licensees and analyzing the responses will be significant. It is estimated that an average of 0.2 person-hour per facility will be comitted, which includes preparation of letters, response by the licensees, and evaluation of the responses by the NRC. (Although costs incurred by licensees are not the subject of this section, they are included here for convenience. Exclusion of these costs from the cost estimates for facility categories does not significantly affect those cost estimates.) Because it is not known how individual Agreement States will schedule inspections in response to the revised Part 20, costs per Agreement State licensee are estimated to be similar. For a total of 17,238 non-reactor licensees (see Section 8.1) and a cost per person-hour of \$46 (SEA 1986), the associated cost estimate is $\$ 160,000$.

\section{Inspector Training}

Because the Part 20 revision is extensive, additional inspector training will be required following publication of the revision. In the five NRC regions, there are approximately 110 inspectors who will need retraining. Each inspector will need to receive an estimated 3 days of retraining, for a total of 2600 person-hours. In addition, an estimated 80 person-hours per region will be needed to revise training procedures and conduct the retraining. This amounts to an additional 400 person-hours for a total of 3000 person-hours. 
One benefit from the immediate retraining required for all inspectors is that routine training will be able to be curtailed for a few years thereafter. Currently, each inspector receives approximately 1 day of routine training per year. If each receives 3 days of training on the revised Part 20 , future training in the short term will be less extensive than usual. This also applies to routine training instruction and training procedure revisions. It is estimated that the marginal inspector training costs associated with the revision are $50 \%$ of the 3000 person-hours estimated in the previous paragraph. The associated cost estimate, based on an hourly rate of $\$ 46$ (SEA 1986), is $\$ 69,000$. These costs are tripled to account for inspector training activities in Agreement States, for a total cost of $\$ 210,000$.

\subsection{EFFECTS ON SMALL BUSINESSES}

The Regulatory Flexibility Act of 1980 (Public Law 96-354, 5 USC 601612) requires that, when a rulemaking action is likely to have a significant impact on a substantial number of small entities, the impact must be addressed specifically. The NRC's Regulatory Analysis Guidelines (USNRC 1984) specify that this analysis should be incorporated into the regulatory analysis for the action.

The NRC specifies that entities are to be considered small businesses for the purposes of the Regulatory Flexibility Act if they meet the following requirements (Hendrickson et al. 1987):

- for most licensees, annual billings of $\$ 3.5$ million or less

- for private practice physicians, annual billings of \$1 million or less

- for state or public educational institutions, an institution supported by a jurisdiction with a population of 50,000 or less

- for other educational institutions, an institution having 500 or fewer employees.

Henderickson et al. (1987) analyzed data on NRC and Agreement State licensees based on the results of licensee surveys (see Section 8.1). These surveys were used to estimate the fraction of the licensees in various categories that could be considered small entities. While the estimates in Hendrickson et al. may overstate the number of small businesses in some cases and understate it in others, they are sufficient to provide an indication of the impact on small businesses that is commensurate with the level of effort and detail expended on other portions of this analysis.

Based on data in Hendrickson et al. (1987), estimates for the fraction of licensees in each facility category that could be classified as small businesses were obtained (see Table 6.1). These fractions are assumed to apply to the number of 1 icensees tabulated in Section 8.1 , although the absolute numbers differ from those in Hendrickson et al. (1987). The licensee 
IABLE 6.1. Fraction of Licensees That May Be Classified as Small Businesses

\begin{tabular}{lr}
\multicolumn{1}{c}{ Facility Category } & Fraction \\
\cline { 1 - 1 } Medical & \\
Private Practice Physicians & \\
Other Facilities & $93 \%$ \\
Well Logging & $21 \%$ \\
lndustrial Radiography & $63 \%$ \\
Manufacturing and Distribution & $40 \%$ \\
Academic/Research Institutions & $32 \%$ \\
Other Measuring Systems & $29 \%$ \\
All Others & $37 \%$
\end{tabular}

categories of commercial power reactors, research and test reactors, and fuel fabrication and processing facilities are assumed to contain no small entities.

Table 6.2, which is based on Tables 8.2 and 8.4 , presents the average impact of the Part 20 revision per facility for each facility category that includes small businesses.

The monetary impact of the Part 20 revision, averaged over all facilities, is not expected to be substantial for most groups of licensees. The most substantial impacts will be borne by medical facilities. However, the average impact does not account for the fact that not all medical facilities (and private practice physicians) will incur these costs; rather, the costs will often be incurred only by those facilities that already have the most

TABLE 6.2. Per-Facility Costs from the 10 CFR Part 20 Revision

\begin{tabular}{|c|c|c|}
\hline Facility Category & $\begin{array}{l}\text { Development and } \\
\text { Imp lementation } \\
\text { Costs, } \$ \\
\end{array}$ & $\begin{array}{l}\text { 0peration } \\
\text { Costs, } \$ / y r\end{array}$ \\
\hline Medical & 1100 & 280 \\
\hline Well Logging & 26 & 97 \\
\hline Industrial Radiography & 340 & 26 \\
\hline Manufacturing and Distribution & 550 & 250 \\
\hline Academic/Research Institutions & 1200 & 220 \\
\hline Other Measuring Systems & 61 & 8 \\
\hline All Others & 46 & 28 \\
\hline
\end{tabular}


extensive radiation protection programs. These facilities are usually the larger businesses that are not classified as "small entities."

Table 6.3 indicates the magnitude of the total cost to small entities of the Part 20 revision, should all such entities incur the average cost given in Table 6.2.

In addition to the above monetary impacts on small businesses, the Part 20 revision will have impacts that were not quantified. As discussed in Section 7.6, the embryo/fetus dose limit may significantly impact small businesses by causing the loss of a trained employee from certain jobs for a temporary period. A small fim usually does not have the ability to shift personnel around without a significant loss in productivity. Licensees may, therefore, be reluctant to employ women of childbearing age because of these costs.

Labeling requirenents for products containing radioactive materials may also impact small businesses. As discussed in Sections 5.2 and 7.7, however, few changes with respect to container labeling are anticipated because most of the quantities of radioactive material that are exempt from labeling are either unchanged or less restrictive than under the current Part 20 quantities. Thus, costs incurred because of new labeling requirements are not expected to be substantial. As described in Section 5.2, a small positive net benefit is expected from the changes in labeling requirements. However, for those cases in which labeling requirements have become more stringent under the revised regulations, small businesses may bear a more significant impact than larger firms if the competitive positions of small businesses in both domestic and international markets are degraded when costs are passed along to customers.

TABLE 6.3. Estimated Total Cost to Small Businesses from the 10 CFR Part 20 Revision

\begin{tabular}{|c|c|c|}
\hline Facility Category & $\begin{array}{l}\text { Development and } \\
\text { Implementation } \\
\text { Costs, } \$ \\
\end{array}$ & $\begin{array}{l}\text { Operation } \\
\text { Costs, } \$ / y r\end{array}$ \\
\hline \multicolumn{3}{|l|}{ Medical } \\
\hline Private Practice Physicians & $1,000,000$ & 260,000 \\
\hline Other Facilities & $1,300,000$ & 320,000 \\
\hline Well Logging & 8,000 & 28,000 \\
\hline Industrial Radiography & 120,000 & 9,000 \\
\hline Manufacturing and Distribution & 170,000 & 80,000 \\
\hline Academic/Research Institutions & 540,000 & 100,000 \\
\hline Other Measuring Systems & 110,000 & 16,000 \\
\hline All others & 20,000 & 12,000 \\
\hline Total & $3,300,000$ & 830,000 \\
\hline
\end{tabular}




\subsection{SUMMARY OF CONSEQUENCES}

In this section, the consequences of the revised Part 20 that are not associated with specific sections of the rule are summarized. Table 6.4 sumarizes these consequences by licensee facility category and is a compendium of the costs identified in Sections 6.1 through 6.3 of this report.

TABLE 6.4. Summary of Marginal Cost Increases from 0ther Consequences of the 10 CFR Part 20 Revision

\begin{tabular}{lrr} 
Facility Category & $\begin{array}{r}\text { Initial } \\
\text { Cost, }\end{array}$ & $\begin{array}{r}\text { Present Value } \\
\text { of Costs, S(a) }\end{array}$ \\
\cline { 2 - 3 } Medical & $2,500,000$ & $-2,300,000$ \\
Well Logging & 12,000 & $-11,000$ \\
$\begin{array}{l}\text { Industrial } \\
\text { Radiography }\end{array}$ & 290,000 & $-260,000$ \\
$\begin{array}{l}\text { Manufacturing and } \\
\text { Distribution }\end{array}$ & 260,000 & $-240,000$ \\
$\begin{array}{l}\text { Academic/Research } \\
\text { Institutions }\end{array}$ & negligible & negligible \\
$\begin{array}{l}\text { Other Measuring } \\
\text { Systems }\end{array}$ & 310,000 & $-280,000$ \\
$\begin{array}{l}\text { Fuel Fabrication } \\
\text { and Processing }\end{array}$ & $1,700,000$ & $-1,500,000$ \\
$\begin{array}{l}\text { Research and Test } \\
\text { Reactors }\end{array}$ & 650,000 & $-590,000$ \\
$\begin{array}{l}\text { Commercial Power } \\
\text { Reactors }\end{array}$ & $17,000,000$ & $-15,000,000$ \\
$\begin{array}{l}\text { All 0thers } \\
\text { NRC }\end{array}$ & 81,000 & $-73,000$ \\
$\begin{array}{l}\text { Total } \\
\text { Total }\end{array}$ & $1,400,000$ & $-1,100,000$ \\
\hline
\end{tabular}

(a) Calculated using methods described in Section $\mathbf{8 . 2}$ of this report. The present values are based on 1989 dollars, a discount rate of $10 \%$, and a 30-year period. A negative sign indicates a negative impact. 


\subsection{QUALITATIVE BENEFITS FROM REVISING PART 20}

10 CFR Part 20 specifies the fundamental requirements for ensuring that workers and the public are protected from the hazards of ionizing radiation resulting from NRC-licensed activities. Consequently, Part 20 is the basic foundation for licensing, inspection, and enforcement activities relating to occupational and public health protection. Because the provisions of Part 20 are based primarily on recomendations by the ICRP and NCRP, recent changes in the basic radiation protection concepts promoted by these organizations have prompted the NRC to revise Part 20 to reflect these latest recommendations. The importance of revising Part 20 was reinforced when the EPA published its recent recomnendations to federal agencies, which essentially stressed that agencies incorporate the recent ICRP and NCRP recommendations in their conduct of programs for the protection of workers from ionizing radiation.

The previous four sections of this report presented a quantitative analysis, where possible, of the costs and benefits of the revision of Part 20. In most cases, quantitative estimates of the identified costs were possible. On the other hand, most of the potential benefits from revising Part 20 cannot be readily quantified. These potential benefits are discussed in this chapter.

Before describing these possible benefits, it is important to be clear about what is meant by a benefit. In social benefit/cost analysis, actions or projects are evaluated insofar as their effects increase or decrease the welfare of the individuals who are affected. Increases in welfare are associated with benefits, and decreases in welfare are associated with costs. A central theme in benefit/cost analysis is an individual's willingness to pay to receive benefits or accept compensation to bear costs. An effect is a benefit if one or more individuals can be identified who would be willing to pay for the effect from their own wealth.

\subsection{POTENTIAL BENEFITS FROM CONSISTENCY WITH NATIONAL AND INTERNATIONAL RECONMENDATIONS}

The primary reason for completely revising Part 20 is that the current requirements are inconsistent with recent international and national recommendations (FR 1986). In 1977, the ICRP published a recommended system of dose limitation based on risk (ICRP 1977). Since that time, this system has been recognized as a major improventent over the old system of dose Timitation by many, but not all health physicists (Skrable et al. 1985; Healy 1982). Also, some other countries have incorporated the recent ICRP recomnendations into their radiation protection standards (Usui 1987). In 1987, the NCRP published its recommendations, which are essentially consistent with, but in some cases more restrictive than, the ICRP recommendations (NCRP 1987). Also in 1987, the EPA published its recomendations on occupational radiation protection (which were signed by the President) in the Federal Register (FR 1987). As a matter of policy, the NRC has considered past Federal Guidance as binding and has implemented the guidance in its regulations. 
Unfortunately, the ICRP, NCRP, and EPA recommendations are not among themselves completely consistent. One reason for the inconsistencies is that the NCRP recommendations and the Federal Guidance (NCRP 1987; FR 1987) were published ten years after the relevant ICRP recommendations (ICRP 1977). Note that the proposed revision of Part 20 was published in 1986, before both the NCRP recommendations and the Federal Guidance were published. A comparison of the revision of Part 20 with these three sets of recommendations is presented in Table 7.1.

Table 7.1 indicates that, in general, the revision of Part 20 is either consistent with or more restrictive than the basic recommendations of ICRP 26 and 30, and is either consistent with or less restrictive than the basic recommendations of NCRP 91. The revision is also generally consistent with the Federal Radiation Protection Guidance. However, the revision provides detailed requirements in many cases where the Federal Guidance provides only general guidance.

Four potential benefits from consistency with national and international recommendations were identified and are discussed in this section:

- the knowledge that regulations are in agreenent with currently accepted scientific concepts

- elimination of confusion caused by terminology that is based on inconsistent definitions and on inconsistent measurement concepts

- savings in teaching resources

- increasing the usefulness and applicability of dosimetry data collected under the provisions of Part 20.

Knowledge that Regulations are in Agreement with Currently Accepted Scientific Concepts. Individuals may benefit from the knowledge that federal regulations on radiation protection are based on currently accepted practice. According to the willingness-to-pay principle, the social benefit from this knowledge is calculated conceptually as the total dollars that the affected individuals would be willing to pay to possess this knowledge.

While no attempt is made here to place a monetary value on this possible benefit, some useful insights can be obtained by inquiring into the type of individual who might benefit from it. For this purpose two groups of individuals are considered: a) workers at risk of receiving occupational doses, and b) members of the general public.

Workers at risk from occupational exposure to ionizing radiation might be comforted by knowing that current regulations reflect the latest scientific information on radiological risk. If the regulations are outmoded, a worker may fear that he is not being afforded adequate protection. The benefit to him from revising the current Part 20 is the reduction in his uncertainty regarding the radiological risk. This benefit will occur even if the revision leads to no substantive change in the current provisions relating to workers. 
TABLE 7.1. Comparison of the Revision of Part 20 with National and International Recommendations

Part 20 Section

20.4: Units of Radiation Dose

20.102: Radiation Protection Programs

20.201: Occupational Dose Limits for Adults

20.202: Compliance With Summation Requirements

20.203: External Dose From Airborne Material

20.204: Determination of Internal Exposure

20.206: Planned Special Exposures

20.207: Occupationa] Dose Limits for Minors

20.208: Dose to an Embryo/Fetus

20.301: Dose Limits for Members of the Public

20.302: Compliance with Public Dose Limits

20.502: Conditions Requiring Indiv. Monitoring

20.601,2,3: Exposure Control in Restricted Areas

20.702,3,4: Respiratory Protection

20.901-6: Precautionary Procedures

20.1001-6: Haste Disposal

20.1102: Records of Radiation Protection Programs

20.1103: Records of Surveys

20.1104: Determination of Prior Occupational Dose

20.1105: Records of Planned Special Exposures

20.1106: Records of Individual Monitoring Results

20.1107: Records of Dose to the Public

20.1108: Records of Haste Disposal

20.1201,2,3: Incident Reporting Requirements

20.1204: Reports of Planned Special Exposures

20.1206: Reports of Personnel Monitoring
Consistency with

Recommendations of

ICRP(a) NCRP(a) $\begin{aligned} & \text { Federal } \\ & \text { Guidance }\end{aligned}$

C I (b,c) C

c(d) $\quad c(d) \quad c(d)$

$c, I(e) \quad c \quad c$

C $\mathrm{C}$ G

I N N

C G G G

C (e) $\quad$ I $(b, c) \quad G$

$\begin{array}{lll}\text { I (e) } & \text { I (b) } & C \\ \text { I (e) } & \text { I (c) } & C\end{array}$

I (e) $\mathrm{C}$ N

I $(e) \quad$ N $\quad$ N

N N N

$N \quad N \quad G$

$N \quad N \quad N$

N N N

N N $\quad$ G

N N $\quad$ G

$N \quad N \quad C$

N N N

$N \quad N \quad C$

N N N N

$N \quad N \quad N$

N N N N

$N \quad N \quad G$

Codes: $C$ - consistent with recommendations (Part 20 may be more detailed)

$G$ - generally referred to in recomendations (Part 20 is more specific)

1 - inconsistent with recommendations

$N$ - not addressed in recommendations

(a) Consistency with ICRP $26 \& 30$ (1CRP 1977, 1CRP 1979) and NCRP 91 (NCRP 1987). For those sections in Part 20 that are not applicable to the recommendations in these documents, they may be applicable to recommendations in other ICRP or NCRP documents.

(b) Revised Part 20 is less restrictive.

(c) The inconsistency is minor.

(d) NRC Regulatory Guides are expected to provide detailed guidance consistent with the recomendations.

(e) Revised Part 20 is more restrictive. 
What can be said about the likely magnitude of this benefit? According to the willingness-to-pay principle, the benefit is equal to the total amount that workers would be willing to pay for the knowledge that, based on the latest scientific findings, the current provisions provide adequate worker protection. But workers who select risky occupations generally perceive their occupational risk to be lower than does the work force at large. Therefore, unless the reductions in uncertainty are relatively large, it seems unlikely that workers would be willing to pay very much to reduce this uncertainty.

There is an interesting sidelight to this effect. A number of studies indicate that occupational risks are reflected in wage levels, so that workers are compensated for the added risk (Low and McPheters 1983). This suggests that if perceptions of risk change, real wages should adjust accordingly. Furthermore, if the risk uncertainty is reduced equally on the upside and downside, then, because individuals tend to be risk-averse, the net benefit will be positive and real wages should adjust lower. It is important to realize, however, that this adjustment in real wages will occur only to the extent that workers are willing to give up real wages in exchange for less risk uncertainty.

Lastly, we inquire whether a regulatory review confers benefits on the general public. In more precise terms, would a regulatory review that led to no changes in public exposures provide a perceived benefit to members of the general public? In response, it is important to note that the provisions of Part 20 deal primarily with occupational dose, which is probably of relatively little concern to the general public; the focus of the general public seems to be on accidental releases. The provisions of the revised Part 20 that do address public dose are not expected to significantly impact the public. Therefore, benefits of the revision to the general public are deened to be insignificant.

Elimination of Confusion Caused by Terminology that is Based on Inconsistent Definitions and on Inconsistent Measurement Concepts. Another possible benefit from updating present regulations is that the update may eliminate some confusion in terminology. For example, under a recent ICRP recommendation (ICRP 1977), total effective dose equivalent is defined as including both internal and external doses, with appropriate weighting factors applied. Under the current Part 20, however, external doses and internal doses are treated separately. In some situations it may not be clear which is the correct method for calculating whole-body dose and this could lead to faulty interpretations.

To demonstrate a real benefit from making definitions and concepts consistent with international practice, it is first necessary to show that the current situation does indeed lead to some confusion. At this time, no such situation has been identified.

Savings in Teaching Resources. The benefit in this category is that health physics students and professionals would not be required to understand two inconsistent systems of dose limitation. Currently, most health physics programs at universities teach both systems, but emphasize the newer system 
because it represents a fundamental improvement over the old system. While older texts are used to teach the principles in the current Part 20, recent textbooks on health physics have all but abandoned the system of dose limitation on which the current Part 20 is based (Cember 1983).

Increasing the Usefulness and Applicability of Dosimetry Data Collected under the Provisions of Part 20. Another possible benefit from bringing current law into agreement with current international standards is the potential for increasing the value of future databases. For example, in meeting reporting requirements to the NRC, licensees do not currently add the risk from internal exposures to the risk from external exposures. Thus, in situations where internal exposures are present, valid measures of risk are not reported and, hence, are not readily available for further research.

In many research endeavors, analysts find occasion to combine data from different sources in order to reach useful conclusions. In combining data, it is important to ensure that the databases are commensurable. This might not be the case if data generated under requirements of the current Part 20 are combined with data generated under ICRP or NCRP recommendations. However, because internal doses are currently rare at most NRC-licensed facilities, and because the revision is based on combining the risks from internal and external doses, it is unlikely that the promulgation of the revision will result in a significant benefit in this area.

\subsection{POTENTIAL BENEFITS FROM REVISED MONITORING REQUIREMENTS}

Two possible benefits are identified in connection with the monitoring requirements imposed by the revised Part 20 . These are benefits from 1) improving ALARA programs and 2) documenting individual doses that could later be used as supporting documents in litigation.

1mproving ALARA Programs. Under the revised Part 20, monitoring will need to be upgraded to provide measurements of both internal and external individual doses that are likely to be in excess of 10 percent of the annual dose limits. By obtaining a more accurate record of the radiological environment within a facility, the facility operator may be able to discover relatively inexpensive (i.e., cost-effective) ways to reduce doses in accordance with ALARA. The extent to which such opportunities currently exist can only be conjectured.

Legal Defense by Documenting 1ndividual Doses. The increased monitoring requirements will make it possible for a licensed firm to maintain better employee records of exposures. Dne function of an employee record is to reduce the uncertainty about whether a future adverse health effect is the result of past exposures. It may be argued, then, that increased monitoring requirements reduce litigation (a societal benefit) by reducing uncertainties about exposures. For instance, if the records show exposures high enough to produce a relatively high probability of causation (PC), then litigants will have an incentive to settle out of court, thus reducing litigation costs. Alternatively, if the records show that exposures were so low that the health effect was highly unlikely to have been caused by radiation exposures 
received at the facility, then the would-be plaintiff has little incentive to pursue a lawsuit. In either case, litigation costs are reduced, and this represents a social benefit. The social benefit is measured as the present value savings in litigation costs (attorneys' fees, court costs, etc.) plus the amount of the judgment that compensates for actual harm done to the plaintiff. For example, punitive damages should not be included since they are not a social cost; rather, they are simply a transfer of monetary assets from one party to another.

Further analysis indicates, however, that a real societal benefit is not likely to be found here. The reason for this is that any financially responsible facility has a sufficient incentive to engage in monitoring for its own legal protection. Since the marginal benefits from increased monitoring will diminish at an increasing rate, there is an optimal level of monitoring which the firm will attempt to discover. The firm's optimizing (profit-maximizing) rule is to add monitoring protection until the marginal cost of the added protection just equals the expected marginal litigation costs. Since the facility is primarily concerned with the private costs rather than the social costs, it will include the cost of expected judgments in its calculation. This means that the marginal private costs will exceed the marginal social costs if the award is in excess of the actual harm sustained by the plaintiff, for example, because of punitive damages. In this case, the unregulated facility will tend to engage in more than the socially optimal level of monitoring, and monitoring requirements beyond this level will further exacerbate the resource misallocation, giving rise to even more excessive net societal costs. As discussed in Section 3.1, most licensees currently monitor occupational doses less than $500 \mathrm{mrem} / \mathrm{yr}$, which is the required level of monitoring under the revised Part 20 . Therefore, the potential benefit from reduced litigation is likely to be small.

\subsection{POTENTIAL BENEFITS FROM REVISED RECORDKEEPING/REPORTING REQUIREMENTS}

One of the proposed reporting requirements will require some facilities to provide to the NRC individual exposure reports for all individuals for whom monitoring was required. In addition, all licensees will be required to notify individuals of the doses that they receive. Two possible benefits have been identified as arising from this requirement: 1) developing a database containing records of individual exposures that are readily converted to risk measures, and 2) providing the basis for a registry under which the accumulated doses of transient workers could be routinely monitored.

Developing a Database of Individual Exposure Records. Whether or not an actual benefit exists here depends on what the NRC will do with the individual exposure records it collects from licensees. For a benefit to exist, the records after collection must 1) be beneficial to workers receiving an annual accounting of their dose for the previous calendar year, 2) be processed by the NRC to produce information beneficial to society, 3) be beneficial to NRC licensees, 4) be made available to researchers outside the NRC who will produce information beneficial to society, or 5 ) be maintained by the NRC in a repository for possible future retrieval for a socially beneficial purpose. 
The first factor could give rise to a social benefit. Workers receiving notification of their prior year's dose might behave in either of two ways. Workers receiving relatively large doses might make an extra effort to avoid unnecessary exposures. On the other hand, workers receiving doses well below the publicized limit might adopt a cavalier attitude toward exposures.

Regarding the second factor (KRC-produced information), a significant benefit is unlikely because the current reporting requirements are virtually the same as the revised requirements except that individual rather than summarized information will be sent to the NRC. Although the summarized information leads to overestimates of collective doses (Brooks 1986), statistical corrections could be applied.

A possible benefit was identified with respect to the third factor, the benefits accruing to licensees. A dose history is required if a licensee needs to ensure that a new worker will not violate the $5(\mathrm{~N}-18)$ formula. Currently, it may be costly to recover the dose history because many licensees currently maintain worker dose records by year rather than by worker. However, the revised Part 20 excludes the $5(\mathrm{~N}-18)$ formula, thereby significantly reducing the need for a worker dose history more than 1 year in the past. If a worker changes jobs in the middle of a calendar year, he may need to produce his dose record for the new employer so that his dose for the remainder of the year can be planned. Since the revised Part 20 will result in better tracking of individual dose histories on NRC Form 4, providing the current year dose for transient workers will have very little cost. The benefit is expected to be small, though, because currently most employers experience little difficulty in obtaining a worker's current-year dose record from the worker's previous employer.

With regard to the fourth factor--making individual dose records available to others outside the NRC--the National Cancer Institute (NC1) has expressed interest in obtaining the individual dose records from the NRC to perform epidemiological studies. The records would be used to establish dose-response relationships from low levels of ionizing radiation. At least 10 years of data will be needed before statistically significant results can be expected from these studies. After the results of these studies are available, they may provide the basis for significant adjustments to dose limits. Of course, not all of the social benefits from more accurate dose limits can be attributed to the existence of the individual dose database; much of the benefit must be assigned to the epidemiological studies themselves.

There is a potential benefit from maintaining a historical database in a repository for future retrieval. Currently, little is known about the effect of dose incidence on an individual's accumulated lifetime risk. For example, we might learn that 2 successive years of 5 rem doses pose much greater risk than if a year of low exposure is interposed. Armed with such knowledge, one could then retrieve and review the lifetime histories of current workers in order to modulate their lifetime risk (Newcombe 1980).

Providing the Basis for a Registry to Monitor Transient Workers. 
represent the majority of workers who currently receive doses greater than $5 \mathrm{rem} / \mathrm{yr}$. Because workers will no longer be permitted to receive annual doses greater than 5 rem (except when the planned special exposure provision is used), some transient workers may falsify their accumulated dose to licensees so that they will be more likely to be hired.

Under the revised Part 20, both the revised requirements for determination of prior dose and the individual dose reporting requirements will provide for improved tracking of transient worker doses. This will reduce the likelihood that a worker will illegally receive doses greater than the limits. In terms of collective dose savings, however, no benefit is anticipated.

\subsection{POTENTIAL BENEFITS FROM ADDITIDNS/REVISIONS TO CURRENT DOSE LIMITS}

The proposed revisions to Part 20 contain several adjustments to current dose limits. Some of the adjustments are more restrictive, and in other cases, the limits are less restrictive (see Section 4.0). Where limits have become stricter, nearly all tasks that are currently undertaken would continue to be undertaken under the stricter dose limits. In cases where the dose limits have been relaxed, one would expect that few new tasks would be added; rather, tasks would be performed by fewer workers.

Assuming that the risk from radiation dose is proportional to dose and has no threshold, no benefit in terms of risk would accrue from dose reallocation if the collective dose remains unchanged (Peterson 1984). However, from a social benefit/cost perspective, there may be social benefits and costs. These derive from the fact that spreading of risk is usually socially beneficial, as discussed below.

Benefits from Spreading of Risk. Studies that undertake to put a dollar figure on the value of a human life typically derive the value by taking the dollar amount that is expended to obtain a reduction in risk and multiplying this by the inverse of the risk reduction. For example, if individuals are willing to pay $\$ 10$ to reduce a fatality risk from $1.0 \mathrm{E}-4$ to $9.0 \mathrm{E}-5$, then the imputed value of life is derived simply as $\$ 10 /(1.0 \mathrm{E}-4-9.0 \mathrm{E}-5)=\$ 10 / 1.0 \mathrm{E}-5$ $=\$ 1.0 E 6$, or one million dollars. The problem with this approach is that it assumes that an individual's willingness to pay to reduce a given increment of risk is independent of the level of risk. Were this independence valid, then we should expect this same individual to play a game of Russian roulette for a certain payment of $\$ 1 E 6 / 6=\$ 1.6 E 5$. Yet, there is no reason why this individual should feel compelled to play for this amount. Russian roulette represents a much greater risk, and the individual might well require a larger amount, perhaps well in excess of a million dollars. Such behavior could not be termed inconsistent or irrational. It simply implies that riskaversion is not a linear function of the risk level (Weinstein, Shepard and Pliskin 1980; Linnerooth 1979).

If risk aversion increases with the level of risk, then there will be a social benefit from spreading the risk over a greater number of individuals. In order to quantify the benefit, the following information is needed: 
1) the level of risk to an individual before risk-spreading, 2) the level of risk to an individual after risk-spreading, and 3) for a representative individual, the functional relationship between willingness-to-pay to reduce risk and the level of risk.

The benefit from risk spreading may need to be adjusted for another effect. If risk is spread, then collective dose may not remain unchanged. To accomplish a task a manager will likely delegate it to the persons who can execute it at lowest cost. If additional workers must then be added (because of dose limitations), then the added workers generally will be less efficient than the original crew. As a result, collective dose may increase (Pelletier and Voilleque 1979). For example, four persons may be able to complete a task with a collective dose of 20 rem, but when five persons are assigned, the collective dose might increase to 23 rem. Collective dose increases although individual doses decrease.

In evaluating the net benefit from the revised dose limits, it is necessary to adjust the benefits from risk-spreading for the "less-efficientworker" effect just described. Considering that the dose distributions to only a small number of workers will be affected by the revised limits and that the anticipated increase in collective dose is small (see Sec-

tion 4.1.1), any potential net costs or benefits are likely to be small.

In a few instances, dose limits that have been revised do not affect current applications. For example, civilian activities involving Pu are essentially nonexistent at $\mathrm{NRC}-1$ icensed facilities. In the future, an activity involving Pu might be discovered that is sufficiently valuable to warrant compliance with existing regulations. However, stricter provisions in the new Part 20 might prevent this activity from occurring. In those cases where the requirements have been relaxed, new activities may be viable imediately or some time in the future.

\subsection{POTENTIAL BENEFITS FROM SUPPLIED GUIDANCE FOR COMPLYING WITH THE REVISION}

The NRC plans to provide some detailed guidance in the form of regulatory guides on how licensees must meet the new Part 20 provisions (see Section 6.3.2). To the extent that the guidance is prescriptive, this will usually make licensee compliance more (socially) costly. It is easy to see why this is so. Consider, for example, a dose limitation with which licensees must comply. Let us assume that there are several different ways of complying with this limitation. Each profit-maximizing licensee will attempt to select the least costly compliance method. Because different licensees operate under different conditions, there is no reason why the least costly compliance method for one licensee will also be the least costly method for other licensees. Thus, a prescriptive approach to enforcement will generally impose higher social costs than necessary, even if the prescribed method is the method that most licensees deem to be the least costly. On the other hand, the absence of guidance often leads licensees to adopt methods that are unnecessarily costly to ensure compliance with possibly ambiguous regulations. 
The benefit from the prescriptive approach is that it will generally make enforcement by the regulating agency easier (i.e., less costly). If compliance with the revision is ensured once well-defined procedures are followed, then the enforcenent agency need only check that the licensees have carried out the prescribed steps. This can also improve the consistency with which inspectors enforce the requirements.

\subsection{POTENTIAL BENEFITS FROM DOSE LIMITS FOR PREGMANT WOMEN AND EMBRYOS/FETUSES}

To estimate the benefit from the dose limits for declared pregnant women, it is necessary to obtain an estimate of the number of pregnant women who currently receive doses in excess of the proposed limits. It is then simply a matter of computing the risk to each embryo/fetus to obtain a value for the benefit. This benefit was estimated in Section 4.3.

However, there may also be unintended costs. Licensees, particularly those with small operations, will be reluctant to employ women of childbearing age. Loss of a trained employee for a temporary period could impose a substantial burden on a small firm, which usually does not have the ability to shift personnel around without a significant loss in productivity. However, because of potential legal liability, licensees may already be engaging in defensive hiring practices, in which case the new Part 2D would provide few added costs or benefits. The problems associated with a separate limit for the embryo/fetus are well documented (Taylor 1985) and are not discussed further in this report.

\subsection{POTENTIAL BENEFITS FRON REVISED LABELING REQUIREMENTS}

The proposed revision of Part 20 includes requirements that affect products containing radioactive materials. The levels of activity for which labeling will be required are lower for some radioactive materials and higher for others than under the current Part 20 (see Section 5.2.1). The main purpose of the proposed labeling requirements is to inform consumers of products posing health risks that exceed some determined level. It is noted that the health risk level at which labeling is required will be approximately the same for all radioactive materials because the exempt quantities are determined from occupational ALIs for each radionuclide.

Because most of the revised exempt quantities are either higher by one order of magnitude than the current exempt quantities or are unchanged, few changes with respect to container labeling are anticipated. For those cases where labeling of containers will no longer be required, there are obvious benefits from the reduced number of labels that must be purchased and affixed. An additional benefit is identified for firms that currently spend resources to ensure that containers do not contain enough radioactive material to require labeling. Because the revised exempt quantities are generally higher than the current values, fewer resources will be required to reduce amounts of radioactive material to exempt levels. 


\section{D SUMMARY OF COSTS AND BENEFITS}

Previous sections in this report included analyses of the costs and benefits of the revision of Part 20 . Where possible, the costs and benefits were discussed with respect to the relevant sections of the rule and the types of licensees that would be affected. In addition, the costs and benefits that would be incurred once were delineated from those that would be incurred annually.

In the following sections, the costs and benefits are summarized so that meaningful evaluations of the impact of the revision of Part 20 can be made. In Section 8.1, the current number of NRC and Agreement State licensees are summarized by facility category. In Section 8.2 , the costs of the revision are summarized by both facility type and Part 20 section. The uncertainties of the cost estimates are also discussed. In Section 8.3 , the benefits of the revision are summarized by section of the revision, and the uncertainties and qualitative aspects of the benefits are discussed. In Section 8.4, a sensitivity analysis of the estimated net benefit is presented. Finally, the conclusions of this analysis are presented in Section 8.5 .

\subsection{COMPENDIUM OF NRC AND AGREEMENT STATE LICENSEES}

In order to assess the impact of the revision of Part 20 on licensees, it was necessary to group the various types of licensees into categories that reflect the type of activities the licensees are involved in. Because both NRC and the Agreement States classify licensees under many categories, it was necessary to condense the number of categories of licensees for this analysis. The data presented below were derived primarily from a compilation of data presented in four references (Hendrickson et al. 1987; CRCPD 1987; Brooks 1986; Brooks, McDonald and Richardson 1982).

The Conference of Radiation Control Program Directors (CRCPD) periodically publishes a report of the number of Agreement State licenses by state and facility type. The most recent report (CRCPD 1987) was used to determine the number of Agreement State licensees in 1985. To determine this number from the data supplied in the report, several translations were necessary. First, the number of licenses issued by all States was determined for the various license categories listed in the CRCPD report. Second, the number of licenses issued by non-Agreement States was subtracted from the tota? number of licenses issued for each category of license. Finally, the total number of licensees was determined by dividing the number of 1 icenses by 1.286, which is estimated to be the ratio of total licenses to licensees (Hendrickson et al. 1987). Although this ratio was derived from data on NRC licensees, the same ratio was assumed to apply to Agreement State licensees for this report.

The number of NRC licensees in 1985 was determined from several sources. For facilities other than power reactors, research and test reactors, and fuel fabrication and processing facilities, the number of licensees in each facility category was determined from a 1983 survey by the KRC's Division of 
Rules and Records (DRR). The data from this survey was analyzed and published (Hendrickson et al. 1987). The number of power reactor and fuel fabrication facilities was determined from the annual radiation exposure summary reports submitted to NRC in 1984 (Brooks 1986). The number of research and test reactor licensees was determined from data submitted to NRC for the year 1979 (Brooks, McDonald and Richardson 1982). 1t was assumed in this report that these data for NRC licensees accurately represent the number of NRC licensees in 1985.

Because the categories of licensees listed in the various references were numerous and not always consistent, it was necessary for this analysis to condense the number of licensees into expressive categories. Ten general categories of licensees were identified based on the primary activities at the facilities. These categories and the associated categories used by NRC and CRCPD to classify licensees are listed in Table 8.1.

In 1985, there were 27 Agreement States. All licensees in Agreement States except power reactors, research and test reactors, and fuel fabrication and processing facilities are licensed by the States. All licensees not licensed by Agreement States are licensed by the NRC. Table 8.21 ists the number of NRC and Agreement State licensees in 1985 for each facility category. For this report, these data are assumed to represent accurately the number of licensees existing in 1989.

The data in Table 8.2 are generally consistent with the ratio of Agreement States to non-Agreement States. One inconsistency, however, is the number of licensees listed in the "Manufacturing and Distribution" facility category. For this category of licensees, NRC licensees outnumber Agreement State licensees by a factor of two. One reason for this apparent inconsistency is that the CRCPD data for Agreement States (CRCPD 1987) are not classified according to the NRC system of licensee classification. It is likely that some of the licensees listed in the "All Others" category for Agreement States would be listed in the "Manufacturing and Distribution" category under the NRC classification system.

Some of the costs of the revision of Part 20 identified in this analys is are directly related to the number of radiation workers at a facility. In order to assess these costs, it was necessary to estimate the number of employees, the number of employees monitored, and the number of employees reported to have measurable doses for each facility category. For facilities other than power reactors, research and test reactors, and fuel fabrication and processing facilities, the number of employees was determined by multiplying the average number of employees per licensee (Hendrickson et al. 1987) by the number of licensees listed in Table 8.2. The total number of employees monitored and the total number of employees having measurable doses were determined from data reported to MRC (Brooks 1986; Brooks, McDonald and Richardson 1982) indicating average numbers of these employees per licensee. The averages were multiplied by the number of licensees in each category listed in Table 8.2. It was assumed in this report that the most recent available data indicating both the average number of employees monitored per 
TABLE 8.1. Categories of Licensees

Facility Category

Medical

Well Logging

Industrial Radiography

Manufacturing and Distribution

Academic/Research Institutions

Other Measuring Sys tems

Fuel Fabrication and Processing

Research and Test Reactors

Comercial Power Reactors

All Others
Types of Licensees Included

Medical institutions (broad and other), medical private practice, teletherapy, cardiac pacemakers, eye applicators, nuclear medicine vans, veterinary, in vitro labs, and other medical

Well logging

One location radiography, multilocation radiography, in-plant radiography, and field radiography

Manufacturing and distribution (broad and other), medical distribution, nuclear pharmacies, pacemaker manufacturing and distribution, other source material, source material shielding, and source material general distribution

Academic institutions (broad and other), and research and development institutions (broad and other)

Fixed gauge, portable gauge, and other measurement systems

Fuel fabrication and processing, UF, conversion and production, uranium mills, and uranium solution mining

Research reactors, test reactors, and critical experiment facilities

Light water reactors, gas cooled reactors

All licensees licensed under 'Other Special Nuclear Material' codes (except pacemaker manufacturing and distribution), nuclear laundry, leak test service, irradiators, byproduct power sources, waste disposal, waste services, civil defense, and others

licensee and the average number of employees having measurable doses per licensee are applicable to the year 1985. Table 8.3 lists employee data for NRC and Agreement State licensees. 
TABLE 8.2. Number of NRC and Agreement State Licensees in 1985

Facility Category

Medical

Well Logging

Industrial

Radiography

Manufacturing and

Distribution

Academic/Research

Institutions

Other Measuring

Systems

Fuel Fabrication and Processing

Research and Test Reactors

Commercial Power Reactors

All others

Total

NRC Agreement State

2,432

4,074

6,506

130

324

454

348

503

851

637

328

965

769

787

1,556

2,236

2,824

5,060

14

0

14

80

0

80

$88^{(a)}$

0

$88^{(a)}$

478

1,274

1,752

7,212

10,114

17,326

(a) 109 reactors are assumed for the analys is in this report based on recent estimates for the year 1989 (ANS 1988).

\subsection{SUMMARY OF COSTS}

This section summarizes the costs identified in this report. The costs are summarized by facility type and Part 20 section, followed by a discussion of the uncertainties inherent in these estimates.

In this report, present values are calculated based on 1989 dollars, a discount rate of $10 \%$, and a 30 -year period. Because the NRC will grant a 5-year implementation period retroactive to January 9, 1986, development and implementation costs identified in this report will be distributed over the years 1986 to 1990 . For this report, it was assumed that $5 \%, 5 \%, 10 \%, 40 \%$ and $40 \%$ of the development and implementation costs identified were or will be incurred in 1986, 1987, 1988, 1989 and 1990, respectively. In effect, 
IABLE 8.3. Employee Data for NRC and Agreement State Licensees in 1985

\begin{tabular}{|c|c|c|c|c|}
\hline Facility Category & $\begin{array}{l}\text { Average No. } \\
\text { Emp loyees } \\
\text { per Licensee }\end{array}$ & $\begin{array}{l}\text { Total No. } \\
\text { Employees }\end{array}$ & $\begin{array}{l}\text { Total No. } \\
\text { Emp loyees } \\
\text { Monitored } \\
\end{array}$ & $\begin{array}{l}\text { Total Mo. } \\
\text { Employees Having } \\
\text { Measurable Dose }\end{array}$ \\
\hline Medical & 460 & $3,000,000$ & 193,000 & 109,000 \\
\hline Well Logging & 170 & 77,100 & 39,300 & 37,000 \\
\hline $\begin{array}{l}\text { Industrial } \\
\text { Radiography }\end{array}$ & 554 & 471,000 & 19,900 & 12,900 \\
\hline $\begin{array}{l}\text { Manufacturing and } \\
\text { Distribution }\end{array}$ & 422 & 407,000 & 127,000 & 49,000 \\
\hline $\begin{array}{l}\text { Academic/Research } \\
\text { Institutions }\end{array}$ & 445 & 692,000 & 93,700 & 27,900 \\
\hline $\begin{array}{l}\text { Other Measuring } \\
\text { Systems }\end{array}$ & 292 & $1,480,000$ & 38,000 & 13,700 \\
\hline $\begin{array}{l}\text { Fuel Fabrication } \\
\text { and Processing }\end{array}$ & $679^{(a)}$ & $9,500^{(a)}$ & 9,500 & 5,800 \\
\hline $\begin{array}{l}\text { Research and Test } \\
\text { Reactors }\end{array}$ & ${ }_{45}^{(a)}$ & $3,600^{(a)}$ & 3,600 & 1,000 \\
\hline $\begin{array}{l}\text { Commercial Power } \\
\text { Reactors }\end{array}$ & $1,920^{(a)}$ & $169,000^{(a)}$ & $169,000^{(b)}$ & $95,000^{(b)}$ \\
\hline All others & 294 & 515,000 & 43,800 & 14,200 \\
\hline All Facilities & 394 & $6,824,200$ & 736,800 & 365,500 \\
\hline
\end{tabular}

(a) Inferred from the number of workers monitored, assuming $100 \%$ of the workers at the facilities were monitored.

(b) A 24\% increase in these numbers is assumed for the year 1989 based on recent estimates for the number of reactors operating in that year.

development and implementation costs were multiplied by $0.91(a)$ to determine their present value (Heaberlin et al. 1983). The one exception is NRC costs to develop regulatory guides because it is expected that some of the guides will be developed after 1990 . Appropriate corrections to the present value calculations were made for those costs.

(a) $\left(0.05 / 1.1^{-2}\right)+\left(0.05 / 1.1^{-1}\right)+\left(0.1 / 1.1^{0}\right)+\left(0.4 / 1.1^{1}\right)+\left(0.4 / 1.1^{2}\right)=$
0.91. 
Operation costs will be incurred annually once the revision is fully implemented. For this analysis, present values were calculated based on a 30-year period beginning in 1989. Present values of operation costs were calculated by multiplying the annual operation costs by 8.60 (Heaberlin et a). 1983). This multiplication factor includes consideration of partial realization of operation costs from 1986 to 1990 (see above paragraph).

\subsubsection{Sumary By Facility Type}

In Section B.1, ten categories of licensee facilities were defined for this analysis. In Table 8.4, the costs identified in this report are summarized by facility type. The costs incurred by NRC are also included in Table 8.4. All costs estimates are based on 1989 dollars.

\subsubsection{Sumary By Part 20 Section}

In this section, the costs of the revision are summarized by section of the rule. In sone cases, costs are attributable to two or more related sections. For example, costs related to increased extremity monitoring are attributable to both the reduced extremity limits and the reduced fraction of the dose limit that requires monitoring. In these cases, the costs were assumed to be evenly divided among the relevant sections.

Some costs are either not attributable to a specific section of the rule or are attributable to many sections. For example, costs related to personnel training cannot be readily associated with a specific section of the rule. In these cases, the costs are summarized by cost description.

Table 8.5 summarizes the costs of the revised rule (in 1989 dollars) by section of the rule. Sections not listed in the table were not identified to have significant associated costs.

\subsubsection{Discussion of Uncertainties}

Each of the individual estimates used to develop the overall estimates provided in Tables 8.4 and 8.5 have an associated uncertainty; therefore, the overall estimates have an associated uncertainty as well.

The single most important cost estimate for this analysis was the est $i-$ mated cost of required modifications at fuel fabrication facilities. Costs of approximately $\$ 10$ million initially and $\$ 2$ million annually per facility have been estimated in the past. However, these estimates are thought to be maximum estimates, i.e., worst case scenarios. Consideration must be given to the possibility that particle size studies, use of respirators, etc., may be used in place of facility modifications. The $\$ 75$ million cost estimate for fuel fabrication facilities could be a factor of five too high or a factor of two too low, depending on the steps that these facilities will actually take in response to the revised dose evaluation requirenrents.

Other assumptions necessary for this analys is were uncertain as well. For example, it was assumed throughout this report that Agreement State licensees will be subject to the same requirements as NRC licensees, 
TABLE 8.4. Quantified Costs Incurred from the Revision of Part 20 by Facility Category

\begin{tabular}{|c|c|c|c|}
\hline Facility Category & $\begin{array}{l}\text { Development and } \\
\text { Implementation } \\
\text { Costs, s } \\
\end{array}$ & $\begin{array}{r}\text { Operation } \\
\text { Costs, } \$ / y r \\
\end{array}$ & $\begin{array}{l}\text { Present Value } \\
\text { of Costs, } \$(a) \\
\end{array}$ \\
\hline Medical & $7,400,000$ & $1,800,000$ & $-22,000,000$ \\
\hline Well Logging & 12,000 & 44,000 & $-390,000$ \\
\hline $\begin{array}{l}\text { Industrial } \\
\text { Radiography }\end{array}$ & 290,000 & 22,000 & $-450,000$ \\
\hline $\begin{array}{l}\text { Manufacturing and } \\
\text { Distribution }\end{array}$ & 530,000 & 240,000 & $-2,600,000$ \\
\hline $\begin{array}{l}\text { Academic/Research } \\
\text { Institutions }\end{array}$ & $1,800,000$ & 340,000 & $-4,500,000$ \\
\hline $\begin{array}{l}\text { Other Measuring } \\
\text { Systems }\end{array}$ & 310,000 & 43,000 & $-650,000$ \\
\hline $\begin{array}{l}\text { Fuel Fabrication } \\
\text { and Processing }\end{array}$ & $33,000,000$ & $5,300,000$ & $-75,000,000$ \\
\hline $\begin{array}{l}\text { Research and Test } \\
\text { Reactors }\end{array}$ & 650,000 & 4,000 & $-620,000$ \\
\hline $\begin{array}{l}\text { Commercial Power } \\
\text { Reactors }\end{array}$ & $30,000,000$ & $4,000,000$ & $-61,000,000$ \\
\hline All Others & 81,000 & 49,000 & $-500,000$ \\
\hline NRC & $1,400,000$ & 210,000 & $-2,900,000$ \\
\hline Totals & $75,000,000$ & $12,000,000$ & $-170,000,000$ \\
\hline
\end{tabular}

(a) The present values are based on 1989 dollars, a discount rate of 10\%, and a 30 -year period. A negative sign indicates a negative impact.

including the time allowed for implementation of the requirements. It is likely that Agreement State licensees will lag behind NRC licensees because Agreement State agencies will need time to evaluate the revised Part 20 and develop appropriate state regulations. If in fact Agreement State licensees take an average of 4 years longer to implement the provisions of the revised Part 20, the present value of the costs for Agreement State licensees would be about 30\% lower than calculated in this report. 
IABLE 8.5. Quantified Costs Incurred from the Revision of Part 20 by Section of the Rule

\begin{tabular}{llll}
\multicolumn{1}{c}{ Section } & \multicolumn{1}{c}{ Description } & $\begin{array}{c}\text { Present Value } \\
\text { of Costs, } \$(a)\end{array}$ \\
\cline { 4 - 4 } 20.201 & & Occupational dose limits for adults & $-12,000,000$ \\
$20.202,20.204$ & Summation of internal and external doses & $-96,000,000$ \\
20.208 & Dose limit for embryo/fetus & $-5,200,000$ \\
20.502 & Conditions requiring individual monitoring & $-1,400,000$ \\
20.1106 & Records of individual monitoring results & $-20,000,000$ \\
20.1107 & Records of dose to the public & $-3,900,000$ \\
20.1206 & Reports of personnel monitoring & $-11,000,000$ (b) \\
NA(c) & Personnel training & $-10,000,000$ \\
NA & Procedure revisions & $-10,000,000$ \\
NA & NRC inspections/training & $-1,100,000$ \\
Total & & $-170,000,000$
\end{tabular}

(a) A negative sign indicates a negative impact.

(b) $84 \%$ of the costs are associated with the revised Part 19 requirements to provide reports to individuals of the doses they received.

(c) Not applicable.

Another assumption inherent in this analysis was that all identified costs must be considered as actual costs. Because many of the costs will not result in an increased use of resources, this assumption may overestimate the actual costs associated with the revision. For example, if a health physicist's hourly wage is $\$ 25$ per hour (including overhead) and he must spend 8 hours revising procedures in response to the revised Part 20, he will most likely not work overtime to accomplish this task. Rather, he will likely omit performing another task of less importance. Because the most important tasks the health physicist performs would likely be worth more than \$25 per hour and the least important tasks would be worth less than \$25 per hour, the associated cost of revising the procedures would be less than $8 \times \$ 25$. Because many of the costs identified in this report may fall under this category, the overail cost estimate may misrepresent the actual costs that will be incurred.

There was one major cost identified in this report that was not quantified: the cost associated with the revised concentration limits in Appendix B for releases into sewers. These costs could be significant with respect to the overall cost estimates provided in this report. 


\subsection{SUMMARY OF BENEFITS}

In this section, the benefits of the revision of Part 20 are summarized. For those cases where the benefits were quantified in terms of cost savings, the present values were calculated using the same methods and assumptions used to calculate the present values of the annual costs (see Section 8.2). For those cases where the benefits were quantified in terms of dose reductions, present values were calculated based on a value of $\$ 1000$ per personrem (Heaberlin et al. 1983) and $\$ 10,000$ per fetus-rem. The latter value was arbitrarily chosen based on the ratio of the embryo/fetus limit to the occupational dose limit for adults. Health effects were discounted in calculation of present values in consideration of the arguments that favor discounting of future radiation effects (Cohen 1983; Nieves et al. 1983). The dependence of the present value calculations on variations in these assumptions is discussed in Section 8.3.2.

\subsubsection{Summary by Part 20 Section}

In Table 8.6, the benefits of the revision are summarized by section of the rule. Some of the benefits are not attributable to a specific section of the rule and are therefore summarized by description only.

\subsubsection{Discussion of Uncertainties}

The estimated benefit of $\$ 44$ million provided in Table 8.6 did not include consideration of many benefits that could not be quantified. It is likely that the actual value of the benefits of the revision, if such a value could be calculated, would be substantially higher than \$44 million. The actual value depends primarily on the actual or perceived importance of consistency with ICRP/NCRP recommendations and the importance of complying with the Federal Guidance. Other benefits that were not quantified are thought to be of less importance.

On the other hand, the assumptions used to determine the present value of the benefits may have resulted in overestimates of the actual benefits. For example, the value assigned to a rem to the embryo/fetus $(\$ 10,000)$ was based on the assumption that a rem to the embryo/fetus is ten times as detrimental as a rem to an adult. If this assumption is valid, then it would be hard to justify any dose to pregnant women that could be avoided by job rotation practices; current practices in industry suggest that this may not be the case. Also, the value of $\$ 1000$ assigned to a person-rem is probably too high based on the actual risk of harm from radiation as compared to the risk of harm from other hazards. However, some believe that health effects should not be discounted to determine present value; at $\$ 1000$ per person-rem and $\$ 10,000$ per fetus-rem, the annual dose reductions identified in this report would be valued at over $\$ 4$ million dollars per year for 30 years, as opposed to a present value of $\$ 36$ million as calculated in this report based on a $10 \%$ discount rate. 
TABLE 8.6. Benefits of the Revision of Part 20 by Section of the Rule

\begin{tabular}{|c|c|c|c|}
\hline$\underline{\text { Section }}$ & Description of Benefit & Annual Benefit & $\begin{array}{l}\text { Present Value } \\
\text { of Benefit, } \$(a)\end{array}$ \\
\hline 20.202 & Decreased collective doses & $540 \mathrm{rem}$ & $+4,600,000$ \\
\hline 20.208 & Reduced doses to the unborn & 300 rem & $+26,000,000$ \\
\hline 20.502 & $\begin{array}{l}\text { Increased knowledge of work } \\
\text { environment } \\
\text { Reduced litigation costs }\end{array}$ & $\begin{array}{l}\mathrm{NQ}(\mathrm{b}) \\
\mathrm{NQ}\end{array}$ & $\begin{array}{l}\text { NQ } \\
\text { NQ }\end{array}$ \\
\hline 20.702 & $\begin{array}{l}\text { Decreased collective doses } \\
\text { Reduced operating costs }\end{array}$ & $\begin{array}{r}610 \text { rem } \\
\$ 880,000\end{array}$ & $\begin{array}{l}+5,300,000 \\
+7,600,000\end{array}$ \\
\hline 20.905 & Reduced operating costs & NQ & NQ \\
\hline 20.1206 & More complete data base & NQ & NQ \\
\hline $\mathrm{NA}(c)$ & $\begin{array}{l}\text { Cons istency with ICRP/NCRP } \\
\text { Recommendations }\end{array}$ & NQ & NQ \\
\hline NA & Consistency with Federal Guidance & NQ & NO \\
\hline Total & & & $+44,000,000(d)$ \\
\hline
\end{tabular}

(a) A positive sign indicates a positive impact.

(b) Not quantified.

(c) Not applicable.

(d) Does not include unquantified benefits.

In consideration of the many uncertainties associated with the benefits from the revised Part 20 , it is likely that the estimated \$44 million (present value) is too low. The information provided in this report should be of help in determining the degree to which the quantified benefits underestimate the overall benefit from the revision.

\subsection{SENSITIVITY ANALYSIS}

Many of the estimates provided in this report were uncertain. In most cases, however, minor variations in the assumptions used to derive the estimates would not affect significantly the conclusions of this report. Probably the most important assumptions were those required to determine the present values of the costs and benefits. The following variations were used to determine the dependence of the calculated net benefits on the basic assumptions: 
0) No variation from the basic assumptions (10\% discount rate, all identified costs and benefits discounted, discount over a 30 -year period, $\$ 1000 /$ person-rem, $\$ 10,000 /$ fetus-rem);

A) Health effects not discounted;

B) Health effects evaluated at $\$ 100 /$ person-rem and $\$ 1000 /$ fetus-rem;

C) $5 \%$ discount rate;

D) Lower-bound estimates of marginal costs incurred by licensees based on optimal compliance, i.e., only those costs thought to be necessary for compliance were included in the evaluation.

Table 8.7 lists the calculated net benefits for each facility category based on the variations listed above.

\subsection{CONCLUSIONS}

Perhaps the most useful method for presenting the costs and benefits identified in this report is to present the net impact per monitored worker by facility category (Table 8.8 ). This allows one to approximately determine the magnitude of the impacts versus the magnitude of a licensee's radiation protection program.

It is apparent that fuel fabrication facilities will incur by far the highest negative impact per employee monitored. The negative impact of $\$ 71 \mathrm{million}$ listed in Table 8.8 includes about $\$ 76 \mathrm{million}$ in costs and $\$ 5$ million in dose savings (540 rem/yr at $\$ 1000$ per person-rem, discounted at $10 \%)$. Of course, there are great uncertainties in these estimates, the greatest of which is the uncertainty whether massive engineering modifications will indeed be necessary at these facilities.

The overall impact on medical facilities was determined to be positive because the anticipated dose savings to the embryo/fetus was estimated to outweigh the costs, even though medical facilities will incur an estimated $\$ 22$ million in costs. However, this conclusion relies heavily on both the est imated dose savings and the cost equated to a rem to the embryo/fetus; there were great uncertainties in both of these estimates.

Considering the best estimates of the quantified costs and benefits and the associated uncertainties, it is unlikely that the benefits associated with the revision of 10 CFR Part 20 will outweigh the costs. However, some of the costs and many of the benefits of the revision were not quantified; the unquantified benefits might have a high enough value to result in a favorable benefit/cost ratio. Because the most important unquantified benefit appears to be that the revision will be consistent with international (ICRP) and national (NCRP and EPA) recommendations, careful evaluation of this benefit is most important in determining whether the revision of Part 20 is acceptable from a benefit/cost standpoint. 
TABLE 8.7. Sensitivity of Net Benefits to Variations in Basic Assumptions

\begin{tabular}{|c|c|c|c|c|c|}
\hline \multirow[b]{2}{*}{ Facility } & \multicolumn{3}{|c|}{ Present Value of Net Benefit (SK) } & \multicolumn{2}{|c|}{ for Variation(a) } \\
\hline & 0 & $\mathrm{~A}$ & $\mathrm{~B}$ & $\mathrm{C}$ & D \\
\hline Medical & $+1,400$ (b) & $+58,000$ & $-20,000$ & $+5,800$ & $+5,400$ \\
\hline Well Logging & -390 & -390 & -390 & -650 & -390 \\
\hline $\begin{array}{l}\text { Industrial } \\
\text { Radiography }\end{array}$ & -450 & -450 & -450 & -590 & -390 \\
\hline $\begin{array}{l}\text { Manufacturing and } \\
\text { Distribution }\end{array}$ & $-2,600$ & $-2,600$ & $-2,600$ & $-4,000$ & $-2,500$ \\
\hline $\begin{array}{l}\text { Academic/Research } \\
\text { Institutions }\end{array}$ & $-4,500$ & $-4,500$ & $-4,500$ & $-6,600$ & $-3,300$ \\
\hline $\begin{array}{l}\text { Other Measuring } \\
\text { Systems }\end{array}$ & -650 & -650 & -650 & -920 & -580 \\
\hline $\begin{array}{l}\text { Fuel Fabrication } \\
\text { and Processing }\end{array}$ & $-71,000$ & $-59,000$ & $-75,000$ & $-100,000$ & $-36,000$ \\
\hline $\begin{array}{l}\text { Research and Test } \\
\text { Reactors }\end{array}$ & -620 & -620 & -620 & -680 & -470 \\
\hline $\begin{array}{l}\text { Commercial Power } \\
\text { Reactors }\end{array}$ & $-46,000$ & $-26,000$ & $-53,000$ & $-61,000$ & $-34,000$ \\
\hline All others & -500 & -500 & -500 & -800 & -480 \\
\hline Total $(c)$ & $-125,000$ & $-37,000$ & $-158,000$ & $-169,000$ & $-73,000$ \\
\hline
\end{tabular}

(a) See text for explanation of variations.

(b) A positive sign indicates a positive impact and a negative sign indicates a negative impact.

(c) Does not include costs that will be incurred by the NRC. 
TABLE 8.8. Estimated Net Impact (Present Value) of the Revision of Part 20

\begin{tabular}{|c|c|c|c|}
\hline Facility Category & $\begin{array}{l}\text { No. of } \\
\text { Employees } \\
\text { Monitored } \\
\end{array}$ & $\begin{array}{l}\text { Net Present } \\
\text { Value of } \\
\text { Impact, } \$(a) \\
\end{array}$ & $\begin{array}{l}\text { Net Impact } \\
\text { per Employee } \\
\text { Monitored, } \$(a)\end{array}$ \\
\hline Medical & 193,000 & $+1,400,000$ & +7.3 \\
\hline Well Logging & 39,300 & $-390,000$ & -9.9 \\
\hline $\begin{array}{l}\text { Industrial } \\
\text { Radiography }\end{array}$ & 19,900 & $-450,000$ & -23 \\
\hline $\begin{array}{l}\text { Manufacturing and } \\
\text { Distribution }\end{array}$ & 127,000 & $-2,600,000$ & -20 \\
\hline $\begin{array}{l}\text { Academic/Research } \\
\text { Institutions }\end{array}$ & 93,700 & $-4,500,000$ & -48 \\
\hline $\begin{array}{l}\text { Other Measuring } \\
\text { Systems }\end{array}$ & 38,000 & $-650,000$ & -17 \\
\hline $\begin{array}{l}\text { Fuel Fabrication } \\
\text { and Processing }\end{array}$ & 9,500 & $-71,000,000$ & $-7,500$ \\
\hline $\begin{array}{l}\text { Research and Test } \\
\text { Reactors }\end{array}$ & 3,600 & $-620,000$ & -170 \\
\hline $\begin{array}{l}\text { Commercial Power } \\
\text { Reactors }\end{array}$ & 209,000 & $-46,000,000$ & -220 \\
\hline All Others & 43,800 & $-500,000$ & -11 \\
\hline Total & 776,800 & $-125,000,000$ (b) & -161 \\
\hline
\end{tabular}

(a) A positive sign indicates a positive impact and a negative sign indicates a negative impact.

(b) Does not include costs that will be incurred by the NRC. 


\subsection{REFERENCES}

American Nuclear Society (ANS). 1988. "World List of Nuclear Power Plants." Nuclear News $31(2): 63-82$.

Booth, L. F., F. L. Bronson, and D. W. Groth. 1985. Dosimetry and Recordkeeping Implications of the Proposed Revisions to 10 CFR 20. AIF/NESP-030. Atomic 1ndustrial Forum, Bethesda, Maryland.

Brodsky, A, 1982. Principles and Practices for Keeping Occupational Radiation Exposures at Medical Institutions As Low As Reasonably Achievable. NUREG-0267, Rev. 1, U.S. Nuclear Regulatory Comission, Washington, D.C.

Brooks, B. G. 1986. Occupational Radiation Exposure at Comercial Nuclear Power Reactors And 0ther Facilities, 1984, Seventeenth Annual Report. NUREG-0713, Vo1. 6, U.S. Nuclear Regulatory Commission, Washington, D.C.

Brooks, B., S. McDonald, and E. Richardson. 1982. Occupational Radiation Exposure, Twelfth Annual Report, 1979. NUREG-0714, Vol. 1, U.S. Nuclear Regulatory Commission, Washington, D.C.

Bunker, A. S. 1985. "Dry Active Waste Management at Nuclear Power Stations." Radiation Protection Management 2(3):23-32.

Cardarelli, R., M. J. Slobodien, K. L. Mossman, A. Brodsky, and J. L. Telford. 1986. "The Effect of Respiratory Protection on Worker Efficiency - ALARA Considerations." Paper presented at the 31 st Annual Meeting of the Health Physics Society, June 29-July 3, 1986, Pittsburgh, Pennsylvania.

Cember, H. 1983. 1ntroduction to Health Physics. 2nd ed. Perganon Press, New York.

Cohen, B. L. 1983. "Discounting in Assessment of Future Radiation Effects." Heaith Physics 45:687-697.

Conference of Radiation Control Program Directors (CRCPD). 1987. "Profile of State and Local Radiation Control Programs in the United States for Fiscal Year 1985." Conference Publication 87-3. Conference of Radiation Control Program Directors, Inc, , Frankfurt, Kentucky.

Cook, J. R. 1981. A Survey of Radioactive Effluent Releases from Byproduct Material Facilities. NUREG-0819, U.S. Nuclear Regulatory Commission, Washington, D.C.

Dionne, B. J., and J. W. Baum. 1985. Occupational Dose Reduction and ALARA at Nuclear Power Plants: Study on High-Dose Jobs, Radwaste Handling, and ALARA Incentives. NUREG/CR-4254, U.S. Nuclear Regulatory Commission, Washington, $\bar{D} . \bar{C}$. 
Environmental Protection Agency (EPA). 1983a. Analysis of Costs for Compliance with Federal Radiation Protection Guidance for Occupational Exposure. Volume I: cost of Compliance with Proposed Radiation Protection Guidance for Workers. EPA/520/1-83-013-1, U.S. Environmental Protection Agency, Washington, D.C.

Environmental Protection Agency (EPA). 1983b. Analysis of Costs for Compliance with Federal Radiation Protection Guidance for Occupational Exposure. Volume II: Case Study Analysis of the Impacts of Proposed Radiation Protection Guidance for Workers. EPA/520/1-83-013-2, U.S. Environmental Protection Agency, Washington, D.C.

Environmental Radiation Protection Standards for Nuclear Power Plant Operations, 40 C.F.R. Part 190, Section 190.1 (1986). (Cited in text as EPA 1986a).

Federal Register (FR). 1987. "Radiation Protection Guidance to Federal Agencies for 0ccupational Exposure. Recommendations Approved by the President." Vol. 52, No. 17, January 27, 1987, U.S. Environmental Protection Agency, Washington, D.C.

Federal Register (FR). 1986. "Part II - Nuclear Regulatory Commission. 10 CFR Parts 19 et al. Standards for Protection Against Radiation; Proposed Rule; Extension of Comment Period and Republication." Vol. 51, No. 6, January 9, 1986, U.S. Nuclear Regulatory Comission, Washington, D.C.

Gitterman, M., and E. W. Webster. 1984. "Shielding Hospital Rooms for Brachytherapy Patients: Design, Regulatory and Cost/Benefit Factors." Health Physics 46:617-625.

Hageman, J. P., J. M. Artz, and G. B. Humphress. 1982. Study of a Recordkeeping System for In-Processing of Transient Workers at Nuclear Power Plants. AIF/NESP-025, Atomic Industrial Forum, Bethesda, Maryland.

Harty, R., W. D. Reece, and J. A. MacLellan. 1986. Extremity Dosimetry at U.S. Department of Energy Facilities. PNL-5831, Pacific Northwest Laboratory, Richland, Washington.

Heaberlin, S. H., J. B. Burnham, R. H. V. Gallucci, M. F. Mullen, R. J. Nesse, L. A. Nieves, J. J. Tawil, M. B. Triplett, S. A. Weakley, and A. R. Wusterbarth. 1983. A Handbook for Value-Impact Assessment. NUREG/CR-3568, U.S. Nuclear Regulatory Commission, Washington, D.C.

Healy, J. W. 1982. "The ICRP Dose Limitation System - Solution or Problem?" Health Physics 42:407-413.

Hendrickson, P. L., M. J. Scott, M. F. Mullen, A. K. Nicholls, and S. A. Smith. 1987. Impact of Proposed Financial Assurance Requirements on Nuclear Materials Licensees. NUREG/CR-4958, U.S. Nuclear Regulatory Comission, Washington, D.C. 
Hendrixson, E. S., D. S. Wagner, and L. Morris. 1986. "Containment Airborne I-131 Control Strategies." Radiation Protection Management 3(3):51-59.

Huggins, T. R., and J. E. Watson, Jr. 1984. "Routine Hand Doses vs. Monitoring Regulations at a Nuclear Power Plant." Health Physics 46:775-781.

International Comission on Radiological Protection (ICRP). 1959. Recommendations of the International Commission on Radiological Protection. ICRP Publication 2, Pergamon Press, 0xford.

International Commission on Radiological Protection (ICRP). 1977. Recommendations of the International Commission on Radiological Protection. ICRP Publication 26, Pergamon Press, 0xford.

International Commission on Radiological Protection (ICRP). 1979. Limits for Intakes of Radionuclides by Workers. ICRP Publication 30, Pergamon Press, 0xford.

International Commission on Radiological Protection (ICRP). 1982. General Principles of Monitoring for Radiation Protection of Workers. ICR $\bar{P}$ Publication 35, Pergamon Press, 0xford.

Kelsey, C. A., R. G. Lane, and F. A. Mettler. 1984. "Comments on 'Proposed Criteria for Issuing Personnel Dosimeters"." Health Physics 47:649-650.

Kemper, I. S., E. J. Kohlerand, and R. J. Scholz. 1984. "One Utility's Low-Level Waste Management Approach to Being in a Region Without a Burial Ground." ANS Transactions 47:76.

Kumazawa, S., D. R. Nelson, and A. C. B. Richardson. 1984. Occupational Exposure to Ionizing Radiation in the United States. A Comprehensive Review for the Year 1980 and a Suminary of Trends for the Years 1960-1985. EPA 520/1-84-005, U.S. Environmental Protection Agency, Washington, D.C.

Lawrence, M. F., J. Skolnik, S. C. Cohen, and D. J. Goldin. 1984. Characterization of the Temporary Radiation Work Force at U.S. Nuclear Power Plants. AIF/RESP-028, Atomic Industrial Forum, Bethesda, Maryland.

Lessard, E. T., X. Yihua, K. W. Skrable, G. E. Chabot, C. S. French, T. R. Labone, J. R. Johnson, D. R. Fisher, R. Belanger, and J. L. Lipsztein. 1987. Interpretation of Bioassay Measurements. NUREG/CR-4884, U.S. Nuclear Regulatory Comission, Washington, D.C.

Linnerooth, J. 1979. "The Value of Human Life: A Review of the Mode1." Economic Inquiry $17(1): 52-74$.

Low, S. A., and L. R. McPheters. 1983. "Wage Differentials and Risk of Death: An Empirical Analysis." Economic Inquiry 21(2):271-280.

Masse, F. 1984. "Low-Level Waste Management Practices in Academic and Medical Institutions." ANS Transactions 47:75. 
McGuire, E. L., M. L. Baker, and J. F. Vandergrift. 1983. "Evaluation of Radiation Exposures to Personnel in Fluoroscopic X-ray Facilities." Health Physics 45:975-980.

Merwin, S. E., R. C. Brown, and J. B. Martin. 1987. "Optimization and ALARA Considerations in the Use of Respiratory Protection in Radiation Areas." Paper presented at the 32nd Annual Meeting of the Health Physics Society. July 5-10, 1987, Salt Lake City, Utah.

National Council on Radiation Protection and Measurements (NCRP). 1987. Recommendations on Limits for Exposure to Ionizing Radiation. KCRP Report No. 91, National Council on Radiation Protection and Measurements, Bethesda, Maryland.

National Council on Radiation Protection and Measurements (NCRP). 1977. Review of the NCRP Radiation Dose Limit for Embryo and Fetus in 0ccupationally Exposed Women. NCRP Report Ko. 53, National Council on Radiation Protection and Measurements, Bethesda, Maryland.

National Emission Standards for Hazardous Air Pollutants, 40 C.F.R. Part 61, Section 61.102 (1986). (Cited in text as EPA 1986b).

National Environmental Studies Project (NESP). 1980. Study of the Effects of Reduced Occupational Radiation Exposure Limits on the Nuclear Power 1ndustry. AIF/NESP-017, Atamic Industrial Forum, Bethesda, Maryland.

Newcombe, H. B. 1980. "Design and Future Uses of National Dose Registers for Regulatory Control and Epidemiology." Health Physics 39:783-796.

Nieves L. A., J. W. Curry, L. J. Hood, and T. M. Tierney, Jr. 1983. Estimating the Economic Cost of Radiation-Induced Health Effects. PNL-4664, Pacific Northwest Laboratory, Richland, Washington.

Nilson, R., and C. W. Malody. 1982. "Radiation Protection Standards in Nuclear Fuel Manufacturing." Paper presented at the Conference on Radiation Issues for the Nuclear Industry, October 3-6, 1982, New Orleans, Louisiana.

Palmer, H. E., C. P. Brim, G. A. Rieksts, and M. C. Rhoads, 1987. Hanford Whole Body Counting Manual. PNL-6198, Pacific Northwest Laboratory, Richland, Washington.

Pate, Z. T. 1986. "1NP0's Impact in the USA." International Atomic Energy Agency Bulletin 28(3).

Pelletier, C. A., and P. G. Voilleque. 1979. Potential Benefits of Reducing Occupational Radiation Exposure. AIF/NESP-010R, Atomic Industrial Forum, Bethesda, Maryland.

Peterson, Jr., H. T. 1984. "Regulatory Implications of Radiation DoseEffect Relationships." Health Physics 47:345-359. 
Robinson, A. V., D. R. Fisher, H. D. Reece, and J. A. MacLellan. 1986. Performance Testing of Radiobioassay Laboratories: In-Vivo Measurements, Pilot Study Report. PNL-5840, Pacific Northwest Laboratory, Richland, Washington.

Rutland, L., and J. M. Tuohy. 1984. "Some Effects of NRC Guidance on Oesign and Operation of an On-Site Radwaste Storage Facility." ANS Transactions $46: 147$.

Ryan, M. L. 1985. "Average Exposures for U.S. Nuclear Plant Workers Hit Record Low in 1984." Inside N.R.C. 7(14).

Ryan, M. L. 1986. "INPO Says Utility Worker Radiation Doses Cut $20 \%$ in 1985." Nucleonics Week 27(13).

Schlenker, R. A. 1986. "Comparison of Intake and Committed Dose Equivalent Permitted by Radiation Protection Systems Based on Annual Dose Equivalent and Committed Dose Equivalent for a Nuclide of Intermediate Effective HalfLife." Health Physics 51:207-213.

Science and Engineering Associates, Inc. (SEA). 1986. Generic Cost

Estimates. Abstracts From Generic Studies for Use in Preparing Regulatory Impact Analyses. NUREG/CR-4627, U.S Nuclear Regulatory Commission, Washington, D.C.

Skrable, K. W., G. E. Chabot, E. L. Alexander, and C. S. French. 1985. "Comitted vs Annual Dose Limits for Internal Radiation Protection and Control." Health Physics 48:123.

Taylor, L. S. 1985. "The Problems of Radiation Double Standards: Exposure of Potentially Pregnant Persons." Health Physics 49:1043-1052.

Thind, K. S. 1987. "Extremity Dose: Its Definition, Standards and Regulatory Limits, Radiobiological Significance, Measurement and Practical Considerations." Health Physics 52:695-705.

Thomadson, B., J. van de Geijn, D. Buchler, and B. Paliwal. 1983. "Fortification of Existing Rooms Used for Brachytherapy Patients." Health Physics 45:607-615.

Tichler, J., and K. Norden. 1986. Radioactive Materials Released from Nuclear Power Plants. NUREG/CR-2907, U.S. Nuclear Regulatory Commission, Washington, D.C.

U.S. Nuclear Regulatory Comission (USNRC). 1975. "Instruction Concerning Prenatal Radiation Exposure." Regulatory Guide 8.13, Revision 1. U.S. Nuclear Regulatory Commission, Washington, D.C.

U.S. Nuclear Regulatory Comission (USNRC). 1981. "Storage of Low-Level Radioactive Wastes at Power Reactor Sites." Generic Letter 81-38, November 10, 1981, U.S. Nuclear Regulatory Comission, Washington, D.C. 
U.S. Nuclear Regulatory Comission (USNRC). 1982. Enclosure 2 - Regulatory Analysis. U.S. Nuclear Regulatory Commission, Washington, D.C.

U.S. Nuclear Regulatory Commission (USNRC). 1983. "Dose Assignment for Horkers in Non-Uniform Radiation Fields." Office of Inspection and Enforcement. I.E. Information Notice No. 83-59, U.S. Nuclear Regulatory Comission, Washington, D.C.

U.S. Nuclear Regulatory Commission (USNRC). 1984. Regulatory Analysis Guidelines of the U.S. Nuclear Regulatory Comission. NUREG/BR-0058, U.S. Nuclear Regulatory Commission, Washington, D.C.

U.S. Nuclear Regulatory Commission (USNRC). 1986. The Identification and Estimation of the Cost of Required Procedural Changes at Nuclear Power Plants. U.S. Nuclear Regulatory Commission, Washington, D.C.

U.S. Nuclear Regulatory Commission (USKRC). 1987a. "Instruction Concerning Prenatal Radiation Exposure." Regulatory Guide 8.13, Revision 2. U.S. Huclear Regulatory Commission, Washington, D.C.

U.S. Nuclear Regulatory Commission (USNRC). 1987b. "Occupational Exposures at Power Reactors Reach All-Time Low in 1986." Highlights of Weekly Information Report, Week Ending July 31, 1987. U.S. Nuclear Regulatory Comission, Washington, D.C.

Usui, N. 1987. "Japan to Tighten Radiation Exposure Rules to Meet ICRP Standards." Nucleonics Heek 28(50), December 10, 1987.

Vallario, R. H., P. M. Lewis, M. F. Mullen, and S. C. Vickroy. 1985. Regulatory Analysis of Recommendations for NRC Policy on Shift Scheduling and Overtime. PNL-5593, Pacific Northwest Laboratory, Richland, Washington.

Weinstein, M. C., D. S. Shepard, and J. S. Pliskin. 1980. "The Economic Value of Changing Mortality Probabilities: A Decision-Theoretic Approach." Quarterly Journal of Economics 94(2):373-396.

West, C. M., L. M. Scott, and H. B. Schultz. 1979. "Sixteen Years of Uranium Personnel Monitoring - in Retrospect." Health Physics 36:665-669.

Wiatrowski, W. A., E. P. Cooke, D. T. Kopp, and D. W. Jordan. 1984. "Radiocontamination in Medical Centers from Diagnostic Nuclear Medicine Procedures." Health Physics 47:297-298. 


\section{DISTRIBUTION}

No. of

Copies

OFFSITE

12 H. T. Peterson, Jr. Radiation Protection and Health Effects Branch

Division of Regulatory Applications

Office of Nuclear Regulatory Research

U.S. Nuclear Regulatory Conmission

Washington, DC 20555

A. J. DiPalo

Regulation Development Branch

Division of Regulatory

Applications

Office of Nuclear Regulatory Research

U.S. Nuclear Regulatory Commission

Washington, DC 20555

B. J. Richter

Regulation Development Branch

Division of Regulatory

Applications

office of Nuclear Regulatory Research

U.S. Nuclear Regulatory

Conmission

Washington, DC 20555
No. of

Copies

ONSITE

50 Pacific Northwest Laboratory

R. C. Adams

W. J. Bair

L. G. Faust

D. R. Fisher

C. A. Geffen

J. R. Johnson

J. A. MacLellan

J. B. Martin

S. E. Merwin (24)

M. F. Mullen (5)

J. M. Selby

K. L. Soldat

K. L. Swinth

J. J. Tawil

R. J. Traub

M. G. Woodruff

Health Physics Department Library

Publishing Coordination

Technical Report Files (5) 
